\title{
V. Die Genfer Verhandlungen über den Atomwaffensperrvertrag 1963-1966
}

\section{Die Position der konservativen Regierung 1963/64}

Anfang des Jahres 1963 waren die Genfer Verhandlungen über das Teststopp-Abkommen wieder einmal festgefahren. Auch auf dem Weg zu einem Nichtverbreitungsabkommen war man seit 1957 keinen Schritt weitergekommen, da die sowjetische Delegation in Genf die MLF in dem Maß attackierte, in dem die amerikanischen Planungen infolge von Nassau an Aktualität gewannen. Zur gleichen Zeit ließ der Abschluß des deutsch-französischen Vertrages Befürchtungen über eine deutsch-französische nukleare Kooperation aufkeimen. Die Briten hatten den Fortbestand ihrer Nuklearmacht und deren Unabhängigkeit in Nassau erfolgreich bewahrt. Allerdings hatte de Gaulle mit seinem Veto den britischen EWG-Beitritt verhindert. In dieser Situation konzentrierte sich die britische Regierung nun auf die Nichtverbreitungspolitik und die Forcierung der Verhandlungen in Genf. Nach dem abgelehnten Beitrittsgesuch mußte Großbritannien in Genf keine Rücksicht mehr auf Frankreich und die übrigen Europäer nehmen. Der britische Status als Kernwaffenstaat war langfristig gesichert, und der Aufstieg der Bundesrepublik zur Atommacht sollte nun verhindert werden. Im März 1963 bat Macmillan den amerikanischen Präsidenten Kennedy, eine neue Initiative bei den Teststopp-Verhandlungen zu starten. Macmillan regte an, er und Kennedy sollten in einem gemeinsamen, persönlichen Schreiben an Chruschtschow vorschlagen, das Teststopp-Abkommen mit einem Nichtverbreitungsvertrag zu verbinden, um den nuklearen Ambitionen der Bundesdeutschen auf Dauer einen Riegel vorzuschieben. ${ }^{1}$

Kennedy antwortete ausweichend, er wolle die Probleme einzeln nacheinander lösen. Macmillan war sich in der Folgezeit auch nicht mehr so sicher, ob die Koppelung eine gute Idee sei. Die multilaterale Atomstreitmacht nehme konkrete Formen an und damit bestehe die Gefahr, daß bei einer Verbindung von Nichtverbreitungs- und Teststopp-Vertrag die Sowjetunion aus Protest gegen die MLF gar kein Abkommen unterzeichnen werde, stellte er fest. ${ }^{2}$ Damit befand sich der britische Premier in der Zwickmühle: Einerseits hätte er gerne NPT-Verhandlungen forciert, andererseits wollte er das TeststoppAbkommen nicht gefährden. Die Aussichten besserten sich erst, als Chruschtschow im Juni 1963 trilateralen Verhandlungen in Moskau zustimmte. Damit war in der Teststopp-Frage ein baldiger erfolgreicher Ausgang zu erwarten. Washington und London verständigten sich im Vorfeld darauf, in Moskau auch das Problem der Nichtweiterverbreitung zu erörtern, um die Basis für weitergehende Gespräche über ein zweites Abkommen zu schaffen. Als jedoch der britische Gesandte, Lord Hailsham, bereits am er-

${ }^{1}$ PRO, CAB 129/113, Macmillan to Kennedy, 16. 03. 1963. Siehe hierzu auch S. 77.

${ }^{2}$ PRO, PREM 11/4556, Macmillan to Ormsby-Gore, 31.03. 1963. 
sten Tag der Moskauer Gespräche das Thema Nichtverbreitungsvertrag anschnitt, fürchtete sein amerikanischer Kollege Harriman, die Briten würden die USA nötigen, die MLF in Moskau zugunsten eines gleichzeitigen Nichtverbreitungsvertrages fallenzulassen. Harriman weigerte sich von da an kategorisch, während der Teststopp-Verhandlungen nochmals mit der Kreml-Führung über einen Atomwaffensperrvertrag zu sprechen. ${ }^{3}$ Außenminister Rusk machte in Gesprächen mit dem britischen Botschafter in Washington umgehend deutlich, daß eine Aufgabe der MLF auf keinen Fall in Frage komme: „Mr. Rusk said he wanted you [Foreign Secretary Home] to know that he was not prepared to pursue a non-dissemination agreement at the expense of the multilateral force. If anyone in London was disposed to use such an agreement to kill the idea of the force the Americans simply would not go along. He felt deeply that the multilateral force was the only way to meet the German problem and that we, the Americans and the Russians had a common interest in bringing it about. ${ }^{44}$ Home schrieb Ormsby-Gore zurück, falls Rusk der Sowjetunion gegenüber die MLF-Pläne rechtfertigen wolle, könne er nur für die USA, nicht aber für Großbritannien sprechen. Er hoffe, es gebe immer noch die Möglichkeit, eine andere Lösung als die MLF zu finden. Großbritannien und die USA sollten den Abschluß eines NPT zügig vorantreiben. ${ }^{5}$

In Moskau wurde zwar im August 1963 das Teststopp-Abkommen unterzeichnet, aber der Versuch, in Moskau zwei Abkommen auf einmal zu erzielen, war fehlgeschlagen. Daher drängte die britische Regierung in Washington auch weiterhin auf Verhandlungen über einen NPT. Im Oktober und November fanden im State Department mehrere Gespräche über das weitere gemeinsame Vorgehen statt. Um den britischen Wünschen entgegenzukommen, schlug Außenminister Rusk schließlich vor, zunächst mit dem Kreml über einen „Mini-NPT“ zu verhandeln. Dieser Plan sah vor, die Weitergabe von Kernwaffen sowie bestimmter, hochmoderner konventioneller Waffensysteme an Staaten außerhalb der jeweiligen Bündnissysteme zu verbieten. Damit wären die MLF und das Problem Bundesrepublik zunächst ausgeklammert worden. Immerhin hätte ein derartiges Abkommen die weltweite Proliferation nachhaltig eingedämmt. Rüstungswettläufe zwischen blockfreien (und damit keiner Bündnisdisziplin unterworfenen) Staaten, wie sie im Falle Indien und Pakistan drohten, wären damit erheblich erschwert worden. Dieser Vorschlag lief jedoch komplett an den britischen Zielen vorbei. Die britische Nichtverbreitungspolitik zielte auf die Bundesrepublik Deutschland. Die britische Regierung argumentierte, dieses Abkommen stehe im Widerspruch zu den britischen Verpflichtun-

\footnotetext{
${ }^{3}$ PRO, PREM 11/4560, Memo by Lord Hailsham, August 1963, ohne genaues Datum. Harriman hatte Befürchtungen geäußert, sein britischer Kollege werde ihm in den Verhandlungen in den Rücken fallen und auch in bezug auf das Teststopp-Abkommen Bedingungen annehmen, die für Washington nicht akzeptabel wären. Wenn intensive Nichtverbreitungsverhandlungen in Moskau zustande gekommen wären, hätte massiver Druck auf Washington entstehen können, falls Großbritannien in der MLF-Frage konsequente Neutralität gezeigt hätte. Harriman hatte zunächst zugestimmt, „to make non-dissemination the second agenda item“. Die Gespräche über einen Nichtverbreitungsvertrag sollten allerdings erst geführt werden, wenn das Teststopp-Abkommen unterzeichnet war. PRO, PREM 11/4559, Hailsham to Macmillan, 19. 07. 1963.

${ }^{4}$ PRO, PREM 11/4560, Ormsby-Gore to Home, 31.07.1963. Seaborg berichtet, daß Präsident Kennedy sogar bereit gewesen sei, die MLF fallenzulassen, falls Harriman damit in Moskau die sowjetische Zustimmung zu einem Nichtverbreitungsabkommen erreichen könne. Rusk und Bundy sprachen sich jedoch dagegen aus. Seaborg, Tide, S. 92.

${ }^{5}$ PRO, PREM 11/4560, Home to Ormsby-Gore, 31. 07. 1963.
} 
gen im Rahmen des Commonwealth. ${ }^{6}$ Rusks Vorschlag wurde nach der ablehnenden Haltung der Briten nicht weiterverfolgt.

Die Briten hatten während der Gespräche im amerikanischen Außenministerium vorgeschlagen, dem Kreml einen Nichtverbreitungsvertrag mit einer escape clause anzubieten. Ein Ausstieg aus dem Vertrag sollte (analog zum Teststopp-Vertrag) möglich sein, wenn ein Staat höchste Sicherheitsinteressen gefährdet sah. Falls sich die Sowjetunion durch eine zukünftige MLF massiv bedroht sehe, könne sie diese Klausel anwenden. Peter Thomas, ein Mitglied der britischen Delegation in Genf, argumentierte gegenüber dem Direktor der amerikanischen Abrüstungsbehörde, Foster, es sei wichtig, so schnell wie möglich zu einem Abkommen zu gelangen - unabhängig davon, wie der Kreml zur MLF stehe und unabhängig davon, ob die Sowjetunion in der Lage sei, den Beitritt Chinas zu garantieren. ${ }^{7}$ Foster blieb hinsichtlich der escape clause skeptisch. Er befürchtete, die Sowjetunion könne den Westen mit der Rücktrittsklausel erpressen. ${ }^{8}$ Trotz der keineswegs zustimmenden Haltung Fosters schlug der britische Außenminister in einem Schreiben an den sowjetischen Außenminister Gromyko umgehend ein Abkommen mit einer Rücktrittsklausel vor.' Dieses Schreiben war der Auftakt zu einem intensiven britisch-sowjetischen Briefwechsel Ende 1963 in Sachen Nichtverbreitungsvertrag. Die Hoffnungen der Briten auf ein baldiges Abkommen schwanden mit Jahresende jedoch weiter, da Gromyko die Rücktrittsklausel als Lösung ablehnte und auf einer Aufgabe aller MLF-Pläne bestand. Premierminister Macmillan bat Chruschtschow im Dezember vergeblich, die sowjetische Haltung nochmals zu überdenken. Bundesaußenminister Schröder hatte unterdessen dem sowjetischen Junktim ein deutsches hinzugefügt. Er machte während eines Außenministertreffens im November 1963 in Paris deutlich, daß Bonn einen NPT erst nach der Gründung einer MLF akzeptieren könne. Die bundesdeutsche Forderung lautete: erst die Gründung der MLF, dann die Unterzeichnung eines NPT. Die Sowjetunion verlangte vor der Unterzeichnung eines NPT die endgültige Aufgabe der MLF-Pläne. Damit waren Ende des Jahres 1963 nach dem vielversprechenden Abschluß des Teststopp-Abkommens im August die Hoffnungen auf ein weiteres Abkommen gegen die Weiterverbreitung von Kernwaffen in weite Ferne gerückt.

Der amerikanische Präsident Johnson eröffnete die Genfer Abrüstungskonferenz im Januar 1964 mit einem ganzen Paket an neuen Abrüstungsvorschlägen. Johnson erklärte, dem Teststopp-Abkommen sollten weitere Abrüstungsmaßnahmen folgen, und nannte fünf Bereiche, in denen die amerikanische Regierung eine Übereinkunft für möglich hielt: a) Eine Erklärung der Supermächte, im Falle von territorialen Streitigkeiten auf die Anwendung von Gewalt zu verzichten; b) Die Begrenzung des Rüstungswettlaufs durch ein „Einfrieren“ (freeze) der Anzahl der Trägersysteme für strategische Kernwaffen; ${ }^{10} \mathrm{c}$ ) Einen Produktionsstopp von spaltbarem Material (cut-off); d) Eine Reduzierung der Kriegsgefahr durch die Errichtung von Kontrollposten; e) Ein Abkommen, in dem sich die Kern-

${ }^{6}$ PRO, FO 371/171116, Records of Conversation, 22. 10. 1963 und 07. 11. 1963.

${ }^{7}$ PRO, FO 371/171116, Record of Conversation between Mr. Thomas and Mr. Foster, 07. 11. 1963.

${ }^{8}$ Ebenda.

${ }^{9}$ PRO, PREM 11/4227, Butler to Gromyko, 12. 11. 1963.

${ }^{10}$ Die Idee eines freeze blieb bis in die achtziger Jahre ein Dauerthema in den internationalen Abrüstungsverhandlungen. Zur Geschichte des freeze siehe: Cole, Nuclear Freeze, Garfinkle, Politics sowie Fröhlich, Freeze Campaign. 
waffenstaaten verpflichteten, keine Kernwaffen an Nichtkernwaffenstaaten weiterzugeben, sowie ein umfassendes Teststopp-Abkommen unter internationaler Überwachung.

Der britische Vertreter in Genf sah sich gezwungen, die Initiative Johnsons zunächst öffentlich zu begrüßen, obwohl man in London mit den Vorschlägen des amerikanischen Präsidenten keineswegs einverstanden war. Gegen eine Gewaltverzichtserklärung und die Errichtung von Kontrollposten hatten die Briten keine Einwände. In einem Memorandum des Foreign Office kamen jedoch schwere Bedenken gegen einen freeze zum Ausdruck. ${ }^{11}$ Die Briten fürchteten, daß die Lieferung des Polaris-Systems einem derartigen Abkommen zum Opfer fallen könne. Ein „Einfrieren“ bestimmter Kernwaffensysteme wurde als Brdrohung der britischen Atommacht betrachtet, da dieses Abkommen nicht nur die Potentiale der Supermächte umfassen sollte. Im Falle eines cut-off sah man in London die Uranversorgung gefährdet. Die Briten bezogen aus den USA waffenfähiges Uran im Austausch gegen Plutonium. Daher wären sie auch von einem bilateralen cut-off betroffen gewesen. Sogar das Nichtverbreitungsabkommen fand kein Gefallen in London. Die Formulierung Johnsons sah nur eine Verpflichtung der Kernwaffenstaaten vor, keine Kernwaffen weiterzugeben. Die Hilfe bei der Entwicklung war jedoch nicht ausdrücklich verboten. Die Nichtkernwaffenstaaten mußten auch nicht explizit auf die selbständige Entwickung von Kernwaffen verzichten. Dies war den Briten zu wenig. Ihnen kam es vor allem darauf an, daß die Nichtkernwaffenstaaten auf den Erwerb und die Entwicklung von Kernwaffen verzichteten.

Die Aufregung in London war ebenso groß wie unbegründet. Die amerikanische Regierung hatte den Briten umgehend zusätzliche Informationen über den geplanten freeze zukommen lassen. Daraus ging hervor, daß die britischen Interessen in jedem Fall gewahrt bleiben würden und das Abkommen von Nassau keinesfalls gefährdet wäre. Über die Einzelheiten war sich die amerikanische Regierung selbst noch nicht im klaren. Der Vorschlag zielte wohl vor allem auf eine Begrenzung der Anzahl der Raketenbasen und ein Verbot der Stationierung antiballistischer Raketensysteme. ${ }^{12}$ Aus der amerikanischen Konzeption war aber sofort ersichtlich, daß der Kreml diesen Vorschlag umgehend zurückweisen würde, da die Pläne eine internationale Überwachung des freeze vorsahen. Die in Europa stationierten amerikanischen Waffen sowie die nuklearen Systeme einer zukünftigen MLF sollten von dem Abkommen ausgenommen sein. Trotzdem machte die britische Regierung ihrer Verärgerung über die amerikanische Initiative Luft und monierte, vor der Rede Johnsons nicht ausreichend konsultiert worden zu sein. ${ }^{13}$ Im April präsentierte der amerikanische Delegierte in Genf, Fisher, einen detaillierten Entwurf, der prompt von Außenminister Gromyko mit dem Hinweis auf die nationalen Sicherheitsinteressen der Sowjetunion abgelehnt wurde. Die USA waren indes nicht bereit, die Idee umgehend zu begraben. Die amerikanischen Vertreter in Genf erklärten, sie sähen in einem freeze weiterhin eine erstrebenswerte Abrüstungsmaßnahme.

${ }^{11}$ PRO, FO 371/176350, President Johnson's Message to the Geneva Disarmament Conference, Memo by A. Pemberton-Pigott (FO), 24. 01. 1964.

${ }^{12}$ Dies geht aus dem oben zitierten Memorandum von Mr. Pemberton-Pigott aus dem FO hervor. Er bezieht sich auf die "background information", die die USA den Briten zukommen ließen. Johnsons Rede war in diesem Punkt sehr allgemein gehalten. PRO, FO 371/176350, President Johnson's Message, Memo by A. Pemberton-Pigott (FO), 24. 01. 1964.

${ }^{13}$ LBJL, NSF, Country File: UK, box 213, Memo of Conversation between Mr. de Palma (ACDA) and Mr. Wilkinson (First Secretary, Brit. Embassy, Washington), 10.02. 1964. 
Die Idee, einen Produktionsstopp für spaltbares Material zu erlassen und eine größere Menge der bestehenden Vorräte für friedliche Nutzung zur Verfügung zu stellen, war seit Atoms-for-Peace ein Dauerthema in den internationalen Abrüstungsverhandlungen. Die USA hatten Mitte 1963 verschiedene Varianten eines cut-off erwogen und dem Kreml vorgeschlagen, gemeinsam mit den USA Uran-235 für die friedliche Nutzung bereitzustellen, was von der Sowjetunion im August 1963 abgelehnt worden war. Johnson griff den Plan nun nochmals auf. Die Verteidigungsexperten in Washington überlegten auch, den cut-off mit einem freeze zu koppeln. ${ }^{14}$ Die Reaktionen aus Moskau waren zunächst sehr reserviert, aber der Produktionsstopp für spaltbares Material sollte ein Tagesordnungspunkt in den internationalen Abrüstungsverhandlungen bleiben. Obwohl das Foreign Office damit rechnete, daß die Kreml-Führung einen Produktionsstopp in absehbarer Zeit nicht akzeptieren werde, waren die Bedenken in London ausgeprägt. ${ }^{15}$ Großbritannien bezog über das sogenannte Barter-Agreement seit 1959 Uran-235 aus den USA und hatte 1963 aufgehört, Uran für militärische Zwecke zu produzieren. Das Abkommen lief über zehn Jahre - bis 1969 -, und die USA erhielten im Austausch Plutonium aus Großbritannien. Im Falle eines cut-off vor 1969 hätte Großbritannien jedoch kein Plutonium mehr produzieren und an die USA liefern können. Die USA waren zwar nicht auf das britische Plutonium angewiesen, aber die Briten auf amerikanisches Uran. Die USA hätten zwar Uran aus bestehenden Vorräten an Großbritannien liefern können, aber das Abkommen hätte neu verhandelt werden müssen. Zudem benötigten die Briten auch weiterhin in Großbritannien produziertes Plutonium. ${ }^{16}$ Aus diesen Gründen war die britische Regierung über die Aussicht auf einen Produktionsstopp nicht begeistert, vor allem da die USA und die Sowjetunion bereit schienen, wenigstens ein cut-back der Produktion von spaltbarem Material anzukündigen. Daher bat Home den amerikanischen Präsidenten, die Uranversorgung Großbritanniens sicherzustellen. Home schlug Johnson vor, die USA sollten Uran für die nächsten fünf Jahre im voraus an Großbritannien liefern. Die Briten würden ihrerseits den USA sofort die entsprechende Menge Plutonium zur Verfügung stellen. Zudem sollten Experten beider Länder über die möglichen Konsequenzen eines cut-off beraten. ${ }^{17}$

Der sowjetische Delegationsleiter in Genf, Zarapkin, hatte die Abrüstungsinitiative Johnsons mit dem Vorschlag beantwortet, alle Nationen sollten sich gemeinsam dazu bereit erklären, sämtliche Bomber zu zerstören. Der als bonfire of bombers bezeichnete Plan wurde von den USA aufgegriffen, aber die USA wollten nur Bomber verschrotten, die in absehbarer Zukunft veraltet sein würden. Außerdem sollte sich ein bonfire auf die Supermächte beschränken, da die nationale Verteidigung vieler kleinerer Nationen haupsächlich auf Bomberstaffeln beruhte. Zarapkin erkärte daraufhin, alle größeren Mächte sollten ihre Bomber verschrotten. Im Verteidigungsministerium in London begann man, um die britische Luftwaffe zu fürchten. Über die Frage, ob Großbritannien ein bonfire of bombers beziehungsweise ein kombiniertes Abrüstungsabkommen begrü-

${ }^{14}$ Seaborg, Tide, S. 399.

${ }^{15}$ PRO/FO 371/176350, Memo on President Johnson's message, 24. 01. 1964.

${ }^{16}$ Der Vorrat an Plutonium und waffenfähigem Uran, den die Briten bis 1969 zu schaffen planten, wurde in der militärischen Planung für bis in die achtziger Jahre als ausreichend erachtet.

${ }^{17}$ PRO, PREM 11/5199, Home to Johnson, 17. 03. 1964. Johnson und Chruschtschow kündigten im April 1964 cut-backs an. 
ßen sollte, entwickelte sich ein Streit zwischen dem britischen Außen- und dem Verteidigungsministerium.

Das Verteidigungsministerium war absolut gegen den Vorschlag. Auch wenn die $V$-Bomber in einigen Jahren veraltet sein würden, basiere die britische nukleare $\mathrm{Ab}$ schreckung bis zur Lieferung der Polaris-U-Boote auf dieser Luftflotte. Auch nach dem Übergang zu einer seegestützten nuklearen Abschreckung wollte man die Bomber nicht aufgeben, die dann in der konventionellen Verteidigung eingesetzt werden sollten. Im Foreign Office war man anderer Ansicht. Außenminister Butler argumentierte, als Großmacht in den internationalen Verhandlungen könne Großbritannien schon aus Prestigegründen eine Beteiligung nicht ablehnen. Eine Nichtbeteiligung stelle zudem die gesamte Abrüstungspolitik der britischen Regierung in Frage. ${ }^{18}$ Butler sprach sich dafür aus, bereits veraltete Bomber einzubringen, die zum Verkauf bestimmt waren. Aber auch damit war das Verteidigungsministerium nicht einverstanden. Bereits veraltete oder ausgemusterte Flugzeuge brächten im Verkauf an andere Staaten beträchtliche Einnahmen, auf die man nur sehr ungern verzichten wolle. ${ }^{19}$ Mitarbeiter des Foreign Offfice schlugen in bilateralen Gesprächen mit den amerikanischen Kollegen eine Mischung aus bonfire und einem freeze vor, bei der die britischen Bombertypen ausgenommen gewesen wären. ${ }^{20}$ Überdies sollte sich dieses Abkommen ohnehin nur auf die beiden Supermächte beschränken. Das britische Verteidigungsministerium war jedoch noch nicht einmal bereit, diesen Alternativvorschlag mitzutragen. Innerhalb der britischen Regierung war es daher nicht möglich, einen Konsens in der Abrüstungspolitik zu finden. Da die amerikanische Reaktion auf den Vorschlag des Foreign Office sehr verhalten war, vertieften sich jedoch die Gräben nicht weiter. Die britische Variante hatte weder aus Sicht der USA noch aus sowjetischer Perspektive Vorteile.

Die Meinungsverschiedenheiten zwischen den beiden britischen Ministerien gingen jedoch nicht auf absolut gegensätzliche Interessen zurück. Im Foreign Office setzte niemand nationale Sicherheit und Erhaltung der unabhängigen Abschreckung für Erfolge in den Abrüstungsverhandlungen aufs Spiel. Auch im Foreign Office waren die Vorschläge Johnsons zum Jahresanfang äußerst kritisch betrachtet worden. Das Verteidigungsministerium witterte Gefahren für die nationale Sicherheit, wo keine bestanden, und war völlig auf die Erhaltung der unabhängigen Abschreckung fixiert. Für Flexibilität in der Abrüstungspolitik war dabei kein Platz. Im Außenministerium versuchte man, verteidigungspolitische Notwendigkeiten und Abrüstung unter einen Hut zu bringen. Nationalen Sicherheitsinteressen sollte ebenso Rechnung getragen werden wie dem Anspruch, eine führende Rolle in der internationalen Politik zu spielen. Die konservative Regierung drängte seit Jahren auf Fortschritte in der Nichtverbreitung und konnte es sich nicht leisten, nun in den Abrüstungsgesprächen als Bremser aufzutreten, ohne erheblich an Ansehen zu verlieren.

Im Hinblick auf die Bemühungen um einen Nichtverbreitungsvertrag hatten die amerikanischen Vertreter in Genf im Anschluß an die Rede Johnsons weitere Vorschläge erwogen, um eine schrittweise Eindämmung von Proliferation zu erreichen. Im Gespräch war eine Erklärung der Nichtkernwaffenstaaten, auf den Erwerb von Kernwaffen zu ver-

\footnotetext{
${ }^{18}$ PRO, DEFE 11/480, Foreign Secretary to Secretary of Defence, 29. 06. 1964.

${ }^{19}$ PRO, DEFE 11/480, Note by Mr. Mackintosh (MOD), 16. 06. 1964.

${ }^{20}$ PRO, FO 371/176417, FO-Memo: Proposed Package Agreement of May 1964, 18. 11. 1964.
} 
zichten. Diese Erklärung war als erster Schritt zu einem umfassenden Nichtverbreitungsvertrag gedacht und sollte die sowjetischen Bedenken gegen die MLF zerstreuen. Während Italien und Kanada Vorbehalte äußerten, unterstützten die Briten diesen Vorschlag nachdrücklich. Das Foreign Office vergaß nicht, die Kollegen im State Department eindringlich darauf hinzuweisen, daß die bundesdeutsche Unterschrift von zentraler Bedeutung sei. ${ }^{21}$ Die Haltung in Bonn war allerdings so negativ, daß die amerikanische Regierung den Plan bereits nach ersten Sondierungen verwarf. ${ }^{22}$ Staatssekretär Carstens ließ wissen, Außenminister Schröder habe bereits deutlich gemacht, daß eine deutsche Verzichtserklärung erst nach der Unterzeichnung eines MLF-Abkommens erfolgen könne. Zugleich erklärte die Bundesregierung, daß sie von einer Rücktrittsklausel nichts halte. Sie würde vom Kreml nur dazu benützt werden, die Gründung einer MLF zu vereiteln. In dieser Frage erhielt Bonn Unterstützung aus Washington. Großbritannien war trotz der erfolglosen Bemühungen, die Sowjetunion für die Rücktrittsklausel zu gewinnen, nicht bereit gewesen, diesen Vorschlag aufzugeben. Daraufhin erklärte Präsident Johnson Premierminister Home bei dessen Besuch im Februar, daß die USA den britschen Vorschlag ablehnten und einen NPT mit einer escape clause nicht mittragen könnten. ${ }^{23}$

Der amerikanische Außenminister Rusk plante unterdessen, die französische Regierung als Vermittler in den Nichtverbreitungs-Verhandlungen mit der Sowjetunion zu gewinnen. Frankreich war zwar offizielles Mitglied der Achtzehn-Mächte-Abrüstungskonferenz, hatte aber an den Verhandlungen über den Teststopp-Vertrag nicht teilgenommen und blieb auch den Verhandlungen über den Nichtverbreitungsvertrag fern. Trotzdem betrachtete Rusk die französische Regierung als geeignet, die Kreml-Führung für einen Nichtverbreitungsvertrag zu gewinnen, da die ablehnende Haltung Frankreichs gegenüber der MLF, so Rusk, hinlänglich bekannt sei. Deshalb solle die französische Regierung in Moskau konkret für den baldigen Abschluß eines NPT werben. ${ }^{24}$ Der britische Botschafter in Paris, Sir Dixon, war von der Argumentation Rusks wenig überzeugt. Er ging davon aus, daß Frankreich den Aufstieg Chinas zur Atommacht nicht blockieren wollte, um so die Hegemonie der Supermächte ins Wanken zu bringen und die chinesische Neutralität gegenüber den französischen Atomtests im Pazifik zu sichern. Frankreich, so Dixon, werde wohl einen NPT erst unterstützen, wenn China Atommacht geworden und in die Vereinten Nationen aufgenommen worden sei. ${ }^{25}$ Trotzdem fragte Di-

${ }^{21}$ PRO, FO 371/176383, FO to Brit.-Del., Geneva, 12. 02. 1964.

22 PRO, FO 371/176383, Lord Harlech to FO, 11.03. 1964.

${ }^{23}$ LBJL, NSF, Country File: UK, box 212, Visit of Prime Minister Douglas-Home, Talking Points Paper, 06. 02. 1964. Freeman behauptet dagegen, Großbritannien und die USA hätten gemeinsam der Sowjetunion eine escape clause angeboten: „Britain and America were understood to have of fered informally an escape clause to the Russians which would enable them to withdraw from any agreement not to disseminate nuclear weapons should the proposed multilateral North Atlantic nuclear force run counter to it." Freeman, Arms Control, S. 198.

${ }^{24}$ PRO, FO 371/176383, FO-Memo: A Possible Approach to the French, 02. 03. 1964.

${ }^{25}$ PRO, FO 371/176383, Dixon to FO, 27. 02. 1964. Diese Einschätzung wird durch die Aufnahme diplomatischer Beziehungen zwischen Frankreich und China am 27.01. 1964 bestätigt. Die Stellungnahme von Außenminister Couve de Murville zum ersten chinesischen Atomtest enthielt keine Verurteilung des chinesischen Handelns, noch nicht einmal kritische Untertöne. Er sah den chinesischen Test vielmehr als eine absehbare und logische Entwicklung. Allerdings forderte Couve keine Nichtverbreitungsmaßnahmen als Reaktion auf den Aufstieg Chinas zur Atommacht, sondern umfangreiche nukleare Abrüstung und schließlich ein Verbot von Kernwaffen. 
xon schließlich den französischen Außenminister Couve de Murville, ob die französische Regierung bereit sei, stellvertretend für Großbritannien und die USA in Moskau für einen NPT zu werben. Couve wollte sich jedoch nicht festlegen. ${ }^{26}$ Dixon und das Foreign Office waren sich bald einig, daß es sinnlos war, diese Angelegenheit weiter zu verfolgen. ${ }^{27}$ Außenminister Rusk sah dagegen nicht, daß eine Unterstützung des NPT de Gaulles Zielen genau entgegenlief. De Gaulle versuchte gerade, die Bundesregierung von einer MLF abzubringen, und hätte sich mit einer Unterstützung des Nichtverbreitungsvertrages in der Bundesrepublik Deutschland alle Sympathien verscherzt. Weder Frankreich noch eine andere Atommacht hatten die Absicht, Kernwaffen an die Bundesrepublik weiterzugeben, deshalb bestand aus französischer Sicht für einen NPT keine zwingende Notwendigkeit. Je länger das sowjetische Junktim zwischen NPT und MLF bestand, desto unwahrscheinlicher wurde ein Zustandekommen der NATO-Streitmacht.

Sir Dixon schlug seiner Regierung daraufhin eine andere Taktik gegenüber Frankreich vor. Die französische Regierung könne nicht dazu gebracht werden, in Moskau für den NV-Vertrag zu werben, aber sie könne dazu gezwungen werden, in der Nichtverbreitungspolitik in Zukunft eine positivere Haltung an den Tag zu legen. Während eines Gipfeltreffens in Manila im April 1964 habe sich Couve de Murville grundsätzlich damit einverstanden erklärt, daß die Außenminister Großbritanniens, Frankreichs und der Vereinigten Staaten das Thema Nichtverbreitung im Rahmen der nächsten NATO-Ministertagung nochmals erörtern sollten. Dixon sah vor, daß während dieser Ministertagung die drei Außenminister eine offizielle Erklärung abgeben sollten, wonach sie sich dem Ziel der Nichtverbreitung von Kernwaffen verpflichtet fühlten. Diese allgemeine Erklärung sollte keine Verpflichtungen beinhalten, wohl aber die Aussage, daß sie in Zukunft eine enge Zusammenarbeit anstrebten, um Weiterverbreitung von Kernwaffen zu verhindern. Eine französische Beteiligung sei nicht unwahrscheinlich, da es sich nur um eine Absichtserklärung handle, und bei einer Weigerung in der Öffentlichkeit der Eindruck entstehe, Frankreich sei gegen Nichtverbreitung. Die Erklärung solle gezielt in der Öffentlichkeit hochgespielt werden, um Frankreich auf Dauer zu verpflichten. ${ }^{28}$ Die britische Strategie, de Gaulle in Sachen Nonproliferation in die Pflicht zu nehmen, scheiterte ebenso wie die amerikanische Variante. Die französische Regierung bezeichnete die Erklärung als überflüssig. Sie sei zudem direkt gegen China gerichtet und treibe Peking nur weiter in die Opposition. Die Hoffnungen des britischen Botschafters, bei entsprechendem Druck auf Paris werde die französische Regierung doch noch einlenken, erfüllten sich nicht.

Die britische Regierung versuchte in der folgenden Zeit möglichst gut die Aufgabe zu erfüllen, die US-Außenminister Rusk für Frankreich vorgesehen hatte. Die Briten war-

EA 19 (1964) 24, S. D 608-610, Rede des französischen Außenministers Couve de Murville vor der Nationalversammlung, 03. 11. 1964.

${ }^{26} \mathrm{PRO}, \mathrm{FO} 371 / 176383$, Dixon to FO, 07. 03. 1964.

${ }^{27}$ PRO, FO 371/176383, FO to Dixon, 13.03. 1964 und Dixon to FO, 17.03.1964. Die Briten waren überzeugt, daß sich de Gaulle gegenüber Moskau keinesfalls für ein Anliegen der ,Angelsachsen" stark machen würde und auch deshalb den NPT nicht aktiv unterstützen wollte, da dieser den Interessen Chinas zuwiderlief.

${ }^{28}$ PRO, FO 371/176384, Dixon to FO, 22. 04. 1964. In der Einschätzung, de Gaulle wolle sich die Option für eine chinesisch-französische Kooperation sichern, geht Dixon vermutlich zu weit. Der General betrachtete das chinesische Atomprogramm sicherlich mit wohlwollender Neutralität, aber es lassen sich keine Hinweise auf Pläne für eine chinesisch-französische Kooperation finden. 
ben bei der Kreml-Führung nachdrücklich für einen Nichtverbreitungsvertrag. Obwohl die Briten nicht weniger als die Kreml-Führung fürchteten, die Deutschen könnten über die MLF auf lange Sicht Kontrolle über Kernwaffen erhalten, waren sie gezwungen, die MLF als geeignetste Maßnahme zu preisen, um „einen deutschen Finger am Abzug" zu verhindern. ${ }^{29}$ Außenminister Butler argumentierte im Juli 1964 in Moskau, daß die Sowjetunion einen NPT vor der Gründung einer MLF anstreben solle. In diesem Fall müsse eine zukünftige MLF den Bedingungen eines NPT entsprechen. Butler versicherte auch, daß das britische Veto in einer MLF von Dauer sein werde. Die Bemühungen der Briten waren aber sowohl in Moskau als auch in Genf vergeblich. Der Kreml war nicht bereit, das Junktim zwischen einer Aufgabe der MLF und dem Abschluß eines NPT fallenzulassen.

Als im Oktober 1964 in Großbritannien die Wahlen vor der Tür standen, mußte die Regierung Macmillan die Genfer Verhandlungen seit dem Abschluß des Teststopp-Abkommens im August 1963 als Serie von Mißerfolgen verbuchen. In bezug auf die jüngsten amerikanischen und sowjetischen Abrüstungsinitiativen war die Regierung gespalten und in erster Linie auf die Erhaltung der nationalen Potentiale fixiert. Sie konnte nicht wie in den Teststopp-Verhandlungen als treibende Kraft mit neuen Initiativen zwischen den Supermächten vermitteln. In den Verhandlungen um einen NV-Vertrag war man seit dem Abschluß des Teststopp-Vertrags keinen Schritt weitergekommen. Die USA akzeptierten keinen NPT, der eine Rücktrittsklausel enthielt. Eine einseitige Verzichtserklärung der Nichtkernwaffenstaaten war nicht durchsetzbar. Die amerikanische Regierung war nicht bereit, die MLF aufzugeben. Außenminister Rusk betonte zudem, daß eine Beteiligung Chinas Voraussetzung für ein Abkommen sei. Die Briten hielten diese Bedingung für unrealistisch und wiesen vergeblich darauf hin, daß auch ein Abkommen ohne chinesische Unterschrift sehr wertvoll sei. ${ }^{30}$ Die amerikanische Politik gegenüber Frankreich war ebenso verfehlt. De Gaulle mit seiner Abneigung gegen den Bilateralismus der Angelsachsen würde niemals eine anglo-amerikanische Idee in Moskau verkaufen. In Großbritannien sah man die französische Position realistischer. Dennoch war auch der britische Versuch aussichtslos, Paris mit einer List auf die anglo-amerikanische Linie zu bringen. Gegenüber der Sowjetunion warb die britische Regierung vergeblich für die Akzeptanz der MLF, die in London nicht weniger verhaßt war als in Moskau.

\section{Die Politik der Labour-Regierung in den Genfer Verhandlungen}

Die Labour-Mannschaft um Harold Wilson hatte bereits vor den für sie erfolgreichen Wahlen deutlich gemacht, daß eines ihrer Hauptziele der Abschluß eines Nichtverbreitungsvertrages sein werde. Wilson war als Oppositionsführer im Juni nach Moskau gereist, um die abrüstungspolitische Zielsetzung einer Labour-Regierung zu erläutern. Er

\footnotetext{
${ }^{29}$ Memo of Conversation between Mr. Zorin and Mr. Thomas (UK-Del., Geneva), 10. 06. 1964.

${ }^{30}$ "It should be noted that on the question of China, Mr. Rusk has usually taken the line with us that Congress would not ratify an agreement to which the Chinese Communists did not adhere. We consider this unfortunate. We know the Chinese will not adhere, but we consider that an agreement without China could still be of the greatest value." PRO, FO 371/176384, FOMemo: Tripartite Meeting in Manila, 13. 04. 1964.
} 
mußte ebenso wie der konservative Außenminister Butler der mißtrauischen Kreml-Spitze versichern, daß die MLF keinen „deutschen Finger am Abzug“ zur Folge haben würde. Er schlug nicht nur den baldigen Abschluß eines NPT vor, sondern auch noch eine zusätzliche Klausel, nach der es Staatsbürgern der Atommächte verboten sein sollte, Nichtkernwaffenstaaten bei der Entwicklung von Kernwaffen zu helfen. Wilson bezeichnete auch eine Einigung über bonfire und freeze als wünschenswert. ${ }^{31}$ Lord Chalfont, frischgebackener Abrüstungsminister der Labour-Regierung, ${ }^{32}$ erklärte im Dezember 1964, Großbritannien werde nun zum Zugpferd in den Abrüstungsverhandlungen: „We in this country have an important and specific role to play: we have our own ideas for initiatives designed to break the stalemate that has frozen serious disarmament negotiations for the last year or so. ${ }^{433}$ Die Labour-Partei beschuldigte die scheidende Regierung, die Abrüstungspolitik vernachlässigt zu haben, und kündigte eine Fülle neuer Initiativen an. Wenig später klangen die Töne der neuen Regierung schon bald sehr viel verhaltener. Ein Memorandum über die freeze-Pläne Johnsons sah vor, nochmals eine Bestätigung zu fordern, daß das Abkommen von Nassau nicht gefährdet sei. Die Lieferung der Polaris-Raketen werde erst im Juli 1969 abgeschlossen sein. Falls vorher ein Abkommen in Reichweite rücke, müßten die USA die Raketen früher liefern. Die Labour-Regierung werde keinesfalls auf einen Teil der Raketen verzichten. Außerdem forderten die Briten, den freeze-Vorschlag der USA so abzuändern, daß die britischen TSR-2 Bomber nicht darunterfielen. ${ }^{34}$ Die neue Regierung wollte den cut-off nicht international unterstützen, bevor die britische Uran- und Plutoniumversorgung sichergestellt war. Der konservative Premier Home hatte um eine vorzeitige Lieferung der bis 1969 vorgesehenen Uranmenge gebeten. Dies hatte die amerikanische Regierung mit dem Hinweis abgelehnt, ein cutoff sei nicht aktuell. Nun wollte die neue Regierung noch einmal eine Anfrage starten, ob Großbritannien zusätzliche Mengen Uran kaufen könne und ob außerdem im Falle eines cut-off die gesamte, bis 1969 zur Lieferung vorgesehene Menge vor dem Inkrafttreten des Produktionsstopps geliefert werden könne. Damit wäre nicht nur die Uranversorgung sichergestellt, sondern auch noch ein kleiner Vorrat gebildet worden. Falls die amerikanische Regierung nicht einverstanden sei, müsse Großbritannien schlimmstenfalls die Uranproduktion für militärische Zwecke wieder aufnehmen und weiterhin Plutonium produzieren (anstatt, wie geplant, 1969 die Plutoniumproduktion einzustellen). ${ }^{35}$

Für die Labour-Regierung stand die Sicherung der unabhängigen britischen $\mathrm{Ab}$ schreckung ebenso an erster Stelle wie für die konservativen Vorgänger. Von einer vorbehaltlosen Unterstützung eines bonfire und freeze, wie Wilson dies in Moskau angekündigt hatte, war keine Rede mehr. Die Labour-Führung schien jedoch ein wenig mehr Flexibilität zu zeigen. Während der Besprechung über den Kurs in der Abrüstungspolitik vom Februar 1965 wurde immerhin beschlossen, Studien über Möglichkeiten zur Aufrechterhaltung eines minimum deterrent erarbeiten zu lassen. Diese Idee sah vor, daß langfristig nur die kleinstmögliche Anzahl an Kernwaffen erhalten bleiben sollte, die

${ }^{31}$ PRO, PREM 11/4894, Memo of Conversation, 10.06. 1964.

${ }^{32}$ Chalfont war als Staatsminster für Abrüstung dem Foreign Office unterstellt.

${ }^{33}$ HL Debs., Vol. 262, c. 575, 17. 12. 1964.

${ }^{34}$ PRO, FO 371/176417, President Johnson's Offer to Freeze Stocks of Certain Nuclear Delivery Vehicles: UK Position, 17. 11. 1964.

${ }^{35}$ PRO, FO 371/176417, Memo by the Foreign Office: The Cut-off of Production of Fissile Material for Weapons Purposes, November 1964, ohne genaues Datum. 
zur glaubwürdigen Aufrechterhaltung der Abschreckungsbalance zwischen Ost und West nötig war. ${ }^{36}$

In bezug auf den Nichtverbreitungsvertrag war die Zielrichtung klar: „Our basic policy must be to continue to press for a non-dissemination agreement and to argue that there is no necessary incompatibility between it and a reorganisation of nuclear responsibilities in NATO. ${ }^{\text {" }}{ }^{37}$ In diesem Punkt war somit eine absolute Kontinuität der britischen Politik gewährleistet. $\mathrm{Da}$ die Chancen für ein globales Abkommen nicht gut standen, schien es nun wichtig, kleinere Dämme gegen Proliferation zu errichten. Die Labour-Regierung hatte dabei offensichtlich zwei Möglichkeiten im Visier: Das Abkommen über die Gründung einer multilateralen NATO-Atomstreitmacht sollte eine nukleare Verzichtserklärung der Nichtkernwaffenstaaten enthalten. Diese Strategie wurde mit der britischen ANF-Konzeption verfolgt. Parallel dazu sollte die britische Delegation in Genf darauf hinarbeiten, eine Mehrheit der Nichtkernwaffenstaaten für eine freiwillige Verzichtserklärung auf den Erwerb von Kernwaffen zu gewinnen. ${ }^{38} \mathrm{Um}$ einem globalen Abkommen näher zu kommen, war Druck auf Washington notwendig. Die Sowjetunion solle eine offizielle Garantie erhalten, daß das amerikanische Veto über die MLF von Dauer sein werde. Ferner müßten die USA ihre starre Haltung hinsichtlich einer Beteiligung Chinas aufgeben. ${ }^{39}$ In diesem Punkt war die amerikanische Regierung ohnehin gezwungen, ihre Position zu überdenken, da der erste chinesische Atombombentest im Oktober 1964 eine Beteiligung Chinas als Nichtkernwaffenstaat hinfällig gemacht hatte. In Großbritannien wirkte sich der chinesische Test nicht nachhaltig auf die Nichtverbreitungspolitik aus. Die britische Regierung hatte eine Beteiligung Chinas für unwahrscheinlich gehalten und mit dem chinesischen Test gerechnet. Es bestand zwar eine gewisse Gefahr, daß die Regierung in Peking Kernwaffen an befreundete Staaten weitergeben könnte, aber dies betraf nicht die Situation in Europa, an der Großbritannien unmittelbares Interesse hatte.

Im Drängen auf einen Nichtverbreitungsvertrag hatten die Briten im Laufe der letzten beiden Jahre einen Verbündeten innerhalb der amerikanischen Regierung bekommen. Die Arms Control and Disarmament Agency (ACDA) argumentierte seit Beginn 1963 verhalten aber stetig dafür, die Chancen für den Abschluß eines Nichtverbreitungsvertrages mit der Sowjetunion zu verbessern und die Außenpolitik entsprechend zu modifizieren. Die ACDA war aus einer kleinen Abteilung für Abrüstungsfragen innerhalb des State Departments entstanden. ${ }^{40}$ Im September 1961 hatte der Kongreß die Gründung einer vom State Department unabhängigen Abrüstungsbehörde genehmigt. ACDA-Direktor Foster protestierte im April 1964 vergeblich dagegen, daß Präsident Johnson den MLF-Befürwortern im State Department freie Hand ließ. Der stellvertretende Direktor Fisher entwarf daraufhin eine „Kompromißstrategie“, um den widerstreitenden Interessen gerecht zu werden. Er ging davon aus, daß die nuklearen Ambitionen der Deutschen

${ }^{36}$ PRO, FO 371/181366, Record of Meeting on Disarmament, 12. 02.1965.

${ }^{37}$ PRO, FO 371/176417, Talking Points on Non-Dissemination, 18. 11. 1964.

${ }^{38}$ PRO, PREM 13/652, Foreign Secretary to Prime Minister, 19.11. 1964. Dieser Vorschlag stammte von Außenminister Stewart. Premierminister Wilson gab seine Zustimmung: „Prime Minister agrees with outline." PRO, PREM 13/652, Note by Sir O. Wright (Private Secretary to PM), 21.11. 1964 .

${ }^{39}$ PRO, FO 371/176417, FO-Memo on Non-Dissemination, 17.11. 1964.

${ }^{40}$ Zur Entstehung der ACDA siehe: Bunn, Arms Control, S. 29-30. 
durch die MLF nur so lange gezügelt werden könnten, als kein weiterer Staat ein nationales Atompotential entwickelte. Sobald aber Indien, Israel und einige andere Länder unabhängige Atommächte würden, werde sich auch die Bundesrepublik nicht mehr mit dem nuklearen Minderstatus in der MLF zufriedengeben. Deshalb sei es wichtig, die MLF so schnell wie möglich unter Dach und Fach zu bringen und zugleich die nichtnuklearen Mitgliedstaaten dazu zu verpflichten, auf den Erwerb eines nationalen Potentials zu verzichten. Gegenüber der Sowjetführung sollten die USA höchstes Interesse am baldigen Abschluß eines NPT verstärkt zum Ausdruck bringen und nicht mehr auf einer chinesischen Beteiligung bestehen. ${ }^{41}$ Die ACDA befürchtete angesichts des sowjetischen Junktims und der europäischen Opposition gegen die MLF, daß die amerikanische Regierung schließlich weder eine MLF noch einen NPT bekommen werde. ${ }^{42}$

Die Kassandrarufe der ACDA wurden jedoch ignoriert. Bei der Besprechung von Fishers Memorandum schien es sogar zweifelhaft, ob Nichtverbreitung überhaupt eines der außenpolitischen Ziele der Johnson-Administration war. Seaborg berichtet, Außenminister Rusk habe überlegt, ob es möglicherweise irgendwann im Interesse der USA liegen werde, Indien und Japan Kernwaffen zu überlassen, falls China ein nukleares Waffenarsenal entwickeln würde. Rusk sei dagegen gewesen, eine Teilnahme Chinas als conditio sine qua non für einen NPT aufzugeben. ${ }^{43}$ Der Vorschlag, eine nukleare Verzichtserklärung der MLF-Mitglieder zu fordern, wurde verworfen, da eine solche Erklärung die nichtnuklearen Europäer gegenüber den übrigen Nichtkernwaffenstaaten diskriminieren würde.

Als Reaktion auf den ersten chinesischen Atomtest ließ Präsident Johnson unabhängig von der Abrüstungsbehörde eine weitere Arbeitsgruppe gründen. Sie wurde nach ihrem Vorsitzenden Roswell Gilpatric als Gilpatric Committee bezeichnet. Das Gilpatric Committee sollte in einem ausführlichen Memorandum das Problem der Weiterverbreitung von Kernwaffen erörtern und neue Leitlinien für die amerikanische Nichtverbreitungspolitik erstellen. Das Ergebnis der Arbeit wurde Johnson im Januar 1965 vorgelegt. Der Gilpatric-Report kam zu der Schlußfolgerung, daß in der Außenpolitik die Prioritäten zugunsten eines NPT geändert werden sollten, und forderte einen radikalen Kurswechsel in der Nichtverbreitungspolitik. ${ }^{44}$ Die ACDA-Mitarbeiter produzierten zu dieser Zeit eine Fülle von Memoranden über die Gefahren der Proliferation. ${ }^{45}$ Zahlreiche Mitglieder des Kongresses forderten Anfang Dezember 1964 in einem Schreiben an Außenminister Rusk, die MLF-Pläne auf Eis zu legen und Non-Proliferation zum wichtigsten Ziel der amerikanischen Außenpolitik zu machen. ${ }^{46}$

Der chinesische Atomtest verlieh jedoch keineswegs nur den Stimmen mehr Gewicht, die nachdrücklich ein Nichtverbreitungsabkommen forderten. Der Aufstieg Chinas zur Atommacht und der zu erwartende Dominoeffekt führten dazu, daß im State Depart-

${ }^{41}$ NSA, MC, Doc. Nr. 981, Memo by Adrian Fisher, 15. 06. 1964.

${ }^{42}$ Bunn, Arms Control, S. 69.

${ }^{43}$ Seaborg, Tide, S. 132.

${ }^{44}$ LBJL, Committee File, box 5, Committee on Non-Proliferation, A Report to the President, 21.01. 1965.

${ }^{45}$ Zum Beispiel: LBJL, NSF, Subject File: MLF, box 23, Program to Limit the Spread of Nuclear Weapons, 03. 11. 1964, Nuclear Weapons Programs Around the World, 03. 12. 1964, Europe, NATO, Germany and the MLF, 12.12. 1964, Security Guarantees and Non-Proliferation of Nuclear Weapons, 28. 12. 1964.

${ }^{46}$ NSA, MC, Doc. Nr. 1062, Letter to the Secretary of State, 07. 12. 1964. 
ment ein ganz neuer Ansatz verfolgt wurde, Proliferation zu bekämpfen. Ein globaler NPT könne dem Problem nicht gerecht werden. Statt dessen müsse jede potentielle zukünftige Atommacht individuell betrachtet werden. Ein Land wie Indien wäre durch die chinesische Bombe direkt bedroht und hätte ganz andere Motive, Kernwaffen zu erwerben, als zum Beispiel die Vereinigte Arabische Republik (Ägypten), die zwar mißtrauisch auf Israel blicke, aber nicht unmittelbar einer nuklearen Bedrohung ausgesetzt sei. Deshalb müßten auch individuelle Maßnahmen ergriffen werden, um weitere nationale Atompotentiale zu verhindern. Rusk machte diese Position in Gesprächen mit Vertretern des Gilpatric Committees deutlich. ${ }^{47}$ In diesem Zusammenhang ist auch die Äußerung Rusks zu verstehen, man müsse vielleicht Indien und Japan Kernwaffen geben. Rusk dachte nicht an nationale Arsenale, wie die Schilderung bei Seaborg impliziert, sondern an die Gründung einer asiatischen MLF. ${ }^{48}$ Walt Rostow, ab 1965 Sicherheitsberater von Präsident Johnson, wurde in seinem Memorandum „A Way of Thinking about Nuclear Proliferation" noch konkreter. Er forderte nicht nur kollektive Sicherheitssysteme in Asien, sondern auch Maßnahmen, um das Prestige von Atomwaffen zu senken, darunter Abrüstungsmaßnahmen der beiden Supermächte und eine Aufgabe der nationalen französischen und britischen Arsenale. ${ }^{49}$ Der chinesische Atomtest bestärkte die Befürworter, den Abschluß eines NPT nun zur top priority in der Außenpolitik zu machen, aber als Reaktion auf den chinesischen Test wurden auch ganz andere Konzepte zur Bekämpfung von Proliferation entwickelt. Die Meinungspalette in Washington war sehr bunt.

Es gab sogar Überlegungen, in einem militärischen Angriff die chinesischen Atomanlagen zu zerstören, um zu verhindern, daß der Aufstieg Chinas zur Atommacht einen weiteren Dominoeffekt zur Folge haben könnte. Ein Papier des State Departments hierzu ging davon aus, daß dieser Angriff auch als gemeinsame Aktion der beiden Supermächte ausgeführt werden könnte. Eine weitere Möglichkeit bestehe darin, ein drittes Land im amerikanischen Auftrag diesen Schlag ausführen zu lassen. Die Studie kam jedoch zu dem Schluß, daß die geringe Bedeutung des chinesischen Atomprogramms das Risiko eines Militärschlags nicht rechtfertige. ${ }^{50}$

Bei einer Zerstörung des chinesischen Atompotentials wäre ein Nichtverbreitungsvertrag in naher Zukunft nicht unbedingt erforderlich gewesen. Der Militärschlag hätte seine Signalwirkung auf potentielle Nachahmer Chinas nicht verfehlt. Die Überlegung, einen Angriff zusammen mit der Sowjetunion durchzuführen, belegt eindrucksvoll, daß

${ }^{47}$ NSA, Unpublished Sources on Nuclear History. Memo of Conversation, 07. 01. 1965. Bluth schreibt, Rusk distanzierte sich erst im Frühjahr 1965 von den Vorschlägen des Gilpatric-Reports, als Bundesaußenminister Schröder in einem Interview erklärte, die Bundesrepublik werde einen NPT erst nach der Gründung der MLF unterzeichnen. Bluth, Britain, S. 163. Rusk hatte jedoch immer schon ganz andere Vorstellungen von Nichtverbreitungspolitik als das Gilpatric Committee.

${ }^{48}$ Siehe Seaborg, Tide, S. 135.

${ }^{49}$ LBJL, NSF, Committee File, box 1/2, Committee on Non-Proliferation (= Gilpatric Committee), Memo by Walt Rostow, 19. 11. 1964.

${ }^{50}$ Spekulationen über derartige Pläne hatte es immer gegeben. Maddock konnte diese Vermutungen nun erstmals mit einem entsprechenden Dokument belegen. Dieses Dokument bezieht sich auf eine Studie des State Departments, die zu dem Schluß kam, ein Militärschlag sei nicht gerechtfertigt. Das vorgelegte Memorandum bezweifelt dies, da es davon ausgeht, daß der Aufstieg Chinas zur Atommacht langfristig im - nicht unwahrscheinlichen - Falle eines amerikanisch-chinesischen Konflikts eine massive Bedrohung darstellen werde. Maddock, Bomb, S. 1-5. 
Proliferation als eine unmittelbare Gefahr für beide Supermächte gesehen wurde. Die USA waren bereit, eng mit der Sowjetunion zusammenzuarbeiten, um die bilaterale Abschreckungsbalance zu verteidigen. Gerade ein chinesisches Atompotential gefährdete den amerikanisch-sowjetischen Bilateralismus unmittelbar. Insofern ging es nicht nur darum, ein Zeichen für andere Staaten zu setzen, die mit Kernwaffenbesitz liebäugelten, sondern ein fundamentales Eigeninteresse beider Supermächte zu wahren.

Als Präsident Johnson die MLF im Dezember 1964 fallenließ, war das Haupthindernis für einen Kurswechsel in der Nichtverbreitungspolitik aus dem Weg geräumt. Trotzdem war der amerikanische Präsident nicht geneigt, die Außenpolitik den Empfehlungen des Gilpatric-Reports anzupassen. Dies geschah weniger aufgrund inhaltlicher Kontroversen sondern mehr aus persönlichen Gründen. Johnson fürchtete offensichtlich, die Außenpolitik werde ihm aus der Hand genommen. ${ }^{51}$ Wahrscheinlich wollte Johnson auch vermeiden, daß die Aufgabe der MLF durch einen abrupten Richtungswechsel in der Nichtverbreitungspolitik allzu deutlich zu Tage trat. Die Abrüstungsbehörde kämpfte aber weiterhin um mehr Einfluß auf die Außenpolitik, und der amerikanische Präsident sollte schließlich doch langsam Kurs auf einen Nichtverbreitungsvertrag nehmen - allerdings nicht in dem vom Gilpatric-Report vorgeschlagenen Tempo.

Anfang des Jahres 1965 legte die Republik Irland in der Vollversammlung der Vereinten Nationen eine Resolution vor, die Proliferation verurteilte und den baldigen Abschluß eines globalen Nichtverbreitungsabkommens verlangte. Dies geschah auf Initiative der amerikanischen Regierung. In Washington sah man die Gefahr, daß im Rahmen der Vereinten Nationen eine Resolution verabschiedet werden könnte, die die geplante MLF attackierte und die USA zur Aufgabe der Pläne aufforderte. Deshalb sollte rechtzeitig eine Resolution, die eine Option für die MLF nicht ausschloß, zur Abstimmung vorliegen. Um der Resolution einen neutralen Anstrich zu verpassen, wurde die irische Regierung gebeten, diese einzubringen. ${ }^{52}$ Damit deutete nichts auf eine baldige Aufgabe der MLF-Pläne hin. Trotzdem war man in London bereits dabei, erste Entwürfe für ein Abkommen zu erstellen. Gleichzeitig suchten die Briten nach weiteren Möglichkeiten für neue Initiativen in der Abrüstungs- und Nichtverbreitungspolitik.

Lord Chalfont wollte als zweiten Damm gegen Nichtverbreitung die Verhandlungen über ein umfassendes Teststopp-Abkommen wiederbeleben. Ein CTBT war nicht durch das MLF-Junktim blockiert und schob der Entstehung weiterer Atommächte einen Riegel vor. Chalfont erwog, dem Kreml inoffizielle bilaterale Verhandlungen mit der britischen Führung vorzuschlagen. Sir Harold Beeley, ein Mitglied der britischen Delegation in Genf, riet statt dessen, einen Vorstoß zu unternehmen, China in die Abrüstungsverhandlungen einzubeziehen. Die sowjetischen Vertreter in Genf unterhielten bereits bilaterale Kontakte mit der amerikanischen Abrüstungsbehörde und legten auf einen weiteren bilateralen Kanal keinen Wert. ${ }^{53}$ Chalfont griff diese Idee auf, indem er einen möglichst baldigen Besuch in Peking ins Auge faßte. Die chinesische Führung zeigte sich al-

${ }^{51}$ Seaborg, Tide, S. 150. Diesen Eindruck gewann auch Premierminister Wilson während seines Besuchs in Washington im Dezember 1964: „The Prime Minister said he had the feeling that the President tended to suspect that he might be pushed around by his own people on defence matters." PRO, PREM 13/103, Memo of Conversation between Wilson and Johnson, 07. 12. 1964.

${ }^{52}$ NA, RG 59, CFPF, DEF 18, box 1593, Memo of Conversation between Mr. Faber (First Secretary, Brit. Embassy) and Mr. de Palma (ACDA), 04. 01. 1965.

${ }^{53}$ PRO, FO 371/181366, Note by Mr. J. Street (FO), 25. 01. 1965. 
lerdings an einem Besuch des britischen Abrüstungsministers uninteressiert. Chalfont setzte auch auf intensive bilaterale Konsultationen mit den Vereinigten Staaten. Ziel war es jedoch nicht, den Plänen der US-Regierung in jedem Fall zu folgen. Der Abrüstungsminister hatte vor, eng mit der ACDA zusammenzuarbeiten, aber unter Umständen die USA auch über eigenständige britische Positionen zu informieren.

Chalfonts Bemühungen zielten darauf, die Anzahl der von den USA geforderten Inspektionen vor Ort zur Überwachung eines CTBT von sieben pro Jahr auf drei zu senken. Eine Einigung schien möglich, da die Sowjetführung 1962 in den Teststopp-Verhandlungen kurzzeitig bereit war, drei Inspektionen zu akzeptieren. Chalfont erklärte im Februar 1965 in einer Rede, die westlichen Atommächte könnten dank verbesserter Überwachungsmethoden die geforderte Anzahl der Inspektionen beträchtlich senken. Dieser Vorstoß war mit der amerikanischen Abrüstungsbehörde nicht abgesprochen. ACDA-Vertreter Freund machte daraufhin klar, daß die Briten mit ihrem Übereifer unter Umständen genau das Gegenteil erreichten. Die britische Initiative, so Freund, provoziere möglicherweise nichts als heftige Gegenreaktionen in Washington. ${ }^{54}$ Trotzdem schnitt Chalfont in seinen Gesprächen mit ACDA-Direktor Foster das Thema noch einmal an. Man verschloß offenbar die Augen davor, daß ein Abkommen mit drei Inspektionen keine Chance hatte, den Kongreß zu passieren, selbst wenn es gelänge, die amerikanische Regierung zur Zustimmung zu nötigen. Die amerikanische Regierung hatte im Herbst 1963 Mühe gehabt, gegen Widerstände im Kongreß und in der militärischen Führung die Ratifizierung des PTBT zu erreichen. Die Briten hatten 1964 vergeblich auf weitere Expertengespräche gedrängt, um in der Frage der Überwachung eine Lösung zu finden. Damals war die konservative Regierung von amerikanischer Seite gebeten worden, nicht weiter darauf zu insistieren, da weder innerhalb der Regierung noch im Kongreß eine Mehrheit für den CTBT vorhanden war. ${ }^{55}$

Der britische Vorstoß erwies sich schon bald als Eigentor. Mit der Aussicht auf ein rasches cut-off-Abkommen entstand die Gefahr, daß Großbritannien nicht genug Plutonium produzieren könnte, um rechtzeitig ausreichende Vorräte zu schaffen. Es gab aber die Möglichkeit, den Sprengkopf für die Polaris-Raketen so zu verbessern, daß weniger spaltbares Material benötigt würde. Dazu war allerdings ein weiterer Test notwendig. Dieser mußte streng geheim bleiben, da die Regierung die internationalen Reaktionen ebenso fürchtete wie den Proteststurm des linken Labour-Flügels. Premierminister Wilson und Verteidigungsminister Healey wollten den Test im Interesse der Sicherung des Polaris-Programms jedoch unbedingt durchführen. Die Position des Abrüstungsministers wurde damit in Washington unmöglich gemacht. Chalfont war nicht nur ein überzeugter Befürworter eines umfassenden Testverbots, sondern auch gegen weitere britische Tests. Damit stand er allerdings innerhalb der Labour-Führungsspitze alleine. Während Chalfont in Washington auf neue Initiativen in den Verhandlungen über einen CTBT drängte, fragte zur gleichen Zeit das Verteidigungsministerium an, ob die Briten

${ }^{54}$ LBJL, NSF, Country File: UK, box 207, Memo of Conversation between Mr. Faber and Mr. Freund, 05. 03. 1965.

${ }^{55}$ PRO, FO 371/176437, UK-Del., Geneva, to FO, 24. 01. 1964. Präsident Johnson sah im Gegensatz zu seinem Vorgänger keine Vorteile in einem Teststopp-Abkommen. Johnson hatte den CTBT nur in seine Abrüstungsinitiative aufgenommen, weil nicht der Eindruck entstehen durfte, die USA seien gegen einen Teststopp. Siehe hierzu: Seaborg, Tide, S. 205-221. 
auf dem Testgelände in Nevada unter strengster Geheimhaltung einen unterirdischen Test durchführen könnten. ${ }^{56}$ Auf dem internationalen Parkett als Vorreiter in der Nichtverbreitung auftretend - unter Umständen auch auf Kosten des engsten Verbündeten -, war man nicht bereit, für sich zu akzeptieren, was man von anderen Nationen verlangte.

Ein weiterer Widerspruch zwischen Anspruch und Wirklichkeit in der britischen Abrüstungspolitik zeigte sich in der Frage der internationalen Inspektion von Atomanlagen. Die USA hatten im Rahmen von Johnsons Abrüstungsvorschlägen angeboten, eine zivile Atomanlage und deren Plutoniumproduktion für Inspektionen der internationalen Atomenergiebehörde freizugeben. Damit sollten die Argumente der Nichtkernwaffenstaaten gegen internationale Kontrollen ihrer zivilen Atomanlagen im Rahmen eines NPT entkräftet werden. Das Foreign Office hatte keine Einwände und schlug vor, den Reaktor in Bradwell und das dort produzierte Plutonium kontrollieren zu lassen. Allerdings bestand das Problem, daß das meiste Plutonium aus Bradwell an die USA geliefert wurde und wenig Material für Kontrollen übrigblieb. Großbritannien hätte ersatzweise die Uranproduktion kontrollieren lassen können, was aber die IAEA wohl nicht als gleichwertig akzeptiert hätte. Eine zweite Möglichkeit bestand darin, daß die USA einer Inspektion der Plutoniumexporte zustimmten. Im Foreign Office wollte man diese Frage offen mit den USA diskutieren. Das Verteidigungsministerium war jedoch strikt dagegen. ${ }^{57}$ Lord Chalfont blieb daher nichts anderes übrig, als in Washington darauf zu verweisen, daß Großbritannien sich dem amerikanischen Vorschlag derzeit nicht anschließen könne. Diese Episode zeigt zum einen, daß die Meinungsverschiedenheiten zwischen dem Außen- und dem Verteidigungsministerium unter der neuen Regierung ungemindert andauerten. Sie zeigt auch, daß die Briten zwar am liebsten sofort einen NPT unterzeichnet hätten, aber nicht in der Lage waren, die notwendigen Bedingungen für eine möglichst breite Akzeptanz eines Abkommens bei den Nichtnuklearen zu schaffen.

Nichtsdestoweniger drängten die Briten auf eine baldige Unterzeichnung eines NPT. Der britische Abrüstungsminister informierte ACDA-Direktor Foster in Washington darüber, daß die Briten beabsichtigten, in Genf einen Vertragsentwurf vorzulegen, sobald Moskau einverstanden sei, die Verhandlungen fortzusetzen. Der britische Entwurf vom Februar 1965, den Chalfont mit Foster diskutierte, ermöglichte die Realisierung der britischen ANF-Pläne, schloß aber eine zukünftige europäische Option der MLF eindeutig aus. Er sah ferner eine unbegrenzte Vertragsdauer vor und enthielt eine Rücktrittsklausel. Die Atommächte wurden nicht namentlich genannt, um die Frage zu umgehen, ob China offiziell als Atommacht anerkannt werden sollte. Die Problematik der internationalen

${ }^{56}$ PRO, PREM 13/123, Memo by the Minister of Defence, 27.1.1965. Minute by the Prime Minister, 27. 01. 1965. Der Test wurde schließlich im September 1965 unbemerkt von der Weltöffentlichkeit durchgeführt. Der Daily Express berichtete fälschlicherweise Ende Oktober über einen angeblich bevorstehenden Test. Der Artikel bezieht sich jedoch zweifelsfrei auf den Test, der im September bereits stattgefunden hatte. Interessant ist folgender Abschnitt des Berichts, der andeutet, daß die Labour-Partei in der Testfrage tief gespalten war: "The Right wing of the Government, led in this case by $\mathrm{Mr}$ Denis Healey, the Defence Minister, is urging that Britain should carry out one more nuclear test. ... The weapon-hating Left wing, led by Lord Chalfont $\ldots$ is insisting that the test would be disastrous, even though it is permitted under the test ban treaty which forbids explosions above ground." The Daily Express, 27. 10. 1965.

${ }^{57}$ PRO, FO 371/181354, FO-Memo: Lord Chalfont's Visit to Washington, März 1965, ohne genaues Datum. 
Überwachung blieb ebenfalls unerwähnt. Falls sich Sicherheitsgarantien für die Nichtkernwaffenstaaten finden ließen, sollte die Anwendung der Rücktrittsklausel von einem Versagen der Garantien abhängig sein..$^{58}$ Foster machte deutlich, daß die Bundesrepublik Deutschland einen Vertrag, der die europäische Option ausschloß, nicht akzeptieren werde. Chalfont schlug daraufhin vor, den Entwurf dahingehend zu ändern, daß die europäische Option erhalten blieb, und zugleich ein explizites Verbot einzufügen, Kernwaffen in nationale Kontrolle der Bundesrepublik zu überführen. Fosters Bedenken waren damit nicht aus dem Weg geräumt. Er hielt die britischen Pläne, so bald wie möglich einen Vertrag vorzulegen, für verfrüht. ${ }^{59}$

Die ACDA plante statt dessen, der Sowjetunion so bald wie möglich nochmals einen modifizierten cut-off gekoppelt mit der Zerstörung von nuklearen Sprengköpfen vorzuschlagen. ACDA-Direktor Foster, der die USA auch bei den Abrüstungsverhandlungen in den Vereinten Nationen vertrat, unterrichtete die britischen Vertreter bei den Abrüstungsverhandlungen, Lord Chalfont und Sir Harold Beeley, im Mai von dem amerikanischen Vorhaben. Chalfont ging auf die Probleme ein, die ein Produktionsstopp für die britische Regierung bedeutete, aber er war zuversichtlich, daß es mit entsprechender amerikanischer Hilfe in der Uranversorgung möglich sei, die Initiative mitzutragen. Er versprach Foster sogar, eine britische Unterstützung auch gegen innenpolitische Widerstände durchzusetzen. ${ }^{60}$ Sir Harold Beeley bestätigte, daß das Foreign Office grünes Licht für eine positive Haltung gegeben habe. Gleichzeitig wies jedoch ein weiteres Mitglied der britischen Delegation in Genf, John Tahourdin, darauf hin, daß es taktisch geschickter wäre, wenn die USA diesen Vorschlag erst bei der Wiederaufnahme der Genfer Verhandlungen präsentierten. Die Verhandlungen benötigten dringend neuen Schwung. Auf amerikanischer Seite vermutete man allerdings wieder einmal eine britische Verzögerungstaktik. ${ }^{61}$ Als die amerikanischen Vertreter in Genf den britischen Kollegen einen Entwurf vorlegten, kam prompt das Veto aus dem Foreign Office. ${ }^{62}$ Die britische Regierung bewies damit einmal mehr, daß auf ihre Loyalität in den internationalen Verhandlungen kein Verlaß war. Foster bekundete schließlich in seiner Rede bei Beginn der neuen Verhandlungsrunde in Genf im Sommer 1965 nachhaltiges amerikanisches Interesse sowohl an einem Produktionsstopp als auch an einem freeze bzw. einer Zerstörung von Waffen- und Trägersystemen.

Besondere Schwierigkeiten bereitete Großbritannien und den USA unterdessen ein Antrag Jugoslawiens, unabhängig von den Verhandlungen in den Vereinten Nationen eine weltweite Abrüstungskonferenz einzuberufen. Die USA waren gegen eine derartige Konferenz, da sie der Sowjetunion und China als Propagandaforum dienen würde. Sollte China teilnehmen, zöge dies wieder Diskussionen über den chinesischen Ausschluß aus den Vereinten Nationen nach sich. Zudem stünde eine derartige Konferenz der Wiederaufnahme der ENDC-Verhandlungen in Genf im Weg. Ferner war die Frage ungelöst,

${ }^{58}$ PRO, FO 371/181387, British Draft Treaty, 22. 02. 1965.

${ }^{59}$ NA, RG 59, CFPF, DEF 18, box 1591, Memo of Conversation between Chalfont and Foster, 08. 03. 1965.

${ }^{60} \mathrm{NA}, \mathrm{RG} 59, \mathrm{CFPF}, \mathrm{DEF} 18$, box 1591, Memo of Conversation between Foster, Chalfont and Beeley, 07. 05. 1965.

${ }^{61}$ NA, RG 59, CFPF, DEF 18, box 1591, US-Del. to UN, New York, to Secretary of State, 12. 05. 1965.

62 PRO, PREM 13/652, FO to Beeley, 02. 06. 1965. 
ob Staaten wie Nordkorea oder Taiwan eingeladen werden sollten. Die Bonner Regierung war gegen die Konferenz, weil sie eine Einladung der DDR befürchtete. Die britische Regierung war von dem Vorschlag ebenfalls nicht begeistert, vertrat aber die Ansicht, daß man sich nicht gegen eine Konferenz aussprechen könne, falls diese von einer Mehrheit gewünscht werde. Damit bahnte sich ein Konflikt zwischen Großbritannien und den USA an. Außenminister Rusk bat die britische Regierung dringend, nicht für die Resolution zu stimmen, um die westliche Einheit zu wahren. Die Briten waren jedoch entschlossen, die jugoslawische Resolution zu unterstützen, da sie eine Mehrheit zu finden schien. ${ }^{63}$ Die USA und die Bundesrepublik zeigten sich offen enttäuscht über die mangelnde Solidarität. Eine ernsthafte Krise wurde nur dadurch vermieden, daß China schließlich eine Teilnahme ablehnte und zunächst ein Ende der Unterstützung für die Regierung von Chiang Kai-shek in Taiwan sowie die Aufnahme in die Vereinten Nationen forderte. Damit war das ganze Vorhaben zunächst wieder in Frage gestellt.

Im Wahlkampf hatte die Labour-Party Fortschritte in den internationalen Verhandlungen um nukleare Abrüstung zu einem ihrer vordringlichsten Ziele erklärt. Den Ankündigungen folgten allerdings keine spektakulären Maßnahmen. In den Verhandlungen verhielt sich die Regierung mehrmals illoyal gegenüber den engsten Verbündeten. In bezug auf die freeze- und cut-off-Vorschläge war die Regierung unflexibel, solange eine ausreichende eigene Uran- und Plutoniumversorgung nicht garantiert war. Sie fürchtete weitere Vorstöße der USA auf diesem Gebiet, denen man in Genf keine uneingeschränkte Zustimmung geben wollte. Eine prestigeträchtige Ankündigung, IAEA-Kontrollen an zivilen Atomanlagen zuzulassen, wurde vom Verteidigungsministerium blockiert. Die USA waren an einem umfassenden Teststopp nicht interessiert. Zudem mußte die europäische Option einer MLF weiterhin offiziell aufrechterhalten werden. Selbst wenn die MLF niemals Wirklichkeit werden sollte, so wollte Johnson einem geeinten Europa nicht die Möglichkeit verbauen, irgendwann eine eigene Atomstreitmacht zu gründen. ${ }^{64} \mathrm{Die}$ Regierung in London geriet in diesem politischen Umfeld mehr und mehr unter Zugzwang. Sie mußte den Wählern beweisen, daß sie es mit der Abrüstung ernst meinte. Die Forderung Chalfonts, die Anzahl der Kontrollen für einen CTBT zu senken, war insofern ungeachtet seines aufrichtigen Interesses an einem Verhandlungserfolg - auch innenpolitisch motiviert. ${ }^{65}$ Wenn schon die Erfolge ausblieben, so mußte doch ein gewisser Aktionismus die Ernsthaftigkeit der britischen Absichten belegen. Dieser trug jedoch wenig dazu bei, einem Abkommen näher zu kommen.

Im Juli 1965 veröffentlichte ACDA-Direktor Foster in der Zeitschrift Foreign Affairs einen Beitrag mit dem Titel „New Directions in Arms Control and Disarmament“. Foster forderte ein "reassessment of priorities" in der Außenpolitik beider Supermächte. ${ }^{66}$ Er erklärte den Abschluß eines NV-Vertrags zum wichtigsten Ziel beider Supermächte, da Proliferation die Interessen der USA und der Sowjetunion massiv gefährde. Foster verlangte nicht explizit, die MLF aufzugeben, sondern appellierte vielmehr an die

${ }^{63}$ NA, RG 59, CFPF, DEF 18, box 1591, US-Embassy, London, to Dept of State, 11. 06. 1965.

${ }^{64}$ Bunn, Arms Control, S. 72.

${ }^{65}$ Gegenüber den ACDA-Vertretern wurde die innenpolitische Motivation von britischer Seite besonders hervorgehoben. LBJL, NSF, Country File: UK, box 207, Memo of Conversation between Mr. Freund and Mr. Faber, 05. 03.1965.

${ }^{66}$ Foster, Arms Control, S. 588. 
Kreml-Führung, ihre Haltung zu überdenken und vor allem den Nutzen ihrer Propaganda gegen das MLF-Projekt kritisch zu prüfen. Trotzdem war dieser Artikel ein Wink mit dem Zaunpfahl an die eigene Regierung, die entgegen den Empfehlungen des GilpatricReports der Nichtverbreitungspolitik nach wie vor kein besonderes Interesse zollte. Zur gleichen Zeit veröffentlichte die New York Times den Report. Diese Plädoyers für einen NP'T waren ganz im Sinne der Labour-Regierung. In London argwöhnte man jedoch auch, daß das wiedererwachte Interesse an Non-Proliferation in Washington Gefahren für das britische Atomprogramm barg. Konkret fürchteten die Briten, der Kongreß werde im Zuge einer globalen Nichtverbreitungspolitik auch einen Stopp der Uranlieferungen an Großbritannien fordern. Die Bedenken gingen noch viel weiter - die USA könnten auch die ANF-Pläne fallenlassen und die Lieferung der Polaris-Raketen stornieren. ${ }^{67}$ In London war man der Ansicht, daß es höchste Zeit sei, mit einem Vorstoß in der Nichtverbreitungspolitik für Furore zu sorgen. Die Genfer Verhandlungen würden sich sonst von den britischen Interessen hinsichtlich der Non-Proliferation immer mehr entfernen. Die Labour-Regierung könnte dann ihr Ziel, treibende Kraft am top table in Genf zu sein, nicht mehr erreichen. Mit der Vorlage eines britischen Vertragsentwurfs hingegen würde Großbritannien - wie in den Teststopp-Verhandlungen - wieder zu einem der Hauptakteure in Genf.

Die Labour-Regierung wollte nicht weniger als die Konservativen eine tragende Rolle in der Weltpolitik einnehmen. Der Status als Großmacht mit internationalen Verpflichtungen in Verteidigungsfragen sollte auch in den internationalen Verhandlungen entsprechend behauptet werden. Premierminister Wilson machte dies gegenüber den USA deutlich: „One thing that we have stressed is the essential recognition that Britain, so far as defense is concerned, must have a world role. ${ }^{68}$ Der Großmachtstatus mußte natürlich auch in den internationalen Verhandlungen entsprechend dargestellt werden. Gerade da der amerikanische Präsident ein gewisses Desinteresse in der Abrüstungspolitik zeigte, sah man in London eine Chance für Großbritannien, verstärkt "haute politique " $z u$ betreiben. ${ }^{69}$ Davon war jedoch bisher - abgesehen von den ANF-Vorschlägen - wenig zu sehen gewesen.

\section{Der Nichtverbreitungsvertrag ruft Differenzen in der NATO hervor}

\section{Die Präsentation des amerikaniscben Vertragsentwurfs (Juli 1965)}

Die britische Regierung plante, den Verbündeten während der NATO-Ratstagung am 7. Juli einen britischen Entwurf für einen Nichtverbreitungsvertrag vorzulegen, obwohl ACDA-Direktor Foster im Gespräch mit Lord Chalfont einige Monate zuvor schwere Vorbehalte gegen die ersten britischen Entwürfe deutlich gemacht hatte. Die Regierung in Washington wurde vorab davon informiert, daß die britsche Regierung erwarte, ihren Entwurf zur Wiedereröffnung der Eighteen Nation Disarmament Conference (ENDC) in Genf Anfang August als gemeinsamen westlichen Vorschlag präsentieren zu können.

${ }^{67}$ PRO, FO 371/181388, Brit. Embassy, Washington, to FO, 24. 06. 1965.

${ }^{68}$ NA, RG 59, CFPF, DEF 1, box 1691, PM Wilson to Dept. of State, 12. 01. 1965.

${ }^{69}$ PRO, PREM 13/316, Memo by Mr. Shaw (Secretary to PM), 12. 02. 1965. 
Das britische Nichtverbreitungsabkommen sah als zentrale Klausel ein Verbot der Weitergabe von Kernwaffen an Nichtkernwaffenstaaten und Staatengruppen vor. ${ }^{70}$ Damit schlossen die Briten eine europäische Option einer MLF oder einen Mehrheitsentscheid über den Einsatz von Kernwaffen definitiv aus. Eine ANF war nach dieser Formulierung jedoch möglich, da sie ein dauerhaftes Veto der Atommächte über die Kernwaffen der Streitmacht enthielt. Der Vertrag enthielt keinerlei Bestimmungen über Verifikation, und er sah auch keine Sicherheitsgarantien für Nichtkernwaffenstaaten vor. Das Problem der Sicherheitsgarantien sollte nach einem Vertragsabschluß separat gelöst werden. Die Frage der internationalen Kontrollen blieb ausgeklammert, um eine höhere Akzeptanz bei den Nichtnuklearen und der Sowjetunion zu erreichen. Die Verpflichtungen waren von unbegrenzter Dauer, aber eine escape clause bot die Möglichkeit zum Rücktritt, falls ein Staat höchste nationale Sicherheitsinteressen gefährdet sah.

Die kanadische Regierung beabsichtigte ebenfalls auf der NATO-Ratstagung einen Entwurf für ein Nichtverbreitungsabkommen vorzulegen. Der kanadische Vertrag unterschied sich ganz erheblich von der britischen Konzeption. Er differenzierte nicht zwischen Staaten und Staatengruppen. ${ }^{71}$ Die kanadische Formulierung ließ damit offen, ob es einem Nichtkernwaffenstaat verboten war, innerhalb einer Staatengemeinschaft Kontrolle über Kernwaffen auszuüben. Die Kanadier sahen für alle Unterzeichnerstaaten eine internationale Kontrolle des Abkommens durch die IAEO vor. Ausgenommen davon waren nur die militärischen Anlagen der Atommächte. Der Entwurf enthielt eine Sicherheitsgarantie für die Nichtkernwaffenstaaten, wobei die Atommächte kollektiv für die Sicherheit der Nichtnuklearen verantwortlich waren. ${ }^{72}$ Der Vertrag sollte erst in Kraft treten, sobald er von allen Atommächten und einer bestimmten Anzahl von Nichtkernwaffenstaaten ratifiziert war. Das Abkommen enthielt keine Rücktrittsklausel und war von begrenzter Dauer, wobei der genaue Zeitrahmen offengelassen war.

Die Briten waren mit dem kanadischen Vorschlag nicht zufrieden und übten deutliche Kritik. ${ }^{73}$ Großbritannien wollte kein Abkommen unterstützen, das eine europäische $O p-$ tion nicht explizit ausschloß. Ferner war man in der Frage der Sicherheitsgarantien und der Überwachung uneins. Die Labour-Regierung behauptete, die Überwachung stelle ein Problem für die nichtnuklearen Staaten dar, was sicherlich nicht ganz von der Hand zu weisen war. Tatsächlich wollten die Briten aber vor allem eine Inspektion der eigenen zivilen Atomanlagen vermeiden. Der britische Entwurf indes erntete von den Verbündeten nicht weniger Kritik als der kanadische von den Briten. Die Bundesrepublik

70 "Each of the nuclear States party to this Treaty undertakes not to transfer control of nuclear weapons to any non-nuclear State, or to any associaton of States. Each of the nuclear States party to this Treaty undertakes not to assist any non-nuclear State in the manufacture of nuclear weapons." PRO, FO 371/181388, British Draft Treaty, Juni 1965, ohne genaues Datum.

71 "The non-nuclear states party to the Treaty untertake not to: a) manufacture nuclear weapons; $b$ ) otherwise acquire control of nuclear weapons; c) permit any individual or association under its jurisdiction to participate in any of the acts prohibited in sub-paras a) and b) of this article." PRO, FO 371/181389, Canadian Draft Treaty, Juli 1965, ohne genaues Datum.

72 "The nuclear states party to the Treaty undertake to come to the assistance of a non-nuclear state, party to the Treaty, which is subjected to nuclear attack, provided the non-nuclear state has not already received a similar assurance from a nuclear state." PRO, FO 371/181389, Canadian Draft Treaty, Juli 1965, ohne genaues Datum.

${ }^{73}$ Einen kurzen Vergleich zwischen dem kanadischen Vertragsentwurf und den britischen Vorstellungen gibt: Freeman, Arms Control Policy, S. 212-214. 
Deutschland lehnte die britische Fassung kategorisch ab. Auch Italien wollte die europäische Option gewahrt wissen. Die USA hatten bereits im Frühjahr in bilateralen Gesprächen erklärt, daß im Interesse einer deutschen Beteiligung eine Chance für die MLF bestehenbleiben müsse. Sowohl Foster als auch Außenminister Rusk fürchteten einen tiefen Riß in der Allianz, sollten die Briten tatsächlich einen Alleingang wagen. In Washington sah man aber auch, daß die Labour-Regierung einen innenpolitischen Erfolg brauchte und deshalb auf die baldige Vorlage eines NPT drängte. "The Government sorely needs a success that will enhance its political credit and standing with the British voter and the field for picking a winner is severely limited. An achievement, or even a start in the right direction, in the disarmament area as a result of British efforts would enhance the Government's standing domestically in considerable measure. "74 Foster schlug Chalfont daher vor, daß die USA einige geringfügige Änderungen anbringen könnten, um innerhalb der NATO einen Kompromiß zu finden, der für alle Mitgliedstaaten tragbar war.

Der amerikanische Alternativvorschlag ließ nach wie vor die Möglichkeit zur Gründung einer MLF offen. ${ }^{75}$ Der Entwurf sah Kontrollen der Nichtkernwaffenstaaten durch die IAEO vor. Die Kernwaffenstaaten sollten einen Teil ihres für zivile Zwecke bestimmten spaltbaren Materials kontrollieren lassen und solches auch den Nichtkernwaffenstaaten zur Verfügung stellen. Der Verzicht auf Sicherheitsgarantien war ohnehin im amerikanischen Sinne. Die USA beließen auch die britischen Vorschläge hinsichtlich unbegrenzter Dauer und einer escape clause. Foster machte gegenüber Chalfont deutlich, daß diese Version die äußerste Grenze einer für die amerikanische Regierung akzeptablen Fassung darstelle. Die amerikanische Formulierung schloß aus, daß die Bundesrepublik durch eine MLF oder eine europäische Atommacht nationale Kontrolle über Kernwaffen erhielte. Da aber die Möglichkeit für einen Mehrheitsentscheid innerhalb einer europäischen Atommacht offenblieb, lehnte das Foreign Office den Kompromiß ab. London machte auch Einwände gegen den Artikel III des amerikanischen Entwurfs geltend. Großbritannien war von der Lieferung spaltbaren Materials aus den USA abhängig und befürchtete, daß dieser Artikel die amerikanischen Lieferungen an Großbritannien er-

${ }^{74}$ NA, RG 59, CFPF, DEF 18, box 1600, Ambassador Bruce to Dept of State, 16. 07. 1965. Freeman begründet die britische Haltung damit, daß der amerikanische Vorschlag eine europäische Option offengelassen habe. Freeman, Arms Control, S. 217. Der innenpolitische Aspekt war jedoch mindestens genauso bedeutend. Die Labour-Partei hatte vor den Wahlen neue Initiativen in der Abrüstungspolitik versprochen. Die Partei stand unter dem Druck des linken Wählerflügels, der mehrheitlich den baldigen Verzicht Großbritanniens auf Kernwaffen wünschte. Hinzu kamen die schwierige wirtschaftliche Lage in Großbritannien und vergebliche Bemühungen der Labour-Regierung 1965, durch eine "Commonwealth peace mission" in Vietnam zu vermitteln. Wilson unternahm noch weitere ergebnislose Versuche, als ,honest broker' in Vietnam zu vermitteln. Auch hier wurde man dem Anspruch einer einflußreichen Großmacht nicht gerecht. Die Erfolglosigkeit der britischen Vermittlungsbemühungen wird vom britischen Premierminister selbst beschrieben: Wilson, Labour Government, S. 105-123. Siehe außerdem zur britischen Position gegenüber der amerikanischen Vietnam-Politik: Steininger, Vietnamkrieg und Arendt, Vietnam sowie Baylis, Defence Relations, S. 153-157, White, Britain, S. 109-114.

75 „Each of the nuclear States party to this Treaty undertakes not to transfer any nuclear weapons into the national control of any non-nuclear State, either directly, or indirectly through a military alliance; and each undertakes not to take any other action which would cause an increase in the total number of States and other organizations having independent power to use nuclear weapons. " LBJL, NSF, Country File: UK, box 208, Dept of State to US-Embassy, London: Draft Non-Dissemination Treaty, 17. 07. 1965. 
heblich einschränken werde. ${ }^{76}$ Eine Annahme der amerikanischen Version kam somit nicht in Frage. In diesem Punkt bestand ausnahmsweise Einigkeit zwischen dem britischen Außen- und dem Verteidigungsministerium. ${ }^{77}$

Die amerikanische Delegation in Genf tat in dieser Zeit alles, um eine Einigung doch noch zu ermöglichen. Foster schlug vor, die Briten sollten zusammen mit der Präsentation des amerikanischen Entwurfs eine öffentliche Erklärung abgeben, daß ein britisches Veto auch bei einer Umwandlung in eine europäische Atommacht auf jeden Fall bestehenbliebe. Schließlich waren die USA sogar bereit, den problematischen Artikel III entsprechend den britischen Wünschen zu ändern und auch auf die Nennung der IAEO zu verzichten. ${ }^{78}$ Chalfont und Sir Harold Beeley bemühten sich unterdessen, herauszufinden, ob eine Einigung mit der kanadischen Regierung möglich sei. Dies war mit den USA abgesprochen. Ein gemeinsam mit Kanada präsentierter britischer Vorschlag, so hatte Beeley gegenüber dem Foreign Office argumentiert, würde beträchtliches Gewicht haben. Kanada genieße unter den Nichtkernwaffenstaaten hohes Ansehen, und die Haltung Kanadas habe für viele Staaten entscheidende Bedeutung. ${ }^{79}$ Das Foreign Office prüfte daraufhin, welche Bestimmungen aus dem kanadischen Entwurf übernommen werden könnten. Kanada solle dazu bewegt werden, Artikel I und II des britischen Textes zu akzeptieren, die die europäische Option einer MLF ausschlossen. Eine Erwähnung von IAEO-Kontrollen kam für die Briten nach wie vor nicht in Frage. Man wollte auch auf der unbegrenzten Dauer des Vertrags bestehen. Allerdings sollte dies alle fünf Jahre überprüft werden können, und für den Fall, daß mehr als zwei Drittel aller Staaten gegen ein Fortbestehen seien, wurde die Möglichkeit vorgesehen, den Vertrag aufzulösen. Das Foreign Office war bereit, folgende Formel als Sicherheitsgarantie für die Nichtnuklearen in den Text aufzunehmen: „Each of the States Party to this Treaty undertakes to provide or support the provision of immediate assistance to any non-nuclear State Party to the Treaty which is the victim of an act of aggression in which nuclear weapons are used. ${ }^{80}$ Die Bedingungen waren jedoch für Kanada nicht akzeptabel. Somit konnten sich die Briten weder mit den USA noch mit Kanada auf einen gemeinsamen Vertragstext einigen.

Nachdem auch dieser Versuch gescheitert war, ließ der britische Außenminister Stewart seinen Kollegen Rusk wissen, daß die Briten nun ungeachtet der Meinung der Verbündeten ihren Entwurf vorlegen wollten. Rusk hatte Stewart zuvor in mehreren Schreiben dringend gebeten, im Interesse der Allianz die britische Position zu überdenken und einen Kompromiß zu akzeptieren. Angesichts der starren Haltung der Briten fand Rusk schließlich sehr deutliche Worte: „I therefore urge that you review your position and hope that you will find it possible, for the sake of allied unity, to revise your draft accordingly. " ${ }^{81}$ Chalfont sah, daß ein britischer Alleingang einen ernsthaften Streit mit der US-Regierung zur Folge haben würde, und riet aus Genf, auf eine Präsentation des britischen Vertrages zu verzichten. Stewart gab daraufhin Anweisung, die Vorlage

${ }^{76}$ NA, RG 59, CFPE, DEF 18, box 1600, US-Del., Geneva, to Dept of State, 05. 08. 1965.

77 PRO, FO 371/181389, FO to Brit. Embassy, Washington, 21.07.1965 bzw. FO 371/181389, Ministry of Defence to Foreign Office, 21. 07. 1965.

${ }^{78}$ PRO, PREM 13/652, Beeley to FO, 11. 08. 1965.

79 PRO, FO 371/181390, Beeley to FO, 31. 07. 1965.

${ }^{80}$ PRO, FO 371/181390, FO to UK-Del., Geneva, 03. 08.1965.

${ }^{81}$ PRO, PREM 13/652, Rusk to Stewart, 06. 08. 1965. 
zurückzuziehen, falls die USA einverstanden seien, ihren Entwurf ohne die britische Unterstützung einzubringen. „Reluctantly I accept that we should agree to the Americans tabling their draft. Lord Chalfont must, however, make very clear our reservations to articles I and II. These articles are so wrong that if, even by silence, we appear to acquiesce, we shall prejudice our whole position for the future. If the Americans should decide not to table their draft, then, despite the difficulties we must table our own. ${ }^{\text {82 }}$ Chalfont und Foster konnten sich in Genf darauf verständigen, daß die USA ihren Entwurf vorlegen sollten, aber die USA befürchteten, Chalfont werde den Anweisungen Stewarts folgen und den amerikanischen Text scharf kritisieren. Dies war jedoch nicht der Fall.

Die britische Regierung erreichte mit diesem Vorstoß genau das Gegenteil dessen, was sie beabsichtigt hatte. Die Presse wertete die Aktion durchgängig als schwere außenpolitische Niederlage der Labour-Regierung. ${ }^{83}$ Premierminister Wilson versucht dagegen in seinen Memoiren, die Episode als Durchbruch in den internationalen Nichtverbreitungsverhandlungen darzustellen. ${ }^{84}$ Der britische Alleingang hätte um ein Haar eine schwere Krise der special relationship heraufbeschworen. Die starre Haltung der Briten führte auch zu einer Verhärtung der deutschen Position. In Bonn fühlte man sich von den Verbündeten in die Enge getrieben. Die bundesdeutsche Regierung brachte sogar gegen den amerkanischen Entwurf schwere Einwände vor. Die Sowjetunion war nicht geneigt, die amerikanische oder die britische Version als Basis für weitere Verhandlungen zu akzeptieren.

Wer war für diese diplomatische Niederlage verantwortlich? Freeman beschreibt die Situation wie folgt: Nach Aussagen von Außenminister Stewart habe Lord Chalfont beabsichtigt, einen Entwurf vorzulegen, und ihn und Premierminister Wilson gedrängt, diesen Vorstoß zu unterstützen. Die mittlere Ebene des Foreign Office sei hingegen dafür gewesen, sich gegenüber den USA absolut loyal zu verhalten. ${ }^{85}$ Aus den Dokumenten ergibt sich jedoch ein etwas anderes Bild. Die Einschätzung, daß viele Mitarbeiter im Außenministerium gegen den britischen Alleingang waren, bestätigt sich. Auch die britische Botschaft in Bonn riet dringend zu einer Annahme, um unnötige Spannungen mit der deutschen Regierung zu vermeiden. ${ }^{86}$ Botschafter Roberts wies vergeblich darauf hin, daß das eigentliche Ansinnen, die Bundesrepublik Deutschland für die Unterzeichnung eines NPT zu gewinnen, mit dem britischen Entwurf nicht erreicht werden könne. Sicherlich ging die Initiative von Chalfont aus. Er hatte bereits im Frühjahr gegenüber Foster deutlich gemacht, daß ihm an der baldigen Vorlage eines Entwurfs lag. Chalfont war jedoch nicht für die Eskalation des Streits verantwortlich. Gerade in der Endphase der Verhandlungen mit den USA sah es so aus, als drängte Außenminister Stewart auf die Beibehaltung des Konfrontationskurses. Der amerikanische Botschafter in London, Bruce, berichtete dem State Department, daß Lord Chalfont zunächst bereit gewesen sei, dem amerikanischen Entgegenkommen ein Stück britisches Entgegenkommen folgen

${ }^{82}$ PRO, PREM 13/652, Foreign Secretary to Undersecretary, 10.08. 1965.

${ }^{83}$ Daily Express, 16.08.1965, Daily Mail, 16.08.1965, Observer, 16. 08.1965, Daily Telegraph, 17. 08. 1965.

${ }^{84}$ Wilson, Labour Government, S. 130.

${ }^{85}$ Freeman, Arms Control, S. 218-219.

${ }^{86}$ PRO, FO 371/181389, Brit. Embassy, Bonn, to FO, 20. 07. 1965. 
zu lassen und die Änderungen zu akzeptieren: „It appears that other ministers on basis of domestic political considerations overwhelmed Chalfont, who in conversation with Emboff [embassy officials] continued to express feelings that US amendments were in same direction he wishes to go on dissemination problem. ${ }^{\text {"87 }}$ Chalfont war in seiner Fixierung auf die europäische Option nicht weniger rigide als seine Kollegen in London, aber er wollte offensichtlich keine ernsthafte Krise der special relationship riskieren. Chalfont hatte immer deutlich gemacht, daß eine enge Kooperation mit den Verbündeten einer der wichtigsten Bestandteile seiner Politik war. In diese Zusammenarbeit sollte Großbritannien eigenständige und unabhängige Ideen und Konzepte einbringen. Ein Bruch der special relationship war hingegen genau das Gegenteil dessen, was Chalfont anstrebte.

Warum beharrte die britische Regierung geradezu verbissen auf einer endgültigen Aufgabe der europäischen Option? Man hatte die Stimmung in der amerikanischen Regierung offensichtlich falsch eingeschätzt und mit viel weniger Widerstand gerechnet. Lord Chalfont erklärte Foster, die britische Regierung habe wahrscheinlich die Bedeutung von Fosters Aufsatz und die Ergebnisse des Gilpatric-Reports überinterpretiert und angenommen, daß ein Nichtverbreitungsvertrag nun auch "top priority " in Washington sei. ${ }^{88}$ Die Labour-Regierung war davon ausgegangen, daß die USA nun dazu gebracht werden könnten, die MLF mit einer europäischen Option auch offiziell aufzugeben. In London wurde das Argument einer deutschen Nichtbeteiligung nicht als Problem gesehen. Die Bundesrepublik, so Chalfont, werde gar keine andere Wahl haben als einem Abkommen beizutreten. Eine Nichtunterzeichnung werde sich Bonn nicht leisten können. ${ }^{89}$ Die Labour-Regierung sah die Möglichkeit, mit einem außenpolitischen Coup einen innenpolitischen Erfolg zu landen. Zugleich wäre die westliche Allianz hinsichtlich eines multilateralen Abkommens auf die ANF festgelegt gewesen. Damit schien der nächste außenpolitische Erfolg in Reichweite. ${ }^{90}$ Die Befürchtungen, die Bundesrepublik könne auf dem Weg über die MLF Atommacht werden, hatten seit Jahren die britische Nichtverbreitungspolitik dominiert. Nun bestand endlich die Chance, dieses Schlupfloch endgültig und dauerhaft zu verschließen. Entsprechend den britischen Vorstellungen bedeutete dies die Einbindung der Deutschen in die ANF und den Abschluß eines Nichtverbreitungsvertrages. Nichtverbreitungspolitik war in Großbritannien hauptsächlich Deutschlandpolitik, wie der amerikanische Botschafter in London treffend bemerkte: "To many Britishers the issue of non-proliferation is simply defined as being whether or not the Germans will have their own nuclear weapons or be able to control the firing of such weapons." 91

${ }^{87}$ NA, RG 59, CFPF, DEF 18, box 1600, Ambassador Bruce to Dept of State, 21. 07. 1965.

${ }^{88}$ FRUS, 1964-1968, Vol. XI, S. 234, Memo of Conversation, 01. 08. 1965.

${ }^{89}$ PRO, FO 371/181390, Memo by Lord Chalfont, 04. 08. 1965.

${ }^{90}$ Bluth und Freeman behaupten, Chalfont sei bereit gewesen, die ANF für einen NPT fallenzulassen. Freeman, Arms Control, S. 219, Bluth, Britain, S. 164. Dies ist prinzipiell richtig, gilt allerdings noch nicht für diesen Zeitpunkt. Chalfont vertrat Ende Juli 1965 noch die Ansicht, sowjetischem Drängen nach einer Aufgabe der ANF dürfe nicht nachgegeben werden. PRO, FO 371/ 181389, FO to Brit. Embassy, Washington, 22. 07. 1965. Chalfont entwickelte diese Überlegungen im Herbst 1965, im Zusammenhang mit der Vorlage eines sowjetischen NPT-Entwurfs. Aus diesem ging hervor, daß Moskau in der Frage einer multilateralen Atomstreitmacht, sei es eine MLF oder eine ANF, bei der harten Haltung bleiben werde.

${ }^{91}$ LBJL, NSF, Country File: UK, box 208, Ambassador Bruce to Dept of State, 16. 07. 1965. 
Warum legte die Johnson-Regierung immer noch soviel Wert darauf, alle Möglichkeiten für eine MLF offenzulassen? Johnson hatte ja eigentlich Ende 1964 die mulitlaterale Atomstreitmacht schon aufgegeben. Nun hätte eine Chance bestanden, auch offiziell eine Kurskorrektur zu vollziehen. Die amerikanische Regierung hätte einer Formulierung, die ein dauerhaftes Veto der USA über eine zukünftige NATO-Atomstreitmacht vorsah, mit Hinweis auf die sowjetischen Interessen zustimmen können. Damit wäre die MLF noch nicht endgültig begraben gewesen und der Bundesrepublik die Aussicht auf eine nukleare Beteiligung nicht genommen worden. Tatsächlich aber hatte die Veröffentlichung des Gilpatric-Reports und des Foster-Artikels ziemlich heftige Reaktionen in Bonn ausgelöst. Außenminister Schröders Interview, in dem er das deutsche Junktim zwischen der Gründung einer MLF und der Unterzeichnung eines NPT bekräftigte, kann neben der innenpolitischen Motivation Schröders als direkte Reaktion auf den vermeintlich neuen Kurs der USA gesehen werden. ${ }^{92}$ Der amerikanische Außenminister Rusk unterstrich daraufhin, die amerikanische Regierung plane keineswegs, die MLF aufzugeben. Der Gilpatric-Report stelle nicht die Haltung der Regierung dar. In Washington hoffte man offensichtlich immer noch, die sowjetische Führung würde das MLF/NPT-Junktim aufgeben. Außerdem wollte man wohl eine Konfrontation mit Bonn vermeiden, da die Bundesrepublik ihre Drohung wahr machen und sich weigern könnte, einen NPT ohne vorherige MLF-Einigung zu unterzeichnen. ${ }^{93}$ Ein Nichtverbreitungsvertrag ohne deutsche Beteiligung hätte ein Fernbleiben der Sowjetunion zur Folge gehabt. Für den Kreml war ein Abkommen ohne die Bundesrepublik wertlos.

Hinzu kamen jedoch noch weitere Aspekte. Die Gründung der MLF war nicht mehr aktuell. In der anglo-amerikanischen Diskussion um die europäische Option der MLF ging es den USA nicht mehr um die faktische Gründung einer NATO-Streitmacht, die irgendwann im Zuge der europäischen Integration in eine europäische Atommacht umgewandelt werden könnte, sondern vielmehr darum, den Europäern nicht die Möglichkeit zu verbauen, in Zukunft eine Form der kollektiven Nuklearverteidigung aufzubauen. ${ }^{94}$ Gleichzeitig gewannen die MLF-Befürworter in der amerikanischen Regierung wieder an Boden. Einerseits stärkte die harte Haltung der Bonner Regierung die Argumentation, daß eine MLF der Preis sei, den man für die deutsche Beteiligung am NPT zahlen müsse. Andererseits widmete der amerikanische Präsident Johnson sein hauptsächliches Interesse der Innenpolitik und dem Vietnam-Krieg. ${ }^{95}$ In der Abrüstungspolitik übernahm Johnson keine Führungsinitiative und überließ dieses Feld komplett seinen Beratern. Daher hatte die europäische Fraktion im State Department wenig Mühe, die MLF langsam durch die Hintertür wieder auf die Tagesordnung der amerikanischen Politik zu bringen.

${ }^{92}$ Küntzel behandelt diesen Zusammenhang ausführlich. Küntzel, Bonn, S. 86. Siehe hierzu auch: Clausen, Non-Proliferation, S. 82. Clausen sieht ebenfalls einen direkten Zusammenhang zwischen Fosters Aufsatz und dem Schröder-Interview.

${ }^{93}$ Küntzel, Bonn, S. 87.

${ }^{94}$ Siehe hierzu: Seaborg, Tide, S. 164-165.

${ }^{95} \mathrm{Zu}$ den politischen Schwerpunkten Präsident Johnsons siehe: Firestone, Lyndon Johnson. Bezeichnend ist, $\mathrm{da} B$ in dieser 400 Seiten umfassenden Aufsatzsammlung über die Politik Johnsons kein einziger Beitrag der Abrüstungs-, Europa- oder NATO-Politik gewidmet ist. 


\section{Eine kurze Renaissance der $M L F$}

Der sowjetische Vertreter in Genf, Zarapkin, wies den amerikanischen Entwurf, den Foster am 17. August der Achtzehn-Mächte-Konferenz präsentierte, umgehend zurück. Die Begründung war, wie erwartet, die mögliche Gründung einer europäischen Atommacht mit deutscher Beteiligung. Die Genfer Konferenz endete Anfang September, ohne einen nennenswerten Schritt weitergekommen zu sein. Die Nichtverbreitungsverhandlungen wurden in der Vollversammlung der Vereinten Nationen fortgesetzt. Dort legte der sowjetische Außenminister Gromyko Ende September einen sowjetischen Vertragsentwurf vor. Dieser schloß sowohl die Gründung einer MLF - mit oder ohne amerikanisches Veto - als auch der ANF kategorisch aus. ${ }^{96}$ Damit war klar, daß von der Kreml-Führung keine Kompromisse in der Frage einer MLF/ANF zu erwarten waren. Die Aussichten auf eine baldige Einigung waren damit nach wie vor sehr gering. Allerdings verständigten sich Foster und Zarapkin in New York darauf, umgehend intensive bilaterale Gespräche aufzunehmen. Diese waren bereits Anfang Juli durch eine geheime Mission des Sonderbeauftragten Harriman nach Moskau vorbereitet worden. Die Vollversammlung konnte schließlich eine Resolution der Nichtnuklearen verabschieden, die allgemeine Bestimmungen eines Nichtverbreitungsabkommens festlegte. ${ }^{97}$ Grundsätzlich sollte der NPT ein ausgewogenes Verhältnis von Pflichten und Verpflichtungen sowohl der Kernwaffenstaaten als auch der Nichtkernwaffenstaaten darstellen. Es dürften keine Schlupflöcher für Proliferation offenbleiben und der Vertrag sollte Abrüstungsmaßnahmen vorsehen sowie effektive Kontrollen beinhalten. Foster und Zarapkin wollten unabhängig von den bilateralen Verhandlungen die Verhandlungen 1966 im Rahmen der Achtzehn-Mächte-Konferenz fortsetzen. Dies konnte jedoch nicht darüber hinwegtäuschen, daß die Vorlage erster Vertragsentwürfe keine Annäherung der unterschiedlichen Positionen bewirkt hatte.

Das anglo-amerikanische Verhältnis überstand die Krise offensichtlich unbeschadet. Die intensiven Kontakte zwischen Foster und Chalfont blieben während der UN-Verhandlungen in New York bestehen. Der britische Abrüstungsminister war aber nicht geneigt, sich nun dem amerikanischen Kurs anzupassen. Im Gegenteil, Chalfont brachte weiterhin seine eigenen Vorstellungen in die Gespräche ein. Im Oktober ließ er Foster wissen, die britische Regierung sei zu dem Schluß gekommen, daß Inspektionen vor Ort zur effektiven Überwachung eines CTBT nicht notwendig seien. Die britische Regierung wisse, daß man sich in Washington dieser Position nicht anschließen könne. Die amerikanische Regierung, so schlug Chalfont vor, solle aber zumindest einem zweijährigen Testmoratorium zustimmen. Gleichzeitig forderte er, die USA und Großbritannien sollten in bilateralen Gesprächen festlegen, wieviel nukleare Mitsprache die Bundesrepublik erhalten solle. Er gab auch zu erkennen, daß London bereit sei, die ANF für einen NPT fallenzulassen, auch wenn dies noch nicht offizielle Haltung der briti-

${ }^{96}$ „Nuclear weapon powers oblige not to transfer nuclear weapons in any form - directly or indirectly through third States or groups of States - to the ownership or control of States or groups of States not possessing nuclear weapons and not to accord to such States or groups of States the right to participate in the ownership, control or use of nuclear weapons." EA 20 (1965) 24, S. D 518-520, Sowjetischer Vertragsentwurf vom 24. 09. 1965.

${ }^{97}$ ENDC/158 (ENDC Documents) submitted to ENDC/PV. 233, 15. 09. 1965. 
schen Regierung war. ${ }^{98}$ Die USA setzten die Konsultationen mit den Briten routinemäBig fort, verhandelten aber von nun an vor allem bilateral mit der Sowjetunion. Foster informierte Chalfont kurz darüber und versprach, die Briten über den Fortgang der Gespräche auf dem laufenden zu halten. Eine Einladung, an diesen Gesprächen teilzunehmen, erhielt London jedoch nicht. Eine britische „Selbsteinladung“ wurde rundweg abgelehnt. ${ }^{99}$ Damit war die britische Regierung von den unmittelbaren Verhandlungen ausgeschlossen.

Der britische Vorstoß hatte viel Porzellan in den deutsch-englischen Beziehungen zerschlagen. Chalfont hatte versucht, den britischen Entwurf in Bonn als eine Initiative gegen die fortscheitende Proliferation in Asien zu verkaufen, was natürlich angesichts der Fixierung der Briten auf die europäische Option völlig unglaubwürdig war. Das Befremden über das britische Verhalten machte Minister Westrick in einem Gespräch mit dem britischen Botschafter in Bonn deutlich: „The Federal Government had been shocked by statements made by Lord Chalfont in Geneva which they had interpreted as meaning that Her Majesty's Government would never allow non-nuclear allies and the Federal Government more specifically any real voice in NATO nuclear strategy. ${ }^{100}$ Der amerikanische Vorschlag kam in der Bonner Beurteilung nicht viel besser weg. ${ }^{101}$ Die Präsentation des amerikanischen Entwurfs löste einen Proteststurm der Bonner Gaullisten aus, der in verbalen Entgleisungen von Altkanzler Adenauer gipfelte, der das Projekt mit einer Auslieferung Europas an die Sowjetunion gleichsetzten. ${ }^{102}$ Während Washington in der folgenden Zeit versuchte, behutsam mit den bundesdeutschen Interessen umzugehen und der Bundesregierung intensive Konsultationen anbot, verhärteten sich die Fronten zwischen Bonn und London.

Chalfont hatte im Verlauf der Verhandlungen über die Vertragsentwürfe mehrfach wissen lassen, daß seiner Meinung nach die Stimme der Bundesrepublik in Genf viel zuviel Gewicht habe. Er bemerkte nicht ohne Verbitterung, daß die Deutschen in Genf auf die USA mehr Einfluß hätten als die Briten. Der Abrüstungsminister schrieb an Außenminister Stewart, er hoffe sehr, daß die Bundesregierung nach den Wahlen ihren Widerstand aufgeben werde. ${ }^{103}$ Anstatt zu versuchen, die Bundesregierung nun für die geplante britische Kompromißlösung - die ANF - zu gewinnen, wollte Chalfont die britische NATO-Streitmacht einem baldigen Abkommen mit der Sowjetunion opfern. Chalfont war nach der Vorlage des sowjetischen Vertrags zu der Überzeugung gelangt, daß der Westen nur bei einer Aufgabe aller nuclear-sharing-Pläne ein Abkommen erreichen werde. Der Bundesregierung, so Chalfont, werde gar nichts anderes übrigbleiben, als diese Entscheidung $\mathrm{zu}$ akzeptieren. ${ }^{104}$

${ }^{98}$ NA, RG 59, CFPF, DEF 18, box 1600 , US-Delegation to UN, New York, to Dept of State, 15. 10. 1965.

${ }^{99}$ LBJL, NSF, Country File: UK, box 215, Visit of PM Wilson, Talking Points: Disarmament and Non-Proliferation, 13. 12. 1965.

${ }^{100}$ PRO, FO 371/181392, Sir F. Roberts to FO, 25. 08. 1965.

${ }^{101}$ Siehe: Hoppe, Teilhabe, S. 270-271.

${ }^{102}$ Siehe auch: Küntzel, Bonn, S. 91-92.

${ }^{103}$ PRO, PREM 13/652, Chalfont to FO, 01.09. 1965.

104 "Chalfont also said he felt that on the question of setting one desideratum against another we should remember that, considering the situation from the point of view of real-politik, the Germans have very little bargaining power, provided of course that the Americans are prepared to take a stand." PRO, FO 371/181367, Discussion with Lord Chalfont, 30. 10. 1965. 
Das Foreign Office war jedoch nicht bereit, die Position des Abrüstungsministers zur offiziellen Politik zu machen, obwohl in London befürchtet wurde, Chalfont liege mit seiner Einschätzung richtig. Die Solidarität mit den Verbündeten gebot ein Festhalten an der ANF. Eine Studie des Foreign Office kam zu dem Ergebnis, daß eine Aufgabe der ANF nicht nur verhängnisvoll für die deutsch-englischen Beziehungen wäre, sondern auch negative Auswirkungen auf die special relationship hätte. ${ }^{105}$ Die USA kämen möglicherweise auf den Gedanken, die special relationship zu kündigen und die Bundesrepublik Deutschland zum wichtigsten Partner im Bündnis zu machen. Im Außenministerium erkannte man, daß die britische Regierung Gefahr lief, ähnlich wie zuvor de Gaulle, zum Außenseiter im westlichen Bündnis zu werden, wenn man dem außenpolitischen Kurs des Abrüstungsministers folgen würde. Der britische Botschafter in Bonn, Sir Frank Roberts, mahnte ebenfalls zu intensiven Konsultationen, da die Briten auf eine Unterstützung der Deutschen in den weiteren Verhandlungen angewiesen seien. Ein Kompromiß zwischen Bonn und London wäre zu dieser Zeit auch gar nicht unmöglich gewesen. Die Gespräche zwischen Stewart und Schröder im Herbst 1965 zeigten, daß sich die moderaten Kräfte in Bonn und London durchaus hätten einigen können. Schröder erklärte im Gespräch mit Stewart, ein dauerhaftes amerikanisches Veto sei akzeptabel und eine Kontrolle per Mehrheitsentscheid, eine majority voting-option, stehe für ihn gar nicht zur Debatte. ${ }^{106}$ Die gesamte MLF-Diskussion war jedoch bereits völlig festgefahren, und auch in diesem Gespräch blieben die starren Positionen bestehen. Schröder beharrte auf einer Überwasserflotte, Stewart pries die ANF ${ }^{107}$ Zudem sprach nicht nur die Labour-Regierung, sondern auch Bonn in der MLF-Frage mit vielen Stimmen. Kurt Birrenbach, enger Vertrauter von Kanzler Erhard, erhob gegenüber den USA die Forderung, die Bundesrepublik müsse in nuklearen Angelegenheiten mit Großbritannien gleichgestellt werden. Die Briten müßten jetzt einer MLF zustimmen und ihre unabhängige Atomstreitmacht aufgeben. Die finanzielle Lage werde die Briten ohnehin dazu zwingen. ${ }^{108}$ Die Fronten zwischen Bonn und London hatten sich verhärtet, der Riß, der mit der Vorlage der Vertragsentwürfe in Genf entstanden war, konnte nicht gekittet werden.

Für die USA skizzierte die amerikanische Botschaft in Bonn nach der Krise in Genf in einem Memorandum die zukünftige Vorgehensweise gegenüber der Bundesrepublik: „We have a double task of education and persuasion. Neither will be easy. We must avoid giving the impression that we are unmindful of their interests. At the same time we should not hesitate to tell them frankly where narrowness of perspective threatens to damage their position in the eyes of the world. " 109 Die Regierung in Bonn sah die nukleare Option als Faustpfand in den Verhandlungen um die deutsche Wiedervereinigung. ${ }^{110}$ Sie setzte - wie in den Verhandlungen um die Wiedervereinigung Anfang der fünfziger Jahre - nach wie vor auf den hardline approach gegenüber der Sowjetunion: Verhandeln aus einer Position der Stärke. Im Zuge der Entspannungspolitik war „die deutsche Frage“ mehr und mehr ein Hindernis für die bilaterale Verständigung mit der

${ }^{105}$ PRO, FO 371/181392, Brief for Bilateral Talks, 08. 10.1965. Chalfont konnte es allerdings nicht lassen, die Möglichkeit der Aufgabe der ANF gegenüber Foster zumindest anzudeuten.

${ }^{106}$ PRO, PREM 13/220, Record of Converation, 19.11. 1965.

107 Ebenda.

${ }^{108}$ Schertz, Deutschlandpolitik, S. 338/339.

${ }^{109}$ NA, RG 59, CFPF, DEF 18, box 1992, US-Embassy, Bonn, to Dept of State, 18. 08. 1965.

${ }^{110}$ Osterheld, Außenpolitik, S. 218. 
Sowjetunion geworden. ${ }^{111}$ Dies wurde den Deutschen in den Verhandlungen um den NPT einmal mehr schmerzlich bewußt. Der rechte Regierungsflügel war außerstande, die amerikanische "Realpolitik“ zu erfassen, fühlte sich von den USA im Stich gelassen und wandte sich an Frankreich. Die USA waren nicht mehr bereit, Verhandlungen mit dem Kreml von Zugeständnissen in der Deutschlandpolitik abhängig zu machen. Insofern war in Washington ein Junktim zwischen Wiedervereinigung und nuklearem Verzicht nicht akzeptabel.

Das Junktim zwischen einer nuklearen Mitsprache und dem NPT wollten die Bonner allerdings nicht aufgeben. Aus bundesdeutscher Sicht war nach den Wahlen im Herbst 1965 der Weg frei für ein Abkommen über die nukleare Beteiligung der Bundesrepublik. Allerdings hatten die Atlantiker im Laufe des Jahres 1965 an ihren Forderungen erhebliche Abstriche gemacht. Natürlich war auch Bonn nicht verborgen geblieben, daß Johnson das Interesse am MLF-Projekt weitgehend verloren hatte und es in Genf hauptsächlich darum ging, die europäische Option theoretisch zu wahren. Fosters Artikel tat ein übriges, diesen Eindruck zu verstärken. Um so erstaunter waren die Deutschen im Herbst, als die Johnson-Regierung die deutsche Regierung ermunterte, ihre genauen Vorstellungen bezüglich nuklearer Mitsprache darzulegen. Die MLF-Lobby hatte angesichts der Führungslosigkeit des Präsidenten auf diesem Gebiet und der Mißerfolge in Genf wieder an Einfluß gewonnen und startete mit einer Flut von Analysen und Konzepten eine erneute Offensive. ${ }^{112}$ Im Dezember war ein Besuch von Kanzler Erhard bei Johnson geplant. Im Vorfeld dieses Treffens sollten sowohl in Washington als auch in Bonn exakte Konzeptionen für die nukleare Beteiligung der Deutschen erstellt werden. In Washington herrschte inzwischen in der MLF-Frage völlige Uneinigkeit. Befürworter und Gegner konnten sich, wie Verteidigungsminister McNamara später den Briten berichtete, nicht auf eine gemeinsame Linie verständigen. ${ }^{113}$

Nachdem die Chancen für eine nukleare Beteiligung offensichtlich wieder gestiegen waren, präsentierten die Deutschen in den Vorbesprechungen Maximalforderungen. ${ }^{114}$

${ }^{111}$ Zur deutschen Frage in den deutsch-amerikanischen Beziehungen und dem Wandel in der amerikanischen Deutschlandpolitik siehe: Haftendorn, Sicherheit; Hanrieder, Deutschland.

${ }^{112}$ Zum Beispiel: LBJL, WHCF, Confidential File, box 44, Memo by John Leddy, A Fresh Start on the Collective Nuclear Problem, 07. 10. 1965. Ebenda: Memo by Walt Rostow, The European Non-Proliferation Problem, 27. 09. 1965. Die MLF-Befürworter im State Department führten gegenüber bundesdeutschen Regierungsvertretern nun ein weiteres Argument für die MLF ins Feld: „Die Lösung des nuklearen Problems stünde im unmittelbaren Zusammenhang mit der monetären Frage. Die Vereinigten Staaten, so erklärte man, seien besorgt um die Währungslage in England, die ernste Auswirkungen auch auf die amerikanische Situation ausüben könne. Eine kollektive nukleare Lösung könne und müsse zu einer Erleichterung der englischen Devisenlage führen, da England allein die Kosten eines nationalen Waffensystems nicht tragen könne." AAPD, 1965, Dok. Nr. 417, Birrenbach an Schröder, 13.11. 1965. Im State Department überlegte man nun offensichtlich, eine britische Beteiligung mit Aussichten auf eine Entlastung der englischen Zahlungsbilanz im Rahmen eines nuklearen Systems erreichen zu können. Es ließen sich aber keine Hinweise finden, daß dieser Aspekt zwischen britischen und amerikanischen Regierungsvertretern besprochen wurde. Auf höchster Ebene wurde darüber sicher nicht gesprochen. PRO, PREM 13/686, Records of Conversation between Wilson und Johnson, 16.-17. 12. 1965.

${ }^{113}{ }_{n}$ We were told that staffs were working overtime preparing position papers in preparation for the Erhard visit and that views were changing daily." PRO, PREM 13/805, UK-Del. to NATO to FO, 17. 12. 1965.

${ }^{114}$ Siehe hierzu: Schertz, Deutschlandpolitik, S. 337-339. 
Die Bonner Regierung erwartete eine Beteiligung an einer multilateralen Atomstreitmacht mit gemischten Besatzungen und einer europäischen Option. Außerdem forderte sie eine Beteiligung an der nuklear-strategischen Planung der NATO in Form einer nuklearen Planungsgruppe (Nuclear Planning Group, kurz: NPG) der führenden NATOStaaten, wie sie Verteidigungsminister McNamara und Sicherheitsberater Bundy bereits als Ersatzlösung für die MLF ins Gespräch gebracht hatten. ${ }^{115}$ Erhard legte Johnson bei seinem Besuch schließlich in einem umfassenden Memorandum die deutschen Vorstellungen dar. Anders als erwartet, ging Johnson jedoch während des Treffens mit Erhard kaum auf die nukleare Frage ein. Der amerikanische Präsident erklärte kurz, daß er einer nuklearen Beteiligung der Bundesrepublik nach wie vor positiv gegenüberstehe. Konkrete Vereinbarungen wurden aber nicht getroffen. ${ }^{116}$ Unmittelbar nach dem Treffen zwischen Johnson und Erhard war der britische Premier Wilson zu Unterredungen bei dem amerikanischen Präsidenten in Washington. In den Besprechungen mit Wilson hatte Johnson dem britischen Premier kurz zu verstehen gegeben, daß er sich keinesfalls mehr für eine NATO-Streitmacht engagieren werde. ${ }^{117}$ Kurz darauf bat jedoch Johnson unter Bezugnahme auf das deutsche Memorandum den britischen Premierminister Wilson, die Anliegen der Bundesrepublik wohlwollend zu prüfen und einer NATO-Atomstreitmacht grundsätzlich zuzustimmen. ${ }^{118}$ Johnson verfolgte damit in der nuclearsharing-Frage einen Schlingerkurs, der sowohl in der Bundesrepublik als auch in Großbritannien nur sehr schwer verständlich war.

Wilson war über die unerwarteten, mahnenden Worte bezüglich der deutschen Interessen äußerst befremdet. In den Antwortschreiben an Erhard und Johnson ging er mit keinem Wort auf das deutsche Memorandum ein, sondern betonte statt dessen die Vorzüge und Möglichkeiten der nuklearen Planungsgruppe. Wilson wies seine Mitarbeiter an, die Korrespondenz mit Johnson in dieser Frage zu verzögern und diskret auf eine Aufgabe aller MLF-Konzepte zu drängen. ${ }^{119}$ Der Premierminister teilte die Auffassung seines Abrüstungsministers, wonach die Pläne für die nukleare Streitmacht (Hardware-Lösung)

${ }^{115}$ Eine genaue Analyse der Entstehungsgeschichte und der konkreten Ausgsstaltung der NPG gibt: Buteux, Nuclear Consultation, S. 39-68. Siehe auch: Haftendorn, Kernwaffen, S. 166-179, Bluth, Britain, S. 179-200.

${ }^{116}$ Zum Treffen Erhard-Johnson siehe Schertz, Deutschlandpolitik, S. 341-342. Interessant sind in diesem Zusammenhang auch die Aufzeichnungen von Staatssekretär Carstens über ein Gespräch mit dem amerikanischen Botschafter McGhee, in dem der Besuch Erhards im Dezember 1965 und die MLF zur Sprache kamen: „Ich wies den Botschafter auf das Gespräch zwischen dem Bundeskanzler und Präsident Johnson in Washington im Dezember 1965 hin, bei dem der Präsident unsere Vorschläge als sehr hilfreich bezeichnet habe. Der Botschafter erwiderte, in einem vorangegangenen Gespräch habe aber Präsident Johnson versucht, dem Bundeskanzler das Projekt auszureden (was richtig ist)." AAPD 1966, Dok. Nr. 268, Aufzeichnungen von Staatssekretär Carstens, 25. 08. 1966.

${ }^{117}$ Aus den Gesprächsprotokollen ergeben sich keine Hinweise, daß Johnson mit Wilson überhaupt über die MLF-Frage gesprochen hat. PRO, PREM 13/686, Records of Conversation, 16.-17. 12. 1965. Aus Wilsons persönlichen Notizen über die Begegnung geht hervor, daß Johnson Wilson kurz über die MLF-Diskussion innerhalb der amerikanischen Regierung im vergangenen Dezember unterrichtete und versicherte, daß er in dieser Frage keine weitere Initiative mehr ergreifen werde. PRO, PREM 13/686, Notes of Prime Minister Wilson, 16. 12. 1965.

${ }^{118}$ Haftendorn, Glaubwürdigkeit, S. 146.

${ }^{119}$ PRO, PREM 13/805, Wilson to Erhard, 03. 01. 1966, Wilson to Johnson, 03. 01. 1966, Sir Oliver Wright (Private Secretary to PM) to Mr. MacLehouse (FO), 16. 03. 1966. 
begraben und die Deutschen mit einer Beteiligung an der nuklearen Planungsgruppe (Software-Lösung) zufriedengestellt werden sollten. Auch das Foreign Office wies in einer ausführlichen Analyse die Forderungen Erhards zurück. ${ }^{120}$ Johnson hatte unterdessen das Problem wieder aus den Augen verloren. US-Botschafter Bruce ließ die britische Regierung im Januar wissen, der Präsident habe noch keine Zeit gehabt, das weitere Vorgehen festzulegen. Zudem sei die Regierung in dieser Frage noch immer tief gespalten. ${ }^{121}$ Vor Überraschungen aus Washington war man damit nach wie vor nicht sicher.

\section{Großbritannien und die Verhandlungen zum Jahreswechsel 1965/1966. Ein Verzicht auf alle nuclear-sharing-Pläne?}

Sicherheitsberater Bundy und Verteidigungsminister McNamara versuchten im Zuge der wiederaufgeflammten MLF-Debatte herauszufinden, ob die Briten nun bereit waren, ihre unabhängige Atommacht aufzugeben, wenn sich dadurch die Chancen für den Abschluß eines NPT erhöhten. Bundy und McNamara hatten folgenden Plan ausgearbeitet: Großbritannien sollte seine Polaris-U-Boote zusammen mit amerikanischen in eine multilaterale Streitmacht einbringen. Die USA, nicht jedoch Großbritannien, würden ein dauerhaftes Veto über diese Flotte haben. Die Bundesrepublik solle an dieser Flotte in einer noch nicht näher definierten Form beteiligt werden. Damit könne man zwei Fliegen mit einer Klappe schlagen. Bonn wäre die geforderte nukleare Mitsprache eingeräumt und das britische Atompotential unter Kontrolle gebracht worden. Die Sowjetunion, so nahm man an, würde möglicherweise eine Flotte mit einem garantierten dauerhaften Veto der USA akzeptieren. ${ }^{122}$ Bundy und McNamarara sondierten daher während des Besuchs von Premier Wilson, welche Vorstellungen die britische Regierung in bezug auf die angekündigte Internationalisierung des britischen Arsenals und die Zukunft Großbritanniens als Atommacht hatte. Die amerikanischen Hoffnungen, dem britischen Atompotential Zügel anlegen zu können, waren gleichwohl unrealistisch. Die ANF-Konzeption der Labour-Regierung hatte bereits deutliche Hinweise auf die Zielsetzung der Nichtverbreitungspolitik gegeben. Premierminister Wilson, Außenminister Stewart und Verteidigungsminister Healey hatten diese grundlegende Frage im Juni 1965 theoretisch erörtert. Dabei bestand absolute Einigkeit, daß Großbritannien auch angesichts der fortschreitenden Proliferation ein eigenständiges Nuklearprogramm unbedingt fortsetzen sollte. ${ }^{123}$

${ }^{120}$ PRO, FO 371/181393, The NATO Nuclear Question, Dezember 1965, ohne genaues Datum.

${ }^{121}$ PRO, PREM 13/805, Sir P. Gore-Booth to FO, 14. 01. 1966.

${ }^{122}$ LBJL, NSF, Country File, UK, box 215, Briefing Paper: Points for Discussion with Prime Minister Wilson, 13.12.1965.

${ }^{123}$ PRO, PREM 13/128, Record of Conversation between Wilson, Stewart, Healey, Zuckerman and Trend, 02. 06. 1965. Interessant ist dabei besonders die Argumentation von Außenminister Healey: „The increasing risk of nuclear proliferation can not now be reduced by our abandoning the nuclear weapons and if a spread should take place, we might need our own weapons for defence purposes. If we decide to keep going the nuclear weapons programme we still retain the option of abandoning it later, should there be advantage in doing so; if we should decide on abandonment now we should be dropping irrevocably a capability which may prove of great value in a future period which we can not now foresee." Healey war damit gegen einen einseitigen Verzicht Großbritanniens, für ihn waren diese Waffen auch ein Faustpfand in der internationalen Politik. 
Unabhängig davon sprach Wilson im Dezember 1965 mit Bundy, McNamara und Ball freimütig über die Zukunft der britischen Abschreckung. Dabei zeigte sich deutlich, daß für den britischen Premier die ANF nicht mehr aktuell war. Wilson plante, die PolarisFlotte in Asien einzusetzen und für Großbritannien eine neue world role in Form einer asiatischen Atomstreitmacht unter britischer Führung zu suchen. ${ }^{124}$ Großbritannien sollte als nukleare Schutzmacht der asiatischen Commonwealth-Staaten Weltgeltung zurückerlangen. Staaten wie Indien würden im Rahmen einer asiatischen Atomstreitmacht oder „Commonwealth-ANF“, wie Außenminister Stewart das Projekt bezeichnete, an der nuklearen Verteidigung beteiligt und dadurch davon abgehalten, eigene Kernwaffen zu entwickeln. Von einer Aufgabe der unabhängigen Abschreckung, wie sie die Labour-Partei im Wahlkampf gefordert hatte, war dabei freilich nicht die Rede. Großbritannien würde natürlich ein Veto über diese Pacific Nuclear Force behalten. Im europäischen Rahmen, so Wilson, wäre die Bundesrepublik nicht mehr unmittelbar mit dem britischen Atompotential konfrontiert, da es in Europa keine Rolle mehr spielen würde. ${ }^{125}$ Die Labour-Regierung sah damit die Zukunft der unabhängigen britischen Abschreckung in Form einer Pacific Nuclear Force unter britischer Führung. Die amerikanischen Verteidigungsexperten waren dieser Idee nicht abgeneigt. Diese Planung entsprach sehr stark der amerikanischen Konzeption, wonach das Problem Proliferation im Hinblick auf die verschiedenen betroffenen Staaten individuell gelöst werden sollte. Wenn durch ein britisches Engagement in Asien nationale Proliferation verhindert werden konnte, schien dies durchaus im amerikanischen Interesse zu liegen.

Lord Chalfont war unterdessen nicht minder weit als Wilson von der ANF entfernt, er hätte allerdings die Hoffnungen Bundys auf eine Aufgabe des nationalen britischen Atompotentials unter Umständen erfüllt. Der Abrüstungsminister ließ eine Studie zu der Frage erstellen, ob eine einseitige Aufgabe der britischen Nuklearmacht die Chancen auf den Abschluß eines NPT erhöhen würde. Was Chalfont allerdings nicht wollte, war eine nukleare Beteiligung und Aufwertung der Bundesrepublik Deutschland. Dem Abrüstungsminister schwebte die Übergabe des britischen Atompotentials an ein neu zu gründendes, internationales Gremium, eventuell im Rahmen der Vereinten Nationen, bzw. die völlige Aufgabe der Kernwaffen vor, um der deutschen Forderung nach nuklearer Mitsprache die Grundlagen zu entziehen. Er wollte diesen Weg gehen, falls sich dadurch die Aussichten auf einen NPT erheblich verbesserten. Dies bedeutete keineswegs, daß er eine Gleichstellung mit den übrigen europäischen Mächten billigend in Kauf genommen hätte. Chalfont dachte, genau wie Wilson, nicht europäisch, sondern an Großbritannien als führende Macht des Commonwealth. Er sah jedoch einen Statusunterschied zu den anderen europäischen Mächten durch die special relationship gewährleistet. Chalfont betonte immer wieder die Bedeutung der engen Zusammenarbeit mit den USA in globalen politischen Fragen. Er verstand die Großmachtrolle Großbritanniens im Kontext eines westlichen Führungsduos, dem die Bundesrepublik Folge zu leisten habe. Großbritanni-

Healey argumentierte in dieser Hinsicht ganz ähnlich wie der rechte Regierungsflügel in Bonn. Ein nuklearer Verzicht könne nur gegen eine entsprechend wertvolle Gegenleistung erfolgen. Gleichzeitig kalkulierte er ganz bewußt mit einem tatsächlichen Einsatz der Kernwaffen - auch unabhängig von den USA. PRO, PREM 13/128, Memo by the Minister of Defence, 11. 06. 1965.

${ }^{124}$ PRO, PREM 13/686, Record of Conversation, 17. 12. 1965.

${ }^{125}$ Ebenda. 
en sollte in enger Kooperation mit den USA eine aktive Sicherheitspolitik im Nahen und Fernen Osten betreiben, unter Umständen auch ohne eigene Kernwaffen. ${ }^{126}$ Dieser entscheidende Punkt machte Chalfont zum Außenseiter innerhalb seiner Regierung. ${ }^{127}$

Die Aufforderung an das Foreign Office, eine Aufgabe des britischen Atompotentials als realistische Möglichkeit in Betracht zu ziehen, war eine Provokation der eigenen Regierung. Chalfont war bereit, tatsächlich eine umfassende nukleare Abrüstung ins Auge zu fassen, vorausgesetzt dadurch könnte eine globale nukleare Abrüstung erreicht werden. Ein Memorandum des Foreign Office kam zu dem Schluß, daß sich die Chancen auf einen NPT durch die Auflösung des britischen Potentials nicht erhöhen würden. ${ }^{128}$ Im Foreign Office argumentierte man, daß dieser Schritt nur gemeinsam mit Frankreich Sinn mache. Sonst bestehe die Gefahr, daß auch andere europäische Staaten versuchen könnten, aus Prestigegründen Atommacht zu werden. Sollte sich Großbritannien freiwillig vom top table zurückziehen, könnte eine andere europäische Macht diesen Sitz anstreben. Außerdem wolle man Frankreich nicht den Rang der einzigen unabhängigen Atommacht in Europa einräumen.

In der regierungsinternen Auseinandersetzung um die Zukunft des britischen Atompotentials zeigte sich einmal mehr, wie sehr die Statusfrage die Diskussion um Nichtverbreitung dominierte. London suchte eine Rolle für die Polaris-Flotte, die die britische Weltmachtstellung garantieren sollte, ohne in Bonn ein Gefühl der Zweitklassigkeit hervorzurufen. Gleichzeitig wollte man unter gar keinen Umständen eine Statusminderung gegenüber Frankreich hinnehmen. In Bonn dachte man ebenfalls in Kategorien von Prestige und internationalem Ansehen. Bonn forderte eben gerade die Aufhebung des nuklearen Minderstatus und nukleare Gleichberechtigung mit Großbritannien im Rahmen einer NATO-Streitmacht. Als die MLF schließlich endgültig aufgegeben wurde, zeigte sich, daß - abgesehen davon, daß man die nukleare Option als bargaining chip gegenüber der Sowjetunion behalten wollte - der einseitige nukleare Verzicht bündnisintern hauptsächlich ein Prestigeproblem war. Staatssekretär Carstens stellte zum NPT fest: „Wenn wir dem Abkommen beitreten, vermindert sich unser Status im Vergleich zu den Atommächten weiter; und zwar nicht nur gegenüber den USA und der Sowjetunion, sondern auch gegenüber unseren europäischen Partnern England und Frankreich, mit denen wir uns an Bedeutung und Einfluß vergleichen können und müssen. " ${ }^{129}$ Genau das versuchte

${ }^{126}$ Chalfont legte sein außenpolitisches Konzept für Großbritannien im April 1964 in der Times dar. The Times, 06. 04. 1964. Siehe hierzu auch S. 119.

${ }^{127}$ So rieten beispielsweise die Beamten im Verteidigungsministerium Healey dringend, Chalfont wegen seiner abrüstungspolitischen Äußerungen zur Ordnung zu rufen. PRO, DEFE 24/223, Mr. Andrew to Mr. Healey, 21. 07. 1966. Healey bat Chalfont daraufhin in einem Schreiben um Zurückhaltung mit Aussagen über eine britische Bereitschaft, nukleare Trägersysteme abzuschaffen. PRO, DEFE 24/223, Healey to Chalfont, 22.07. 1966.

${ }^{128}$ PRO, FO 371/181393, FO-Memo: Non-Dissemination and the UK-Deterrent, November 1965, ohne genaues Datum.

${ }^{129}$ AAPD, 1966, Dok. Nr. 367, Aufzeichnungen von Staatssekretär Carstens, 14. 11. 1966. Carstens' Memorandum lag sowohl Außenminister Schröder als auch dem designierten Bundeskanzler Kiesinger und dem zukünftigen Außenminister Brandt vor. Schröder vermerkte in einem Begleitschreiben: „Ich bin im wesentlichen einverstanden - Bedenken habe ich nur gegen Darstellung der niederländischen Rolle und gegen Teile des Frankreichkapitels." Ebenda, Anmerkung 1. Über den geringen militärischen Nutzen der MLF war man sich sowohl in Bonn als auch in Washington im klaren, siehe: Schertz, Deutschlandpolitik, S. 338. 
London zu verhindern. Der Abrüstungsminister ging insofern neue Wege, als er die britische Weltmachtstellung nicht auf den Besitz von Kernwaffen zurückführte, sondern die britische world role über die special relationship gewährleistet sah.

Die britische Regierung hatte die ANF stillschweigend fallengelassen. Diese Position durfte mit Rücksicht auf die Bundesrepublik und die USA noch nicht die offizielle Politik darstellen. Die amerikanische MLF-Politik war völlig unberechenbar. Die Briten waren Anfang 1966 im unklaren darüber, welchen Kurs Washington nun weiter verfolgen würde. In London hoffte man, die USA würden schließlich und endlich die Hardware-Lösung zugunsten eines NPT begraben und versuchen, die Bundesrepublik für eine nukleare Planungsgruppe zu gewinnen. Andererseits befürchtete die Regierung nach dem Schreiben des amerikanischen Präsidenten, Washington werde irgendwann tatsächlich Druck auf London ausüben, einer Hardware-Lösung zuzustimmen. Gleichzeitig war die Sowjetunion immer noch nicht bereit, das Junktim zwischen einem Verzicht auf alle Konzeptionen über nukleare Mitsprache in der NATO und dem NPT aufzugeben. In dieser Situation blockierte die ungelöste nuclear-sharing-Frage nicht nur eine Neuordnung innerhalb des westlichen Bündnisses, sondern vor allem ein Vorankommen in den Genfer Verhandlungen. Der britischen Regierung war nun daran gelegen, diese Situation endlich zu klären. Innerhalb der NATO mußte eine Lösung gefunden werden, damit die NPT-Verhandlungen konstruktiv weitergeführt werden konnten. Es bestand die Gefahr, daß die Sowjetunion angesichts eines endlosen Taktierens um die MLF die Verhandlungen beendete. Zugleich mußte der Kreml dazu gebracht werden, diese Lösung zu akzeptieren. Insofern erachtete London an zwei Fronten Überzeugungsarbeit und „Entscheidungshilfe“ für unerläßlich. Der Westen mußte in der Nichtverbreitungspolitik auf eine einheitliche Linie gebracht werden, die nach Möglichkeit ein Entgegenkommen gegenüber den Vorstellungen in Moskau beinhaltete. Den Kreml mußte man davon überzeugen, daß der Westen an einem Abkommen nachhaltig interessiert und Kompromißbereitschaft vorhanden war.

Ende des Jahres 1965 forderte der britische Delegierte in Genf, Sir Harold Beeley, in einem langen Schreiben an das Foreign Office, daß das Außenministerium so schnell wie möglich eine Lösung der nuclear-sharing-Frage in Angriff nehmen solle. Beeley bezeichnete alle Verhandlungen mit der Sowjetunion als sinnlos, bevor nicht geklärt sei, wie die NATO-interne nukleare Mitsprache konkret aussehen solle. Zudem sei ein weiteres Verzögern der Verhandlungen mit der Sowjetunion gefährlich, da diese langsam die Geduld mit dem Westen verliere. ${ }^{130}$ Lord Chalfont forderte ebenfalls ein Ende der Diskussionen und einen eindeutigen Beschluß. Er fürchtete, die Johnson-Regierung strebe nun doch eine Hardware-Lösung an, daher solle die Entscheidung so bald wie möglich fallen. ${ }^{131}$ Chalfont wies Foster in den bilateralen Gesprächen Ende Januar 1966 auch darauf hin, daß die Problematik der nuklearen Mitsprache nun baldmöglichst gelöst werden müsse. Die Briten planten daher, während der anglo-amerikanischen Gespräche noch einmal einen Vertragsentwurf vorzulegen. Sollten sich die USA und die übrigen NATO-Verbündeten auf diese Version einigen können, wäre immerhin in der Frage der Nichtverbreitung endlich eine gemeinsame westliche Position erzielt.

Der zweite britische Vertragsentwurf war so formuliert, daß die Gründung einer europäischen Atomstreitmacht möglich war, vorausgesetzt, eine der bisherigen europäischen

${ }^{130}$ PRO, FO 371/187460, Beeley (UK-Del., Geneva) to Street (FO), 29.12. 1965.

${ }^{131}$ PRO, FO 371/187460, Record of Conversation in the FO, 06. 01. 1966. 
Atommächte behielt ein dauerhaftes Vetorecht. ${ }^{132}$ Dieser Entwurf war damit weniger restriktiv als der erste. Als die Briten diese Fassung in Washington vorlegten, stellte sich jedoch heraus, daß auch die ACDA den bisherigen amerikanischen Entwurf überarbeitet hatte und ebenfalls einen neuen Text besprechen wollte. Nach längeren Diskussionen um Nuancen in der Formulierung waren Chalfont und Beeley einverstanden, dem amerikanischen Entwurf zuzustimmen. ${ }^{133}$ Die USA waren in der Frage der europäischen Option den Briten ein kleines Stück entgegengekommen. Die britische Regierung verstand den Text so, daß eine europäische Option nur noch mit Beteiligung einer der bisherigen europäischen Atommächte möglich sei. Allerdings schloß der Text nach der britischen Interpretation eine majority-voting option, also Kontrolle per Mehrheitsentscheid, noch nicht aus. ${ }^{134}$ Damit war erstmals eine anglo-amerikanische Einigung über den zentralen Artikel eines Vertragstextes erzielt worden. Großbritannien wollte nun so schnell wie möglich die Zustimmung der übrigen NATO-Partner einholen, um den Text dann in trilateralen Gesprächen mit der Sowjetunion zu diskutieren.

Neben dem zähen Ringen mit dem engsten Verbündeten setzte die Regierung in London auf intensive Kontakte zum Kreml, um die tatsächlichen Chancen für einen NPT zu erforschen und die Moskauer Führung nach Möglichkeit für eine Kompromißlösung zu gewinnen. Lord Chalfont war bereits Anfang Dezember 1965 in Moskau gewesen. Im Februar 1966 reiste Premierminister Wilson in Begleitung des Abrüstungsministers in die Sowjetunion. Premierminister Wilson schlug ein Treffen der drei führenden Atommächte vor, um, wie in den Verhandlungen um den PTBT, in trilateralen Gesprächen einen Kompromiß zu finden. ${ }^{135}$ Wilson wollte auf diesem Weg Großbritannien zurück an einen Tisch der „Großen Drei“ holen, nachdem sich die USA geweigert hatten, die Briten in die bilateralen Diskussionen mit einzubeziehen. ACDA-Direktor Foster gab dem sowjetischen Außenminister Gromyko auf dessen Anfrage hin zu verstehen, daß die USA keine trilateralen Gespräche auf Außenministerebene wünschten. ${ }^{136}$

Der Abrüstungsminister, der im März 1966 noch einmal zu Gesprächen in Moskau war, hatte in erster Linie versucht herauszufinden, ob die Sowjetunion im Falle einer Aufgabe der Hardware-Lösung tatsächlich bereit sei, einen NPT zu unterzeichnen. ${ }^{137}$ Chalfont

${ }^{132}$ PRO, FO, 371/187460, British Draft Treaty, Januar 1966, ohne genaues Datum.

${ }^{133}$ Beeley erklärte am Ende der Diskussionen: „Since the UK believed we now had a better treaty, it would support it, and it would not volunteer any statements or reservations regarding the European option part of the problem." NA, RG 59, CFPF, DEF 18, box 1595, Memo of Conversation, 20. 01. 1966. Freeman spricht hingegen davon, daß die USA diesen Entwurf trotz der britischen Ablehnung Ende März in der ENDC vorgelegt hätten. Freeman, Britain's Arms Control Policy, S. 223.

${ }^{134}$ PRO, FO 371/187460, Street (FO) to Barnes (FO), 25. 01. 1966. Der zentrale Artikel I des amerikanischen Entwurfs war äußerst umfangreich und wird deshalb hier nicht wiedergegeben. Er befindet sich in PRO, FO 371/187460, US-Draft Treaty, Januar 1966, ohne genaues Datum. Es zeigt sich, daß die Entwürfe im Laufe der Zeit immer komplizierter wurden und die Frage, was die jeweilige Formulierung definitiv ausschloß bzw. erlaubte, kaum noch zu beantworten war. In der folgenden Zeit gab es im Foreign Office immer wieder Auseinandersetzungen über die Interpretation verschiedener Formulierungen.

${ }^{135}$ PRO, PREM 13/1251, Memo of Conversation, 23. 02.1966.

${ }^{136}$ PRO, PREM 13/1251, Brit. Emb., Moscow, to FO, 22. 03. 1966.

${ }^{137}{ }_{n}$ Lord Chalfont asked on the hypothetical assumption that the West had to stop discussing consultation on nuclear problems, what would be regarded as a satisfactory sign of this. Mr. Gromyko said that either separately or jointly they should say that they had no such plans. There was no 
fragte Gromyko, wie ein Verzicht auf die nuclear-sharing-Pläne für die Kreml-Führung zufriedenstellend zum Ausdruck gebracht werden könne. Gromyko gab mit der expliziten Zusicherung, Moskau werde dieses westliche Zugeständnis nicht propagandistisch ausschlachten, deutlich zu verstehen, daß die Aussicht auf eine multilaterale NATOStreitmacht für die Sowjetunion das zentrale Hindernis gewesen war und ein definitives Ende dieser Pläne den Weg für den NPT frei machen werde. Chalfont empfahl daraufhin seiner Regierung eine „concerted action against the hardware solution" ${ }^{138}$. Hinzu kam noch, daß die Sowjetunion den anglo-amerikanischen Vertragstext Ende März in Genf ablehnte. Der sowjetische Delegierte Roschtschin argumentierte, daß ein Verbot von control über Kernwaffen nicht ausreiche. Roschtschin unterstrich, der Sowjetunion komme es darauf an, auch access und transfer zu verbieten. ${ }^{139}$ Dies zielte einmal mehr auf die $n u$ clear-sharing-Pläne des Westens. Premierminister Wilson war indes zur selben Überzeugung gekommen wie Chalfont. Wilson ließ auch gegenüber amerikanischen Regierungsvertretern keinen Zweifel mehr daran, daß er - sollten die USA doch noch auf einer NATO-Flotte bestehen - eine Kraftprobe innerhalb des Bündnisses riskieren werde. Wilson erklärte gegenüber Arthur Goldberg, dem amerikanischen Botschafter bei den Vereinten Nationen: „What now had become crystal clear to him [Wilson] was that he would be totally opposed to any solution of the nuclear problems of the Alliance which would give the Germans any access to nuclear hardware... If it ever became necessary for him to bang the table in dealing with the affairs of the Alliance, it would be on this subject that he would bang it." ${ }^{140}$ Die ACDA-Führung sollte nun zur Aufgabe der majorityvoting option überredet werden. Der britische Botschafter in Washington, Dean, richtete im Juni 1966 ein entsprechendes Schreiben an ACDA-Direktor Foster. Dieser teilte die Ansicht der britischen Regierung; er war aber realistisch genug zu sehen, daß die amerikanische Regierung nicht in der Lage war, eine Entscheidung zu treffen. ${ }^{141}$

Der verstärkte Druck, die MLF-Pläne endgültig fallenzulassen, wurde von Sir Shuckburgh, dem britischen Vertreter bei den Vereinten Nationen, und dem britischen Botschafter in Bonn, Roberts, nicht begrüßt. Beide forderten mehr Rücksicht auf die Bundesrepublik. Zunächst müsse die durch den französischen Austritt aus der NATO im März 1966 provozierte Krise innerhalb des Bündnisses gelöst werden. Frankreich hatte - nicht unerwartet - den Austritt aus dem Bündnis mit Wirkung vom 1. Juli 1966 erklärt. ${ }^{142}$

fear that the Soviet Government would make public capital of a Western abandonment of position. They would simply take note of it and proceed with the negotiations. This was because each side would gain equally by such act." PREM 13/1251, Record of Conversation, 22. 02. 1966. 138 PRO, PREM 13/1251, Chalfont to FO, 26. 03. 1966.

${ }^{139} \mathrm{Zu}$ den genauen Details der Roschtschin-Begründung siehe: Seaborg, Tide, S. 177-178.

${ }^{140}$ PRO, PREM 13/805, Memo of Conversation, 04. 03. 1966. Interessant ist in diesem Zusammenhang folgender Eindruck aus Washington über die angebliche Haltung der britischen Regierung: „Dazu berichtete Botschafter Knappstein, Washington, bereits am 30. November 1965, im amerikanischen Außenministerium bestehe der Eindruck, daß die Haltung von Stewart, der offenbar von Chalfont beeinflußt sei, und auch die von Healey gegenüber hardware-Lösungen recht negativ erscheint. In etwas geringerem Maße gelte das von Wilson selbst. Vermutlich werde die britische Regierung sich letzten Endes doch zu einer hardware-Lösung verstehen..." AAPD, 1965, Dok. Nr. 468, Anm. 6.

${ }^{141}$ PRO, FO 371/187465, Dean to Hood, 01.06.1966.

${ }^{142}$ Zum Austritt Frankreichs aus der NATO siehe: Haftendorn, Glaubwürdigkeit, S. 11-23 sowie Bozo, France, Kap. 2 und Harrison, Reluctant Ally, S. 49-71. 
_Dieser Schritt muß im Zusammenhang mit de Gaulles Ablehnung der Strategie der flexible response, seinen Vorstellungen von der Rolle Frankreichs in der NATO - seinem Vorschlag einer nuklearen Dreierherrschaft von 1958 - und dem Nassauer Abkommen gesehen werden und war eine Herausforderung an die Vereinigten Staaten, die Frankreich eine gleichberechtigte Rolle im westlichen Bündnis und nukleare Kooperation verweigert hatten. In dieser Situation warnte Roberts davor, die ohnehin angespannten Beziehungen zu Bonn zusätzlich mit der MLF-Diskussion zu belasten. ${ }^{143}$ Der amerikanische Außenminister war ebenfalls der Ansicht, daß die Regierung in Bonn zunächst mit dieser Krisensituation genug zu tun habe. Er sah eine Stabilisierung des westlichen Bündnisses als vorrangig an. Rusk machte auch in den Gesprächen mit dem britischen Außenminister deutlich, daß seiner Meinung nach die Verhandlungen mit der Sowjetunion um den Nichtverbreitungsvertrag erst einmal zurückgestellt werden sollten. ${ }^{144}$ Damit prallten trotz der anglo-amerikanischen Einigung über einen Vertragstext nun zwei Extrempositionen aufeinander. Rusk sah in bezug auf den NPT keinen akuten Handlungsbedarf. Für ihn war klar, daß die Atommächte ohnehin nicht weiterverbreiten würden. Er hatte wiederholt deutlich gemacht, daß für ihn das Problem nicht in Bonn, sondern in der Eigeninitiative von Staaten wie Indien und Israel liege, dem man auf bilateraler Ebene begegnen solle. Der britische Premier Wilson und die britische Delegation in Genf drängten darauf, den Weg für einen NPT so schnell wie möglich frei zu machen. Dafür war man auch durchaus bereit, die Deutschen ein wenig rude zu behandeln.

Die Erwartungen bezüglich einer französischen Mitarbeit in Genf waren schon vor dem französischen NATO-Austritt nahezu auf den Nullpunkt gesunken. Ende des Jahres 1965 hatten noch verschiedene Anzeichen aus Paris darauf hingedeutet, daß Frankreich im folgenden Jahr möglicherweise seinen Sitz in der Genfer Konferenz einnehmen würde. Frankreich war den Genfer Verhandlungen mit der Begründung ferngeblieben, in Genf würde nicht über tatsächliche nukleare Abrüstung verhandelt, sondern über eine Zementierung des nuklearen Klubs der Atommächte. Diese ablehnende Position resultierte aus der Haltung de Gaulles, der die force de frappe als ein Instrument betrachtete, das nukleare Monopol der Supermächte zu brechen und die Glaubwürdigkeit der Abschreckung wiederherzustellen, die durch die Strategie der flexible response verlorengegangen war. Im Laufe des Jahres 1965 hatte die französische Regierung allerdings mit dem Kreml über Abrüstungsfragen gesprochen. Gromyko unterstützte bei einem Besuch in Paris im Mai eine Forderung Frankreichs nach einer Konferenz der Atommächte. Die französische Regierung vertrat in der Abrüstungspolitik einen Ansatz, der in direktem Gegensatz zu den britischen und amerikanischen Zielen stand. Frankreich forderte umfassende nukleare Abrüstung der Supermächte als ersten Schritt, dann werde sich das Problem der Nichtverbreitung von selbst lösen. Die Briten drängten darauf, zunächst die Gefahr der Weiterverbreitung von Kernwaffen zu bannen, danach könne über Abrüstung verhandelt werden. Im Oktober hattte Außenminister Couve die französische Haltung nochmals deutlich gemacht. Die Kommentare aus London waren wenig freundlich: „The French approach to non-dissemination contains elements of practically every attitude of which we disapprove. M. Couve follows the most extreme Indian position in suggesting that measures of nuclear disarmament should precede a non-dissemination

${ }^{143}$ PRO, FO 371/187466, Shuckburgh to Hood, 17.6. 1966, sowie Roberts to Hood, 01. 07. 1966.

${ }^{144}$ PRO, PREM 13/1251, Record of Conversation, Juni 1966, ohne genaues Datum. 
agreement. . . Fortunately whether France is or is not prepared to sign a non-dissemination treaty is of less importance than in the case of the Test Ban Treaty, except as a disruptive example to the near-nuclear states. ${ }^{\text {" } 145}$

Folglich war man im Foreign Office über das französische Fernbleiben in Genf nicht unglücklich. Auf eine Anfrage der britischen Botschaft in Paris, ob Frankreich doch noch zu einer Teilnahme bewegt werden solle, kam man im Foreign Office zu dem Schluß, daß die Franzosen in Genf nur "furchtbare Nervensägen" wären. ${ }^{146}$ Einige Monate später versuchten die USA herauszufinden, ob eine Chance bestehe, daß Frankreich seinen Sitz in Genf doch noch einnehme. ${ }^{147}$ Der nächste Paukenschlag de Gaulles war jedoch keineswegs eine Ankündigung der französischen Teilnahme in Genf, sondern der Austritt Frankreichs aus der NATO. Damit endeten zugleich die anglo-amerikanischen Bemühungen, Frankreich zur Zusammenarbeit in Genf zu bewegen. Gleichzeitig bestand nun die Notwendigkeit, Solidarität mit der Bundesrepublik zu zeigen, um Bonn auf seiten der USA zu halten.

\section{Die Einigung der Supermächte Ende 1966}

\section{Großbritannien und die bilateralen Verhandlungen}

Mit dem französischen NATO-Austritt rückten die Sicherheitsinteressen der Bundesrepublik wieder stärker in das Blickfeld der westlichen Allianz. Damit schienen die Chancen für eine nukleare Beteiligung der Bundesrepublik wieder zu wachsen. Unterdessen war allerdings der Druck auf Präsident Johnson, den Weg für ein Nichtverbreitungsabkommens frei zu machen, beträchtlich gestiegen. Im Januar hatte Senator John Pastore, zweiter Vorsitzender des Joint Committee on Atomic Energy, eine Resolution eingebracht, die verstärkte Maßnahmen des Präsidenten forderte, um das Problem der Weiterverbreitung von Kernwaffen so schnell wie möglich zu lösen. ${ }^{148}$ Im März fanden verschiedene Anhörungen im Senat statt, bei denen unter anderem der Außen- und der Verteidigungsminister sowie die ACDA-Führung über die Nichtverbreitungspolitik Rede und Antwort stehen mußten. Die Differenzen innerhalb der Johnson-Regierung zwischen Befürwortern und Gegnern eines NPT offenbarten sich dabei an den Vorträgen von Rusk und McNamara. McNamara, Foster und Seaborg lieferten gleichwohl zusammen mit Senator Pastore ein überzeugendes Plädoyer dafür, dem Abschluß eines NPT nun eindeutigen Vorrang vor einer kollektiven NATO-Nuklearstreitmacht einzuräumen. ${ }^{149}$ Die Pastore-Resolution wurde schließlich im Juni im Senat ohne eine einzige Gegenstimme angenommen. Johnson gratulierte Pastore in einem Schreiben zu diesem Er-

${ }^{145}$ PRO, FO 371/181393, Brit. Embassy, Paris, to FO, 22. 10. 1965. Minute by Stuart (FO), 28. 10. 1965.

${ }^{146}$ PRO, FO 371/181365, Brit. Embassy, Paris, to FO, 21. 12. 1965. Minute by Street (FO), 06. 01. 1966.

147 NA, RG 59, CFPF, DEF 18, box 1592, Memo of Conversation, 19. 02. 1966.

${ }^{148}$ Seaborg, Tide, S. 180. Bunn, Arms Control, S. 73.

${ }^{149}$ Seaborg gibt einen genauen Überblick über die verschiedenen Argumente. Danach erklärte vor allem Verteidigungsminister McNamara in einer engagierten Rede, daß es ein absolutes Sicherheitsinteresse der USA sei, die Anzahl der Atommächte auf die bestehenden zu begrenzen. Siehe: Seaborg, Tide, S. 181-182. 
folg und informierte ihn davon, daß er ACDA-Direktor Foster angewiesen habe, so bald wie möglich einen neuen Anlauf zu starten, um ein Abkommen mit der Sowjetunion zu erreichen.

Die Pastore-Resolution hatte damit ihren Zweck erreicht. Die Idee zu dieser Resolution stammte von ACDA-Vize Fisher, der nach Möglichkeiten gesucht hatte, den Präsidenten indirekt positiv zu beinflussen, denn die Abrüstungsbehörde hatte keinen direkten Zugang zum Präsidenten. Fisher war es leid, daß Johnson alle abrüstungspolitischen Vorschläge mit dem Außenminister, aber niemals mit der ACDA-Führung besprach. Von Rusk war in bezug auf den NV-Vertrag keine engagierte Haltung zu erwarten. Das eindeutige Votum des Senats gab dem Präsidenten die Sicherheit, daß er mit einem Nichtverbreitungsvertrag keinerlei Gefahr lief, im Kongreß eine Niederlage hinnehmen zu müssen. Johnson hatte eine traumatische Angst davor, ein Debakel à la Wilson zu erleben, dies hatte sich schon deutlich in der MLF-Frage gezeigt. Mit dem positiven Votum des Senats war für Johnson ein ganz entscheidender Unsicherheitsfaktor beseitigt. Der Präsident konnte sich nun des Rückhalts und der Unterstützung der Abgeordneten sicher sein.

Die ACDA-Führung nahm auch weiterhin über Umwege Einfluß auf den Präsidenten. Fisher wandte sich zusammen mit Spurgeon Keeny, einem Mitglied des Gilpatric Committee, sowie John McNaughton, einem engen Vertrauten von Verteidigungsminister McNamara, an den neuen außenpolitischen Berater des Präsidenten, Bill Moyers. ${ }^{150}$ Moyers wurde nach eingehenden Gesprächen mit der ACDA-Führung zu einem überzeugten Befürworter eines NPT und machte seinen Einfluß bei Johnson geltend. Nach der Annahme der Pastore-Resolution fielen die Argumente der Abrüstungsbehörde auch bei Johnson auf fruchtbaren Boden. ${ }^{151}$ Am 5. Juli signalisierte Johnson während einer Pressekonferenz nicht nur der Sowjetunion, sondern auch der eigenen Regierung, daß er in der Nichtverbreitungspolitik eine Entscheidung getroffen hatte: „We are doing everything we can to reach an agreement on such a treaty. We are very anxious to do it. We hope the Soviet Union will meet us and find an acceptable compromise in language which we can both live with. ... We think it is the most important decision of our time and we are going to do everything to bring people together on it. " 152 Johnsons Aussage war klar: Die USA würden von nun an in den bilateralen Verhandlungen nicht mehr versuchen, Forderungen, die die Gegenseite ablehnte, in dem Vertragstext zu verankern, sondern sich bemühen, einfache Formulierungen zu finden, die beide Seiten zu ihren Gunsten interpretieren konnten. Eine Einigung der Supermächte sollte nun innerhalb von wenigen Monaten gelingen.

Warum erfolgte die Entscheidung des Präsidenten so spät? Immerhin war Johnson anders als Rusk oder Sicherheitsberater Rostow - kein überzeugter Befürworter einer nuklearen NATO-Streitmacht. Johnsons ganzes außenpolitisches Interesse galt dem Vietnamkrieg. Dies wurde insbesondere zum Jahreswechsel 1965/66 deutlich. Erhard und Wilson waren im Dezember 1965 nach Washington gekommen, um die nuclearsharing-Frage zu klären. Mit beiden sprach Johnson aber hauptsächlich über Vietnam.

\footnotetext{
${ }^{150}$ Bunn, Arms Control, S. 73-74. Bunn nannte diese Gruppe „the cabal within the Johnson-Administration".

151 Bunn, Arms Control, S 74.

152 Documents on Disarmament 1966, S. 405.
} 
Die ACDA-Führung hatte, anders als unter Präsident Kennedy, keinen direkten Zugang zum Präsidenten. Johnson befürchtete mangelnde Unterstützung für ein Nichtverbreitungsabkommen im Kongreß, und mit Sicherheitsberater Rostow und Außenminister Rusk waren seine engsten Berater auf die nukleare Hardware-Lösung fixiert und an einem NPT uninteressiert. Rusk registrierte allerdings als einer der ersten den Prioritätenwechsel im Weißen Haus und vollzog innerhalb kürzester Zeit eine Kehrtwendung. Er wies bereits Ende Juni die ACDA-Führung an, den jüngsten hochkomplizierten Vertragsentwurf durch einen vereinfachten Text zu ersetzen. ${ }^{153}$

Der neue sowjetische Delegationsleiter in Genf, Roschtschin, erklärte Ende Juli, daß das Kernstück eines Vertrags das Verbot des "Transfers“ von Kernwaffen sein müsse. ${ }^{154}$ Foster griff diese Aussage Roschtschins auf und wies Fisher in Genf an, seinem sowjetischen Kollegen eine einfache Formulierung vorzulegen, die ohne nähere Definition schlichtweg "the transfer of nuclear weapons" verbieten würde. Fisher sollte diesen Entwurf auf für beide Seiten unverbindlicher Basis mit Roschtschin diskutieren. ${ }^{155}$ Roschtschin lehnte die Formulierung ab, da sie ein Verbot des Transfers an Nichtkernwaffenstaaten, nicht jedoch an Staatengruppen, vorsah. Foster schlug daraufhin in einem Memorandum an Rusk folgendes weitere Vorgehen vor: „I think in order to obtain a treaty, we would have to prohibit the transfer of nuclear weapons to a non-nuclear weapon state either directly or indirectly through a group of states. ... I would recommend a letter from the President to the Chancellor indicating that a NATO force involving mixed ownership of nuclear weapons supplied by the US does not appear to be feasible... Once this had been accomplished the United States would be in a position to undertake serious negotiations with the Soviet Union ...." ${ }^{156}$ Johnson war noch nicht bereit, Erhard die Illusion im bezug auf die MLF zu nehmen, aber die beiden Außenminister Rusk und Gromyko vereinbarten, daß eine amerikanisch-sowjetische Arbeitsgruppe umgehend beginnen solle, einen gemeinsamen Text zu formulieren. Als sich diese Gruppe unter der Leitung von Foster und Roschtschin einige Wochen später auf einen ersten Entwurf geeinigt hatte, traf sich Präsident Johnson mit seinen engsten Beratern in Camp David, um über den Text zu beraten. Dort wurde beschlossen, die Formulierung zurückzuweisen. Johnson befürchtete, eine Annahme könne die NATO vor eine Zerreißprobe stellen und die Deutschen dazu veranlassen, dem Vorbild de Gaulles zu folgen.

Anfang Dezember 1966 akzeptierten Rusk und Gromyko unter Vorbehalt folgende Version: „Each nuclear-weapon State Party to this Treaty undertakes not to transfer to any recipient whatsoever nuclear weapons or other nuclear explosive devices or control over such weapons or explosive devices directly, or indirectly; and not in any way to as-

${ }^{153}$ Seaborg, Tide, S. 189.

${ }^{154}$ Die Betonung lag dabei auf "transfer". Die Sowjetunion hatte an dem letzten amerikanischen Entwurf kritisiert, daß er nur "transfer of control " verbieten würde, nicht aber "transfer of weapons". Die entscheidende Phase der bilateralen Verhandlungen zwischen der Sowjetunion und den USA ist sowohl bei Bunn als auch bei Seaborg minutiös dokumentiert. Bunn gehörte der Gruppe an, die ab September an der Formulierung eines gemeinsamen Textes arbeitete. Daher wird das amerikanisch-sowjetische Ringen um einen gemeinsamen Text im folgenden verhältnismäßig knapp behandelt. Zu den verschiedenen Formulierungen, die zur Diskussion standen, siehe insbesondere: Bunn, Arms Control, S. 75-79.

${ }^{155}$ LBJL, NSF, National Security Council History, NPT, box 55, Foster to Fisher, 27. 07. 1966.

${ }^{156}$ LBJL, NSF, National Security Council, History, NPT, box 55, Foster to Rusk, 30. 08. 1966. 
sist, encourage, or induce any non-nuclear-weapon State to manufacture or otherwise acquire nuclear weapons or other nuclear explosive devices, or control over such weapons or explosive devices. " 157 Die Formulierung "to any recipient whatsoever" zielte nicht direkt auf das Problem der nuklearen Teilhabe innerhalb von Staatengruppen und schien damit für die Deutschen ein klein wenig leichter verträglich als die letzte Version, die die Staatengruppen explizit genannt hatte. Trotzdem umfaßte der Text auch ein Weitergabeverbot an Staatengruppen. Außerdem verbot er nicht nur „transfer of control“, sondern auch „transfer of ownership“. Dies waren die zentralen westlichen Zugeständnisse an Moskau. Er erlaubte die Gründung einer nuklearen Planungsgruppe und die Stationierung von amerikanischen Atomwaffen auf NATO-Gebiet, solange diese Waffen unter der Kontrolle und im Besitz der USA blieben. Er erlaubte auch, daß ein zukünftiges vereintes Europa die Nachfolge Frankreichs und Großbritanniens als Kernwaffenstaat antreten könnte. Damit hatte Johnson den Europäern die Chance auf eine nukleare Verteidigung gewahrt. Diese Interpretation war für den Westen von zentraler Bedeutung. Bei der Unterzeichnung des Vertrags 1968 veröffentlichten die USA ein separates Memorandum, das die westliche Interpretation enthielt. Die US-Regierung hatte deutlich gemacht, daß sie den Vertrag nicht ratifizieren könne, falls Moskau öffentlich dieser Interpretation widerspräche. Die Einigung der Supermächte über den zentralen Artikel I im Dezember 1966 wurde in geheimen bilateralen Verhandlungen erzielt. Die engsten Verbündeten hatten spätestens mit der Entscheidung Johnsons, dem NV-Vertrag Prioriät einzuräumen, den Anschluß an die amerikanische Nichtverbreitungspolitik verloren.

Der britische Abrüstungsminister sah Anfang Juli 1966 die Aussichten für ein Abkommen positiv, da in den USA die Befürworter eines NV-Vertrags langsam die Oberhand gewännen und Johnson nach der Eskalation in Vietnam einen außenpolitischen Erfolg dringend benötige. "With a firm push from the Prime Minister", so Chalfont, könne noch im Sommer ein Vertrag unterzeichnet werden. ${ }^{158}$ Die Briten hatten zudem unerwartete Hilfe erhalten. Ende Juli machten die Vertreter der Niederlande, Belgiens, Norwegens und Kanadas auf einer NATO-Sitzung überraschend klar, daß sie für den baldigen Abschluß eines NPT waren und daher eine Aufgabe der europäischen Option mit der Möglichkeit eines Mehrheitsentscheids wünschten. Der Vertreter der Niederlande brachte sogar einen entsprechenden Änderungsvorschlag für den amerikanischen Vertragsentwurf ein. ${ }^{159}$ Damit verstärkte sich auch der Druck auf die amerikanische Delegation in Genf. In einer Besprechung der Western Four in Genf ${ }^{160}$ drängten nun General Burns aus Kanada und Lord Chalfont gemeinsam die ACDA-Vertreter zur Aufgabe. Burns wies deutlich darauf hin, daß abgesehen von Deutschland und Italien kein NATO-Staat für eine Beibehaltung der derzeitigen Position sei. Die kleineren Mitglieder des Bündnisses hatten neben dem NPT nach dem Austritt Frankreichs aus der NATO noch einen weiteren Grund, gegen einen Mehrheitsentscheid innerhalb einer NATO-Streitmacht und auch gegen eine Hardware-Lösung überhaupt zu sein. Nun war klar, daß Frankreich niemals einer NATO-Nuklearstreitmacht beitreten würde. Eine britische Beteiligung

157 Zitiert nach: EA 23 (1968) 14, S. D 322.

${ }^{158}$ PRO, FO 371/187467, Memo by Lord Chalfont, 04. 07. 1966.

${ }^{159}$ PRO, FO 371/187466, UK-Delegation to NATO to FO, 20. 07. 1966.

${ }^{160}$ Die USA, Kanada, Großbritannien und Italien waren die vier NATO-Mitglieder in der Achtzehn-Mächte-Abrüstungskonferenz in Genf. 
war mehr als fraglich. Damit wäre die multilaterale NATO-Flotte eine von den USA und der Bundesrepublik dominierte Streitmacht, in der die Stimmen der übrigen NATO-Mitglieder kaum noch Gewicht hätten.

Nachdem ein Treffen zwischen Johnson und Wilson für Ende Juli geplant war, hatte Chalfont erklärt, der Premierminister solle den amerikanischen Präsidenten bei dieser Gelegenheit noch einmal nachhaltig auf die Bedeutung des Nichtverbreitungsvertrages hinweisen. Johnson brachte das Thema Nichtverbreitungspolitik allerdings mit keinem Wort zur Sprache. Statt dessen konzentrierte sich das Gespräch im wesentlichen auf den Vietnamkrieg. ${ }^{161}$ In dieser Situation schlug Chalfont vor, die USA und Großbritannien sollten gemeinsam den Deutschen erklären, daß es keine Hardware-Lösung mehr geben werde. Außerdem sollten beide Staaten umgehend einen gemeinsamen Vertragsentwurf vorlegen, der der Sowjetunion entgegenkäme. ${ }^{162}$ Der Abrüstungsminister hatte zuvor Sir Harold Beeley angewiesen, aus den vorliegenden Vertragsentwürfen der Sowjetunion und der USA einen compromise-treaty zu basteln. Dieser sollte nun den USA vorgelegt werden. Chalfont ging somit davon aus, daß die Verhandlungen zwischen der Sowjetunion und den USA in einer Sackgasse steckten und dringend eine neue Initiative benötigten. In London bemerkte man nicht, daß die USA das Thema nuclear-sharing benutzten, um zu testen, wie ernsthaft der sowjetische Verhandlungswille war. Chalfont verlangte, die Bundesregierung erst vor den Kopf zu stoßen und dann mit der Sowjetunion zu verhandeln. Die USA gingen unterdessen genau den umgekehrten Weg. ${ }^{163}$ Dort war man der Ansicht, daß ein offizielles Statement über die Aufgabe der majority-voting option zu

${ }^{161}$ Johnson bat Wilson vergeblich, wenigstens ein symbolisches Truppenkontingent zu entsenden. Arendt, Vietnam, S. 258. Die mangelnde Unterstützung in Vietnam machte die Johnson-Regierung für das britische Drängen in der Nichtverbreitungsfrage sicher nicht empfänglicher. Arendt spricht sogar davon, daß der Streit um Südostasien und das britische Truppenkontingent „den Tiefpunkt der special relationship markierte“. Arendt, Vietnam, S. 258.

${ }^{162}$ PRO, FO 371/187438, Memo by P. Buxton (FO, Private Secretary to Lord Chalfont), 05. 08. 1966. Dieser Kurs war mit dem Außenminister abgesprochen: Memo by Lord Chalfont for the Secretary of State, 16. 08. 1966.

${ }^{163}$ Das Memo Chalfonts an den Außenminister offenbart, daß die britische Regierung den entgegengesetzten Ansatz verfolgte. Es weist zudem auch auf das zentrale Problem des britischen Ansatzes hin: Der Westen würde einseitig eine Option aufgeben, ohne zu wissen, was die Sowjetunion zu akzeptieren bereit war. Wie weit würde der Kreml den westlichen Atommächten entgegenkommen? Andererseits war Chalfont nicht bereit, die Probleme der US-Regierung in bezug auf die Bundesrepublik anzuerkennen. Zudem zeigt es, daß auf der Planungsebene des Foreign Office große Unsicherheit über die Vorgehensweise herrschte. Insofern erscheint es lohnenswert, das Memo an dieser Stelle ausführlich zu zitieren. "The policy is controversial in the following respects: i) we do not know that the Russians will even tacitly accept nuclear consultation. Some people in the Foreign Office are convinced that they would not. But I believe that they will, if we can find means of assuring them that we are ruling out any new nuclear force, any mixed manning and any kind of joint ownership of nuclear weapons. ii) To reach the position proposed the Americans have a long way to move. First, they must agree to close the remaining gap in their own treaty, the European Option, which would permit a majority of non-nuclear powers to override the nuclear ones in a mixed association; but they are already moving this way, if only because they are virtually isolated on the issue apart from the Germans. Secondly and more seriously, they must bring themselves at length to agree that any hardware solution to nuclear sharing is a bad one and to tell the Germans so - or to support us if we do. There is a strong body of opinion in the Foreign Office that the Americans will not wear this policy at present and that it is unwise anyway because of the bad effect that it would have on German policy generally." PRO, FO 371/ 187438, Memo by Lord Chalfont, 16. 08. 1966. 
überhaupt nichts führen werde, außer zu Verbitterung in Bonn. Vielmehr sollte in geheimen Verhandlungen mit der Sowjetunion sondiert werden, welche Chancen und Möglichkeiten auf ein Abkommen bestünden. Bestimmte Optionen konnten dann ebensogut stillschweigend aufgegeben werden.

Die Regierung in London wurde über den Fortgang der bilateralen Verhandlungen nur noch gelegentlich informiert. ${ }^{164}$ Der neue britische Außenminister Brown erfuhr im Oktober bei einem Treffen mit US-Außenminister Rusk nur, daß die USA planten, der Sowjetunion einen neuen Entwurf für den Artikel I vorzulegen. Rusk überreichte Brown einen Text mit der Bitte um einen britischen Kommentar. Außenminister Brown ließ wissen, die britische Regierung finde die Formulierung nicht optimal. Er gab allerdings auch zu verstehen, daß in London niemand daran glaube, daß die Kreml-Führung diese Fassung akzeptieren werde. Die britische Delegation in Genf stimmte mit dieser Ansicht überein. Allerdings kritisierte Beeley gegenüber ACDA-Vertreter de Palma den amerikanischen Text aus einem ganz anderen Grund: „Beeley said the new formulation with the unqualified obligation not to relinquish control raised a serious political problem for his government which had pledged to internationalize its deterrent. When I expressed surprise that the UK seemed to want to hold open options of the kind they have been urging the US to close, he stressed that this was a political problem and implied that the problem was largely presentational. ... I told him it was hard for me to take this seriously ... and I wondered how real the prospect was in view of recent indications that the UK intended to retain its deterrent. "165 Damit verstärkte die britische Regierung einmal mehr den Eindruck, daß sie konstruktiven Verhandlungen eher hinderlich als förderlich war. Beeley sah wohl plötzlich das Problem, daß die Labour-Partei bei den nächsten Wahlen nicht mehr mit dem Versprechen, die unabhängige nukleare Abschreckung aufzugeben, die linken Wählerstimmen mobilisieren könne. Davon abgesehen wollte Lord Chalfont sicherlich die Möglichkeit erhalten, im Zuge weiterer Abrüstungsmaßnahmen die britische Atomstreitmacht unter internationale Verwaltung zu stellen. Beeley übergab de Palma schließlich noch den britischen Enwurf als Alternativvorschlag und bat seinen Kollegen, diesen eingehend zu prüfen.

Foster unterrichtete Lord Chalfont Ende Oktober über die amerikanisch-sowjetische Arbeitsgruppe und die Gespräche in Camp David, denen die Ablehnung des ersten gemeinsamen Entwurfs der Arbeitsgruppe folgte. Der Regierung in London wurde also erst zu diesem Zeitpunkt klar, daß eine Einigung unmittelbar bevorstand und die britische Kritik ebenso überflüssig war wie der jüngste britische Vertragsentwurf. Chalfont verfügte nun, die Briten sollten keine weitere Initative mehr ergreifen, um die bilateralen Verhandlungen nicht zu stören. ${ }^{166}$ In Washington war allerdings unterdessen der Eindruck entstanden, daß Großbritannien den Entwurf ablehnte, den Rusk seinem briti-

\footnotetext{
${ }^{164}$ Dies zeigt sich ganz deutlich an der Korrespondenz zwischen dem FO und der britischen Delegation in Genf beziehungsweise der britischen Botschaft in Washington. Schreiben wie das folgende Beispiel sind zahlreich und werden im Laufe des Jahres 1966 immer mehr: „We have received no report on this Foster/Roshchin meeting from you and John Street has said on his return that he heard no news of it while he was in Geneva. It may be that the Americans have deliberately neglected to tell us about it, lest it should influence our stand on the draft treaty." PRO, FO 371/ 187465, Stuart (FO) to Richardson (Geneva), 27. 06. 1966.

${ }^{165}$ NA, RG 59, CFPF, DEF 18, box 1593, Memo of Conversation, 19. 10. 1966.

${ }^{166}$ PRO, FO 371/187470, Stuart (FO) to UK-Mission to UN, New York, 07. 11. 1966.
} 
schen Kollegen Brown gegeben hatte. Chalfont sah hinter diesen in Washington zirkulierenden Vermutungen eine Intrige innerhalb der amerikanischen Regierung. Die NPTGegner wollten die Gespräche beenden und den Briten dann die Verantwortung dafür zuschieben. Botschafter Dean in Washington wiegelte $a b$, aber die britische Botschaft empfahl ebenfalls, die bilateralen Verhandlungen nicht mehr zu beeinflussen, da das anglo-amerikanische Verhältnis in Sachen Nichtverbreitungspolitik sehr angespannt sei. ${ }^{167}$

Mitte November war ein Besuch des britischen Außenministers Brown in Moskau geplant. Die sowjetisch-britischen Gespräche verliefen im Hinblick auf den Nichtverbreitungsvertrag allerdings ergebnislos. Browns Besuch konnte die bilateralen amerikanisch-sowjetischen Verhandlungen nicht positiv unterstützen. Die Kreml-Führung gewann in den Gesprächen mit Brown den Eindruck, daß die britische Regierung über den Stand der Verhandlungen nicht auf dem laufenden war, und sah in dem britischen Außenminister auch keinen ernstzunehmenden Verhandlungspartner mehr: „Dobrynin [Soviet Ambassador in Washington] said that when Brown raised the subject of non-proliferation, he did not seem to be very aware of what had been going on. The Soviets had decided in fact that he was uninformed of recent Soviet-US exchanges on the subject and played the talks accordingly. " 168 Kurz vor Browns Besuch in Moskau hatte die ACDA die Briten davon unterrichtet, daß die jüngste amerikanische Version nicht die Zustimmung der sowjetischen Seite gefunden habe, aber nun die Formulierung "not to transfer to any recipient whatsoever nuclear weapons or other nuclear explosive devices" diskutiert werde.

Daraufhin kam in London wieder einmal Angst um die britische Atommacht auf. „To any recipient whatsoever" bedeutete, daß auch der nukleare Transfer unter Kernwaffenstaaten, d. h. zwischen den USA und Großbritannien verboten wäre. Im Foreign Office konnte man sich allerdings nicht mehr darauf einigen, welche Haltung Brown zu dieser Frage in Moskau einnehmen sollte. Brown sollte das Problem nach Möglichkeit nicht zur Sprache bringen und eine Diskussion um die neue Formulierung vermeiden. Die britische Regierung wirkte somit in Moskau noch uninformierter, als sie es ohnehin war. Sir Harold Beeley entwarf daraufhin einen Gegenvorschlag für Artikel I, der Proliferation unter Kernwaffenstaaten explizit erlaubte. Im Foreign Office war man jedoch mehrheitlich dagegen, diesen Entwurf als Änderungsvorschlag den USA zu präsentieren. Dem britischen Außenministerium ging es nicht darum, zu verhindern, daß die Einigung wegen britischer Einwände verzögert wurde. Man wollte vielmehr eine internationale Diskussion um das Thema vertikale Proliferation verhindern. ${ }^{169}$ Zunächst war die britische Regierung nicht müde geworden, die USA zur Aufgabe bestimmter Positionen zu drängen und Kompromißbereitschaft anzumahnen. Nun, da ein Abkommen in greifbare Nähe gerückt war, ging es wieder einmal vordringlich um die Sicherung britischer Interessen. Tatsächlich hätte überhaupt kein Grund zur Sorge bestanden, da es sich bei dem

167 PRO, FO 371/187471, Dean to FO, 29. 10. 1966.

168 NA, RG 59, CFPF, DEF 18, box 1594, Memo of Conversation, 29. 11. 1966.

${ }^{169}$ PRO, FO 371/187475, Stuart (FO) to Street (FO), 09. 12. 1966: „I wonder whether Sir H. Beeley's gimmick is in fact a good idea. Presentationally it looks bad since it draws attention to the permissibility of proliferation between the nuclear states. This is already hidden in the text by the fact that transfer to an individual nuclear state is not forbidden. But the proposed amendment brings the possibility to the surface and might reopen the whole question of vertical and horizontal proliferation." 
Nassauer Abkommen um den Verkauf eines nuklearen Trägersystems und nicht um Kernwaffen im eigentlichen Sinne handelte. Die Weitergabe nuklearer Sprengköpfe war in der nationalen amerikanischen Gesetzgebung ohnehin verboten. In diesem Punkt war auch für Großbritannien mit der Gesetzesänderung von 1958/59 keine Ausnahme gemacht worden.

Der Besuch Browns in Moskau belegte einmal mehr, daß am top table der internationalen Politik kein Platz mehr für Großbritannien war. Browns Mission war in bezug auf den NPT völlig überflüssig. Die Regierung in London war - trotz britischer Vorstöße - niemals eingeladen worden, an den bilateralen Verhandlungen der Supermächte teilzunehmen. Großbritannien wurde zwar als einziger Verbündeter über die informellen Gespräche zwischen der Sowjetunion und den USA informiert, jedoch nur nachträglich, ohne vorherige Konsultationen. Streckenweise tappte die britische Regierung genauso im dunklen wie die übrigen westlichen Verbündeten. ${ }^{170}$ In den Teststopp-Verhandlungen hatten in der Endphase intensive trilaterale Gespräche in Moskau zum Erfolg geführt. In den Verhandlungen um den NV-Vertrag war Großbritannien nur noch einer von mehreren Verbündeten, denen Bericht erstattet wurde. Einfluß auf den Verhandlungsverlauf hatte die Regierung in London nicht mehr. Mitte Dezember 1966 teilte Foster dem britischen Botschafter in Washington mit, daß sich die USA und die Sowjetunion prinzipiell auf einen gemeinsamen Artikel I geeinigt hätten und Außenminister Rusk bereits erste Gespräche mit dem bundesdeutschen Außenminister Brandt führe. ${ }^{171}$ Durch den Regierungswechsel in Bonn im November waren die Hoffnungen der amerikanischen Regierung gestiegen, daß der Vertragsentwurf in Bonn nicht auf blanke Ablehnung stoßen werde. ${ }^{172}$ Die scheidende Regierung Erhard hatte im Laufe des Jahres 1966 den Anschluß an die amerikanische Nichtverbreitungspolitik verloren und eine eigene Initiative ergriffen, die den Interessen der USA entgegenlief.

\section{Die Bundesrepublik Deutschland und die Einigung der Supermächte}

Die Bundesrepublik Deutschland wurde im Laufe des Jahres 1966 von der internationalen Staatengesellschaft mehr und mehr als Haupthindernis in den Verhandlungen um den NPT betrachtet. Der sowjetische Premier Kossygin erklärte im Februar 1966 vor

170 "It looks rather as if something is up and that the Americans do not want to confide in us at this stage. ... So it seems to us as if things are starting to move here, though how far the Americans have got in their bilaterals with the Russians is unclear." PRO, FO 371/187470, UK-Del. to UN to FO, 11. 10. 1966. Zu diesem Zeitpunkt arbeitete die bilaterale Arbeitsgruppe schon über zwei Wochen an einer gemeinsamen Formulierung. Auch wenn der erste Versuch in Camp David abgelehnt worden war, so bestand doch die Aussicht auf eine baldige Einigung.

171 PRO, FO 371/187475, Dean to FO, 19. 12. 1966.

${ }^{172}$ Der neue Außenminister Brandt erklärte im Gespräch mit dem amerikanischen Botschafter in Bonn: „Man hoffe, daß ein Nichtverbreitungsvertrag in einer Weise ausgehandelt werden könne, der den legitimen Interessen der nichtnuklearen Partner des Bündnisses voll Rechnung trage. Um eine Hardware-Lösung wolle man sich nicht bemühen. Wichtig sei aber die gemeinsame Erörterung und Festlegung der strategischen Konzepte sowie der strategischen Planung." AAPD, 1966, Dok. Nr. 390, Gespräch des Bundesministers Brandt mit dem amerikanischen Botschafter McGhee, 08. 12. 1966. Brandt erklärte auch gegenüber Außenminister Rusk den deutschen Verzicht auf die Hardware-Lösung: FRUS 1964-1968, XIII, Memo of Conversation, 16. 12. 1966, S. 517. 
der ENDC, daß die Sowjetunion von der Notwendigkeit des NPT überzeugt sei und einen baldigen Abschluß wünsche. Die Kreml-Führung betonte, daß bei einer Preisgabe der nuclear-sharing-Pläne ein Abkommen sofort möglich wäre. Somit verstärkte sich der Eindruck, daß ausschließlich die amerikanische Rücksicht auf Bonn ein Vorankommen in dieser wichtigen Frage verhinderte. Viele NATO-Verbündete waren es leid, deutsche Bedürfnisse und Optionen wahren zu müssen. In dieser Situation trat die Bundesregierung die Flucht in die Offensive an. Die Friedensnote, die die Regierung Erhard im März 1966 an alle Staaten der Welt richtete, beinhaltete ein bundesdeutsches Konzept zur Eindämmung von Proliferation. Ein globales Abkommen sei unmöglich, so die Aussage der Friedensnote, daher solle die Weiterverbreitung von Kernwaffen Schritt für Schritt verhindert werden. In einem ersten Schritt sollten die Nichtkernwaffenstaaten der beiden Bündnisse dem deutschen Beispiel folgen und ihren Verzicht auf Kernwaffen erklären. Danach könnten Erklärungen der neutralen Nichtkernwaffenstaaten und schließlich der Kernwaffenstaaten folgen. Obwohl die Friedensnote insgesamt sowohl in der östlichen als auch in der westlichen Welt reserviert bis ablehnend aufgenommen wurde, hielt die Bonner Regierung an ihrer Haltung fest. ${ }^{173}$

Eine neue Initiative auf diesem Gebiet startete die Bundesregierung allerdings erst einige Monate später. Zunächst standen die Verhandlungen mit Paris über die Zukunft der französischen Streitkräfte in der Bundesrepublik im Mittelpunkt der Bonner Außenpolitik. Anfang Oktober wurden die Nichtverbreitungsvorschläge der Friedensnote neu belebt. Bonn plante, alle Nichtkernwaffenstaaten der NATO und des Warschauer Paktes aufzufordern, gemeinsam mit der Bundesrepublik auf die Herstellung von Kernwaffen zu verzichten. Zunächst holten die Deutschen die Stellungnahmen der westlichen Verbündeten zu diesem Vorhaben ein. Die Briten wandten ein, daß die Bundesrepublik im Gegensatz zu den übrigen Nichtkernwaffenstaaten nur eine bereits bestehende Verpflichtung - den bundesdeutschen Verzicht von 1954 - bestätigen würde. Sie sahen daher wenig Aussicht auf Erfolg. ${ }^{174}$ In Washington reagierte man entsetzt. Anfang Oktober stand in den geheimen bilateralen Gesprächen zwischen den USA und der Sowjetunion eine Einigung über einen NPT kurz bevor. Der unpassende deutsche Vorschlag würde erneutes Mißtrauen auf östlicher Seite aufkommen lassen. Die italienische Regierung war verunsichert, da sie von Bonn zu einer Teilnahme aufgefordert worden war, aber bereits erfahren hatte, daß die USA strikt gegen die Initiative waren. ${ }^{175}$ Der erneute deutsche Vorstoß war damit schon im eigenen Lager ein diplomatischer Fauxpas. Allerdings fanden zunächst nur die USA deutliche Worte. Die Regierung in Rom bat die Bundesregierung, die Initiative zunächst ruhen zu lassen. Die Briten waren bemüht, ihre Kritik vorsichtig

${ }^{173}$ Zum Zusammenhang zwischen Nuklearpolitik und Friedensnote siehe: Küntzel, Bonn, S. 94-97. Bluth geht sogar davon aus, daß ein deutscher Vorstoß in der Nichtverbreitungspolitik der ursprüngliche Zweck der Friedensnote gewesen sei: „It should be emphasized that the peace not was initally designed as a response to the problem of non-proliferation and that the emphasis on Deutschlandpolitik in the final version was a later addition by Karl Carstens in the Foreign Ministry." Bluth, Britain, S. 166. Zur Friedensnote der Bundesregierung siehe auch: Haftendorn, Sicherheit, S. 278-294.

${ }^{174}$ In Bonn wußte man sehr wohl um dieses Problem. AAPD 1966, Dok. Nr. 241, Aufzeichnungen des Ministerialdirektors Werz, 29. 07.1966.

${ }^{175}$ Britische, italienische und amerikanische Reaktionen auf die deutsche Initiative in: PRO, FO 371/ 187469, FO to Brit. Embassy, Bonn, 07. 10. 1966, Brit. Embassy, Rome, to FO, 13. 10. 1966, Brit. Embassy, Washington, to FO, 08. 10. 1966. 
zu formulieren, da sie angesichts des Drängens auf den Verzicht der majority voting option die Beziehungen zur Bundesrepublik nicht auch noch in dieser Frage belasten wollten. Deshalb wiesen die Briten nur darauf hin, daß sie die Erfolgsaussichten äußerst gering einschätzten. ${ }^{176}$

Daraufhin ließ die Regierung in Bonn ungeachtet aller Hinweise auf eine Einigung der Supermächte und ungeachtet der negativen Haltung der Verbündeten einen Entwurf unter allen NATO-Mitgliedern zirkulieren. Die ACDA konnte das Ausmaß der deutschen Uneinsichtigkeit nicht verstehen und mutmaßte daraufhin, außer den USA hätte keiner der Verbündeten gegenüber Bonn ein klares Wort gesprochen. ${ }^{177}$ Washington machte der Bundesregierung im folgenden unmißverständlich klar, daß man umgehend einen endgültigen Verzicht auf diese Pläne wünsche. Dies war gleichwohl gar nicht mehr erforderlich. Das außenpolitische Debakel fiel mit dem Sturz der Regierung in Bonn zusammen. Diese Episode zeigte, daß die Regierung Erhard in der Nichtverbreitungspolitik im Laufe des Jahres 1966 den Bezug zur Realität völlig verloren hatte.

Die amerikanische Hinhaltetaktik war daran nicht ganz unschuldig. Die amerikanische Regierung hatte Bonn über den tatsächlichen Stand der Verhandlungen nicht informiert, um nicht möglicherweise unnötig oder vorzeitig Spannungen zu erzeugen. Allerdings war seit der Rede Johnsons Anfang Juli klar, daß der amerikanische Präsident nun ein Abkommen forcierte. Die Bundesregierung erhielt im Laufe des Sommers 1966 zahlreiche Hinweise, daß die USA einen Kurswechsel in der Nichtverbreitungspolitik beabsichtigten. ${ }^{178}$ Während des Treffens zwischen Erhard und Johnson im September 1966 war die NATO-Streitmacht kein Thema mehr gewesen. ${ }^{179}$ Der sowjetische Außenminister Gromyko hatte im Oktober verlauten lassen, man sei von einem Abkommen nicht mehr weit entfernt. Im Oktober meldeten auch bereits verschiedene Zeitungen, daß Moskau und Washington im Hinblick auf den NV-Vertrag handelseinig seien. Das blinde Festhalten an einer theoretischen Option ohne Blick auf die politischen Realitäten trug auch seinen Teil zum Sturz der Regierung Erhard bei. Die Ablösung der Bundesregierung erleichterte wiederum der amerikanischen Regierung die endgültige Zustimmung zum amerikanisch-sowjetischen Kompromiß. Nach ersten Gesprächen mit dem zukünftigen Außenminister Brandt schien die neue Regierung bereit, auf eine Hardware-Lösung zu verzichten und mehr Flexibilität in der Nichtverbreitungspolitik zu zeigen.

${ }^{176}$ PRO, FO 371/187475, Smart (Brit. Embassy, Washington) to Street (FO), 18. 11. 1966.

177 Ebenda.

178 „Im ganzen hatte ich den Eindruck, daß der Botschafter - mutmaßlich auf ausdrückliche Instruktion von Washington - mir klar machen wollte, daß die Amerikaner das Projekt einer gemeinsamen nuklearen Streitmacht nicht weiter verfolgen möchten." AAPD, 1966, Dok. Nr. 268, Aufzeichnung des Staatssekretärs Carstens, 25. 08. 1966. Botschafter Schnippenkötter über ein Gespräch mit Arthur Barber, einem Berater von Verteidigungsminister McNamara: „Wir [die Bundesregierung] machten uns von dem Verhandlungsstand am Genfer Konferenztisch ein unvollständiges Bild. Er dürfe nicht alles sagen, wolle mir aber nicht verschweigen, daß es in den letzten 6-8 Wochen ermutigende zweiseitige Kontakte gegeben habe. . . Andererseits seien MLF, ANF und andere Hardware-Lösungen tot. ... Den Präsidenten aber würde unser Abschied von Hardware ungeheuer erleichtern." AAPD, 1966, Dok. Nr. 291, Schnippenkötter an Carstens, 15. 09. 1966.

${ }^{179}$ Auch die Verteidigungsminister McNamara und von Hassel schnitten das Thema nicht an. AAPD, 1966, Dok. Nr. 301 und 302, Gespräch des Bundesministers von Hassel mit dem amerikanischen Verteidigungsminister McNamara, 27.09. 1966, Gespräch des Bundeskanzlers Erhard mit Präsident Johnson, 27.09. 1966. 
Obwohl mit dem Regierungswechsel in Bonn die Aussichten auf eine positive Haltung der Bundesrepublik gewachsen schienen, fürchteten sowohl die USA als auch Großbritannien einen deutschen Proteststurm als Antwort auf die Mitteilung, man habe sich mit der Sowjetunion auf die zentralen Artikel eines Vertrages geeinigt. In London wurde ein Strategiepapier erstellt, welches das weitere britische Vorgehen im Falle hartnäckigen deutschen Widerstands diskutierte. Die Briten sahen drei Möglichkeiten: a) die amerikanische Regierung dringend zu bitten, sie möge massiven Druck auf Bonn ausüben, b) selbst gegenüber der deutschen Regierung scharfe Töne anzuschlagen, c) einen eigenen britischen Vertragsentwurf in Genf vorzulegen. ${ }^{180}$ Letztendlich war man jedoch mit keinem dieser Vorschläge zufrieden. Die britische Regierung drängte die USA ohnehin schon seit langem, Bonn gegenüber mehr Entschlossenheit zu zeigen. Die Vorlage eines britischen Entwurfs würde nicht weiterhelfen und die Verbündeten nur verärgern. Ein weiterer britischer Entwurf würde von der Sowjetunion auch nicht ernst genommen werden. Andererseits wollte sich die britische Regierung auch nicht direkt an Bonn wenden, $\mathrm{da}$ eine Initiative ohne die amerikanische Unterstützung wenig bewirken konnte.

Hinzu kam, daß Großbritannien zu dieser Zeit mit der Bundesrepublik über den Devisenausgleich für die in der Bundesrepublik Deutschland stationierten britischen Truppen verhandelte. Angesichts der schweren Finanzkrise in Großbritannien wollte die LabourRegierung das entsprechende Abkommen nur verlängern, falls die Bundesregierung in Zukunft zu einem vollständigen Devisenausgleich bereit war. Ansonsten drohte die Labour-Regierung, den Großteil der britischen Truppen aus der Bundesrepublik abzuziehen. ${ }^{181}$ In dieser Frage erwartete die Regierung in London von der Bundesregierung erhebliche finanzielle Zugeständnisse. Die Verhandlungen über den Devisenausgleich waren auch schon ein wesentlicher Grund dafür gewesen, daß die Briten im Herbst 1966 in der nuclear-sharing-Frage nicht direkt auf die deutsche Regierung einwirken wollten. ${ }^{182} \mathrm{Da}$ diese Verhandlungen noch nicht abgeschlossen seien, sei es unklug, so das Memorandum des Foreign Office, Bonn nun in der Frage des Nichtverbreitungsvertrages unter Druck zu setzen. Außerdem stehe eine erneute Bewerbung der Briten um die EWG-Mitgliedschaft bevor. Die Regierung in Bonn dürfe keinesfalls mit einer Fülle von britischen Forderungen überhäuft und verärgert werden. ${ }^{183}$

In Washington waren die Befürchtungen hinsichtlich der deutschen Reaktion auf die Einigung mit der Sowjetunion nicht minder groß. Die amerikanische Regierung wandte sich zunächst an Kanada mit der Bitte, in Bonn um Unterstützung für die Artikel I und II zu werben. Die Kanadier waren aufgrund ihrer Rolle als sachliche und unvoreingenommene Fürsprecher der Nichtkernwaffenstaaten am ehesten geeignet, in Bonn Gehör zu finden. Das mußte auch die britische Regierung zugeben, deren Extremposition in Sachen Nichtverbreitung hinlänglich bekannt war. Das Foreign Office informierte die britische Botschaft in Bonn über ein Schreiben des kanadischen Außenministers Martin an seinen deutschen Kollegen Brandt. Im Foreign Office wies man noch einmal ausdrücklich darauf hin, daß von britischer Seite Zurückhaltung geübt werden müsse. Man sei

${ }^{180}$ PRO, FO 371/187475, FO-Memo: Non-Proliferation Treaty, 21. 12. 1966.

${ }^{181} \mathrm{Zu}$ den Verhandlungen über den Devisenausgleich zwischen der Bundesrepublik und Großbritannien siehe: Haftendorn, Kernwaffen, S. 227-286.

${ }^{182}$ PRO, FO 371/187474, FO-Memo: Non-Proliferation of Nuclear Weapons, 02.11. 1966.

${ }^{183}$ PRO, FO 371/187475, FO-Memo: Non-Proliferation Treaty, 21. 12. 1966. 
von der amerikanischen Seite gebeten worden, unnötige Diskussionen mit den Deutschen zu vermeiden.: „The plea that the Germans should not be put in the position where they could be accused of treaty breaking sounds to us more like an excuse than a reason but it is interesting that the German Government are still taking the line which they did in 1965 that a treaty would only be acceptable if it contributed to reunification and detente in Europe. ... In view of the fact that the German Government may regard us with some suspicion as the advocates of a more restrictive treaty than they would wish to accept ... I think, we must be cautious in commenting to the Germans on the US draft, since at this stage our enthusiastic support might be misinterpreted." ${ }^{184}$ Der Bericht über die ersten deutschen Reaktionen deutete schon an, daß sich die westlichen Atommächte hinsichtlich der deutschen Bereitschaft, den Vertragstext zu akzeptieren, keine Illusionen machen durften.

Tatsächlich konnten die USA nicht wie geplant im Februar 1967 zur Eröffnung der ersten Sitzungsperiode der ENDC gemeinsam mit der Sowjetunion einen Vertragsentwurf vorlegen. Der Grund dafür war die Haltung der westlichen Verbündeten. Küntzel schreibt, die NATO habe sich „auf Betreiben der Bundesrepublik und Italiens geweigert, den USA ein diesbezügliches Verhandlungsmandat zu erteilen" ${ }^{\text {"185 }}$. In der Bundesrepublik Deutschland war Anfang des Jahres 1967 eine öffentliche Kampagne gegen den Vertrag gestartet worden, die alle bisher geäußerten Vorbehalte gegen den Nichtverbreitungsvertrag bei weitem übertraf. Diese öffentliche Polemik wurde von der Aussage des neuen Bundeskanzlers Kiesinger gekrönt, der von „atomarer Komplizenschaft“ ${ }^{\text {“ wischen den }}$ Supermächten sprach. ${ }^{186}$ Gleichzeitig erwartete die Bundesregierung jedoch weitreichende amerikanische Zugeständnisse bei der Neuregelung des Devisenausgleichs für die amerikanischen Streitkräfte in Deutschland. Die Bundesrepublik verhandelte nicht nur mit Großbritannien, sondern seit einiger Zeit auch mit den USA über ein neues Offset-Abkommen, da sich Mitte 1966 gezeigt hatte, daß die Bundesregierung ihre laufenden Verpflichtungen nicht einhalten konnte. ${ }^{187}$ Die deutsch-amerikanischen Beziehungen waren damit Anfang des Jahres 1967 auf einem Tiefpunkt angelangt. ${ }^{188}$

Die Situation besserte sich erst, als sich der erste Proteststurm in Deutschland gelegt hatte. Im Ausland hatte man die deutsche Reaktion mit Betroffenheit und Unverständnis zur Kenntnis genommen. Die Bundesregierung hegte daraufhin schwere Befürchtungen, international für das Scheitern der Verhandlungen verantwortlich gemacht zu werden. Aufgrund der unklaren Situation im westlichen Lager hatte die Sowjetunion zunächst

${ }^{184}$ PRO, FO 371/187475, Street (FO) to Stark (Brit. Embassy, Bonn), 10. 01. 1967.

${ }^{185}$ Küntzel, Bonn, S. 156.

${ }^{186}$ Eine genaue Analyse der deutschen Kampagne gegen den NPT Anfang 1967 findet sich bei Küntzel, Bonn, S. 157-160. Zum Vorwurf der atomaren Komplizenschaft siehe auch: Küntzel, Bonn, S. 164, Schertz, Deutschlandpolitik, S. 421.

${ }^{187}$ Aus den ursprünglich bilateralen Off-set-Verhandlungen zwischen der Bundesrepublik und Großbritannien wurden damit trilaterale Verhandlungen zwischen der Bundesrepublik, Großbritannien und den USA. Siehe hierzu: Haftendorn, Kernwaffen, S. 252-286.

${ }^{188}$ Der amerikanische Deutschlandexperte und Delegationsleiter in den Off-set-Verhandlungen, McCloy, beklagte sich in einer Sitzung bitter über die Äußerungen der Bundesregierung im Zusammenhang mit dem Nichtverbreitungsvertrag. Haftendorn, Kernwaffen, S. 273. Kiesingers Aussagen über die atomare Komplizenschaft hatten Johnson so sehr in Wut versetzt, daß er sich zunächst kategorisch weigerte, mit Kiesinger überhaupt über den NPT zu sprechen. Schertz, Deutschlandpolitik, S. 421. 
davon Abstand genommen, der Vorlage eines gemeinsamen Textes zuzustimmen. Die Kreml-Führung fürchtete, die USA würden im Interesse der Bundesrepublik weitere Änderungswünsche anbringen und den Text erneut verändern. Die Johnson-Regierung versuchte nun in intensiven bilateralen Verhandlungen, die Bundesrepublik zur Zustimmung zu bewegen, mit dem Erfolg, daß die Bundesregierung von ihrer kompromißlosen Ablehnung abrückte und sich fortan darauf konzentrierte, in diesen Verhandlungen mit den USA so viele Verbesserungen wie möglich zu erzielen. Dies bedeutete, daß Bonn nun nicht mehr nur die Option auf eine Atomstreitmacht der Vereinigten Staaten von Europa gewahrt wissen wollte. Die Liste der deutschen Vorbehalte wurde unendlich lang. Die Bonner Regierung erklärte, die Möglichkeiten zur friedlichen Nutzung der Atomenergie würden erheblich eingeschränkt, die vorgesehenen Kontrollen seien diskriminierend und umfassende Sicherheitsgarantien für die Nichtkernwaffenstaaten erforderlich. Maßnahmen zur nuklearen Abrüstung wurden ebenso angemahnt wie eine befristete Geltungsdauer des Vertrags. Obwohl über den Kontrollartikel keine Einigung erzielt werden konnte, verständigten sich die Supermächte schließlich darauf, der ENDC im August erstmals gleichlautende Vertragstexte zu präsentieren. ${ }^{189}$ Der strittige Kontrollartikel blieb zunächst ausgeklammert.

In London argwöhnte man unterdessen auch, die Bundesregierung könne versuchen, andere Nationen zum Widerstand gegen den NPT zu mobilisieren, um dann einen breiten internationalen Feldzug gegen den Vertrag anzuführen. Diesen Bestrebungen wollte das Foreign Office dadurch Einhalt gebieten, daß möglichst bald Konsultationen mit den Staaten geführt werden sollten, die für deutsche Propaganda gegen den Vertrag anfällig schienen. ${ }^{190}$ Die Briten versuchten schon seit einger Zeit, die Probleme auszuklammern oder zu beseitigen, die andere Staaten dazu bewegen könnten, zusammen mit der Bundesrepublik eine Mehrheit der Nichtkernwaffenstaaten gegen den Vertrag aufzubringen. Immerhin hatten bereits viele Staaten schwere Vorbehalte gegen den Vertrag deutlich gemacht. Mit der Lösung der nuclear-sharing-Frage und der Einigung der Supermächte war noch kein globales Abkommen erzielt. Den Interessen der Staaten, die keine Kernwaffen besaßen, mußte ebenfalls Rechnung getragen werden.

${ }^{189}$ Die Kreml-Führung wollte keinen gemeinsamen Entwurf vorlegen. Sie bestand auf zwei separaten, aber gleichlautenden Texten.

${ }^{190}$ Andrew Stuart aus dem Foreign Office bemerkte zu den verschiedenen Gerüchten über deutsche Konsultationen mit Japan, Indien und Indonesien folgendes: „It seems not unlikely that the Germans, if hard pressed, might turn to other non-nuclear states for support on the contents of a non-proliferation treaty. This underlines the desirability of being able to talk to the Japanese and others about the treaty as soon as possible as they are almost certainly getting only a onesided account which could give trouble. ... The particular questions on which there might be an identity of view between the Germans and other non-nuclears are guarantees and safeguards and other elements of a package deal." PRO, FO 371/187475, Note by A. Stuart, 30.12. 1966. 